\title{
Understanding the Role of Competition in Video Gameplay
}

Satisfaction 


\title{
Understanding the Role of Competition in Video Gameplay Satisfaction
}

\author{
By
}

Sepandar Sepehr, B.Sc., M.Sc.

A Thesis Submitted to the School of Graduate Studies

In Partial Fulfillment of the Requirementsfor the Degree

Doctorate of Philosophy, Business Administration

McMaster University

(C) Copyright by Sepandar Sepehr, December 2014 
Ph.D. Thesis - Sepandar Sepehr; McMaster University - DeGroote School of Business.

DOCTORATE OF PHILOSOPHY

Business Administration (Information Systems) - 2014
McMaster University

Hamilton, Ontario

TITLE: Understanding the Role of Competition in Video Gameplay Satisfaction
AUTHOR:
Sepandar Sepehr, B.Sc., M.Sc. (McMaster University)
SUPERVISOR: $\quad$ Prof. Milena Head
PAGES: $\quad$ xiv, 179 
Ph.D. Thesis - Sepandar Sepehr; McMaster University - DeGroote School of Business.

\begin{abstract}
Considerable amount of time is spent playing video games in today's society. There are various elements in video games that make them entertaining and satisfying, which can be leveraged to provide engaging and satisfying experiences in educational and workplace contexts. One of the key elements in many video games is competition. Based on Self-Determination Theory (SDT) and the Theory of Flow, this dissertation explores the process through which competition makes a video game satisfying. A structural model is proposed that examines the impacts of Situational Competitiveness (manipulated via different modes of competition) and Dispositional Competitiveness (as a personality trait) on gameplay experience. The proposed model is validated through an experimental design study with 104 university students. The results show that the perception of video game competitiveness has a strong direct and indirect (mediated through Challenge and Arousal) effect on Flow experience and Satisfaction. While an individual's personality impacts the perception of a game's competitiveness, this perception can also be influenced by the mode of competition (playing against a computer, stranger or friend). Additionally, Social Presence is found to play a role by mediating the relationship between the mode of competition and Situational Competitiveness.
\end{abstract}


Ph.D. Thesis - Sepandar Sepehr; McMaster University - DeGroote School of Business.

\section{ACKNOWLEDGEMENTS}

I would like to thank several individuals and organizations for their generous support throughout the last few years.

First, I would like to express my sincerest gratitude to my extraordinary supervisor, Dr. Milena Head. Without exaggeration, completion of this work would not be possible if it were not for her constant support and guidance. Since my first meeting with Dr. Head, before applying to the Ph.D. program, I noticed that I would be very fortunate to work under such a kindhearted person's supervision. And I was not wrong. Receiving her continuous encouragement and knowing that I could always trust her guidance were the main reasons for me to continue through this challenging process. Dr. Head's intellectual contributions and emotional support made this dissertation possible.

Thanks also go to my supervisory committee members, Dr. Khaled Hassanein and Dr. Brian Detlor. They both made significant contributions to this dissertation by guiding me throughout various steps of the process, in particular on refining my proposed model, designing the experiments of this research, and preparing the final document. It was a great honour for me to have Dr. Hassanein and Dr. Detlor on my supervisory committee.

I should hereby thank Dr. Norm Archer for his generous donations that enabled me to receive the Norm Archer Endowed Prize, and for his valuable feedback on my dissertation as the internal examiner and as professor in one of my Ph.D. courses.

In addition, a thank you to my dear friends Amir Tavasoli and Farzad Nikfar, my siblings, in particular Babak and his family, my aunt Shohreh, and our new family member, Don Ferrito, with whom I never felt alone during the past few years. 
Ph.D. Thesis - Sepandar Sepehr; McMaster University - DeGroote School of Business.

I would also like to thank the DeGroote Community at large, in particular Deb R. Baldry, Dr. Catherine Connelly, Iris Kehler, Sandra Stephens, and Carolyn Colwell for their tremendous support.

I was very fortunate to receive the financial assistance of Social Sciences and Humanities Research Council of Canada and the Ontario Graduate Scholarship Program in the last two years, for which I am truly grateful.

Last, but certainly not least, I cannot thank my wife (and PhD partner in crime) enough for her endless patience and belief in me, which motivated me to overcome the challenges I faced during the past few years and keep my sanity. Thank you. 
Ph.D. Thesis - Sepandar Sepehr; McMaster University - DeGroote School of Business.

\section{تقديم به آنها كه رفتند}


Ph.D. Thesis - Sepandar Sepehr; McMaster University - DeGroote School of Business.

\section{TABLE OF CONTENTS}

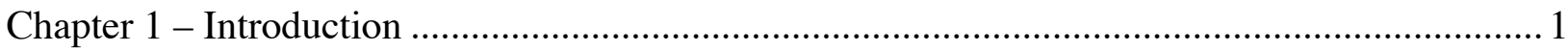

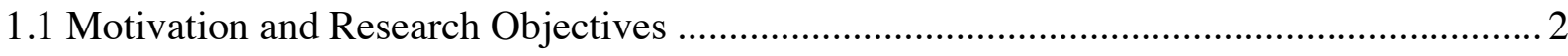

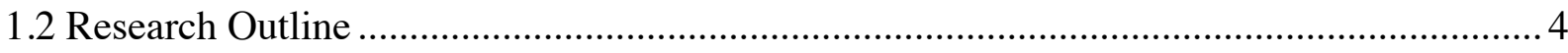

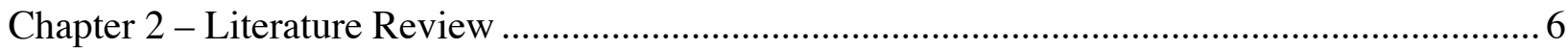

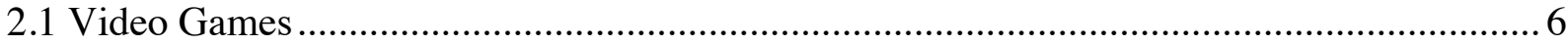

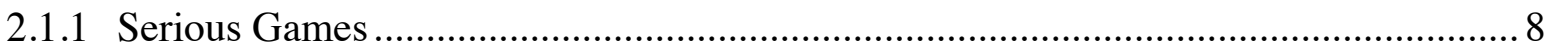

2.1.2 Beyond Serious Games: Gamification ......................................................... 15

2.2 Extant Literature Review on Video Game Experience ............................................... 17

2.2.1 Studies with the Focus on Competition and Game Elements .............................. 17

Chapter 3 - Theoretical Framework and Development of Research Model............................. 24

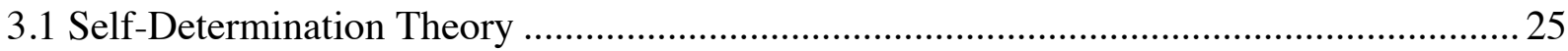

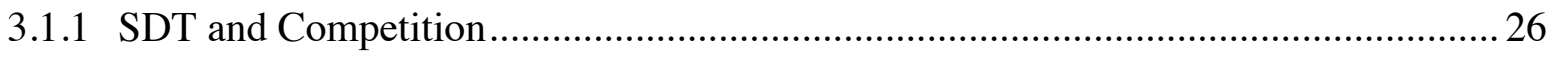

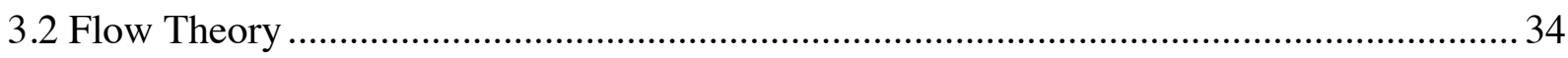

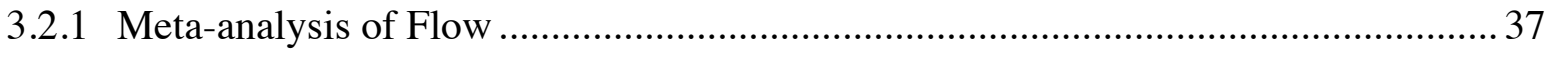

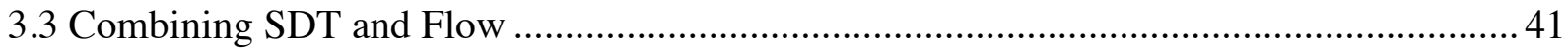

3.4 Proposed Research model and Hypotheses ............................................................ 43

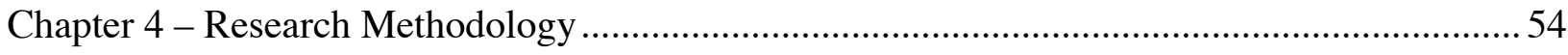

4.1.1 Data Collection Procedure ............................................................................. 54

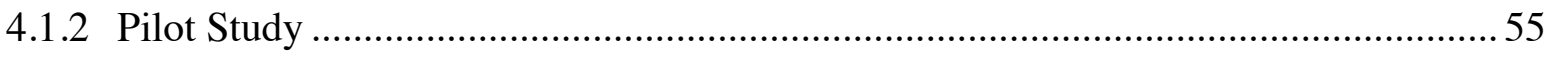

4.1.3 Data Collection Procedure ................................................................................ 56

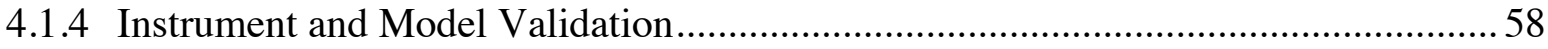

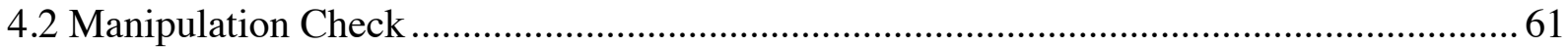

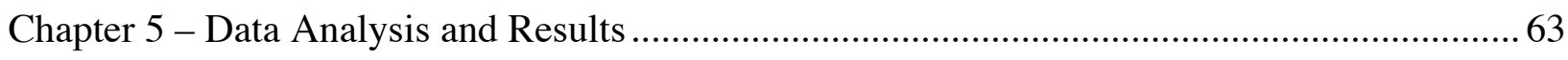

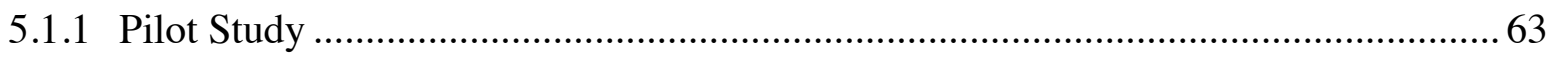

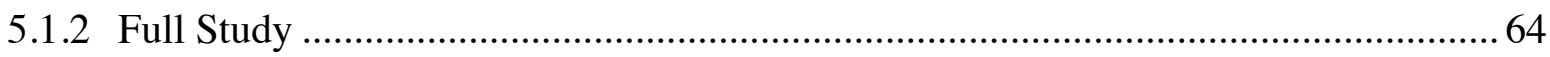

5.1.3 Participant Demographics and Control Variables ........................................... 66

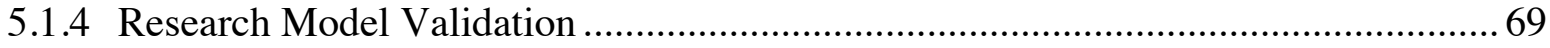

5.1.5 The Structural Model Evaluation ..................................................................... 74

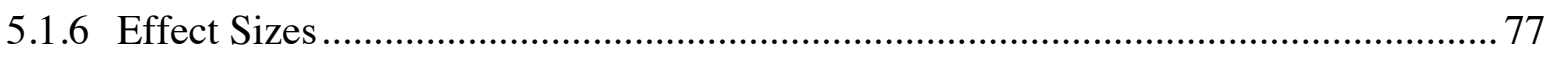

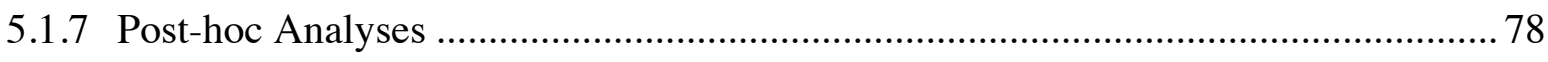


Ph.D. Thesis - Sepandar Sepehr; McMaster University - DeGroote School of Business.

Chapter 6 - Discussion and Conclusion ....................................................................... 91

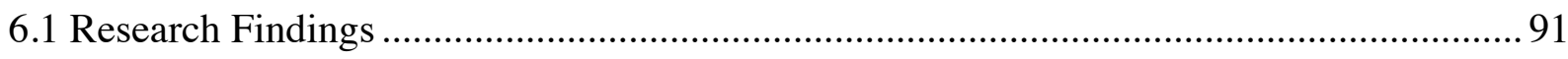

6.1.1 Research Objective 1: The Effect of Situational Competitiveness on Flow .............91

6.1.2 Research Objective 2: The Role of Competition Mode on the Level of Situational Competitiveness and Social Presence ......................................................... 95

6.1.3 Research Objective 3: The Effect of Personality Traits on Situational

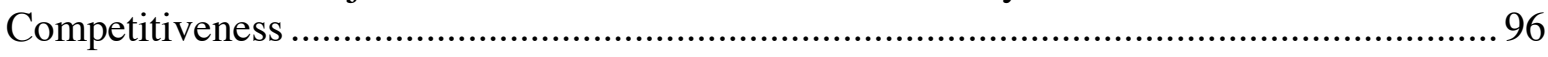

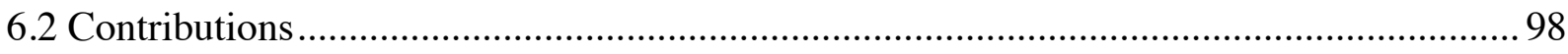

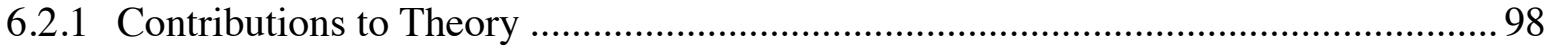

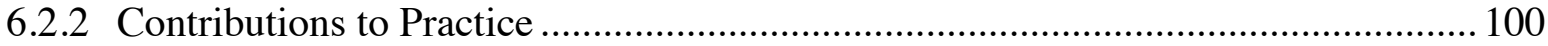

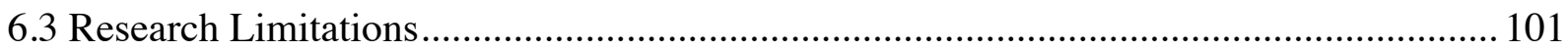

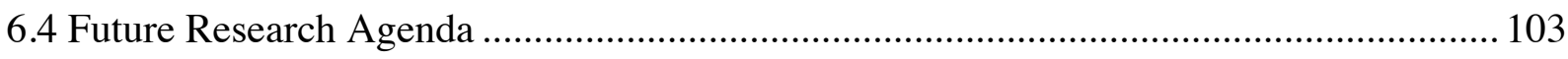

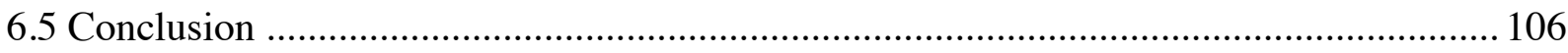

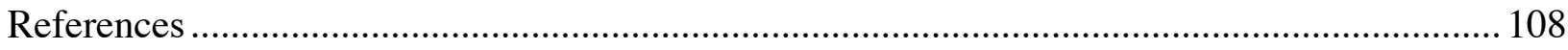

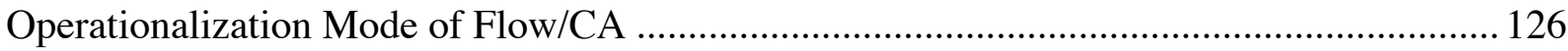

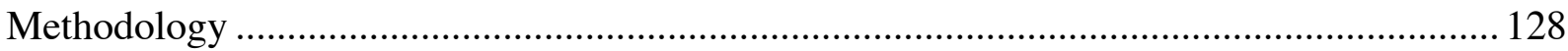

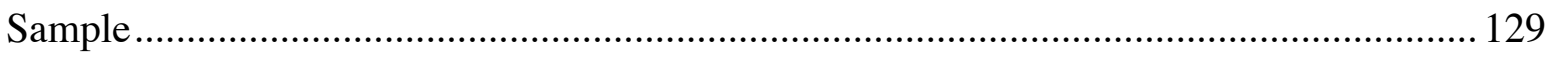

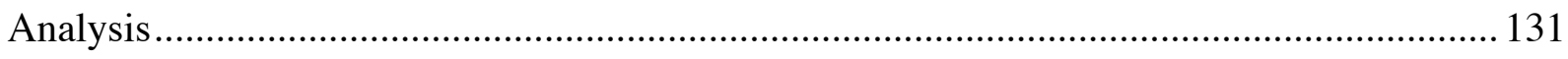

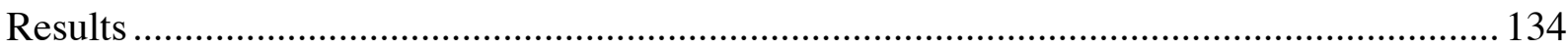

Moderator: Operationalization Method …............................................................... 134

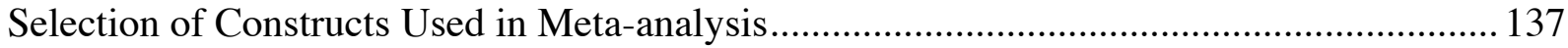

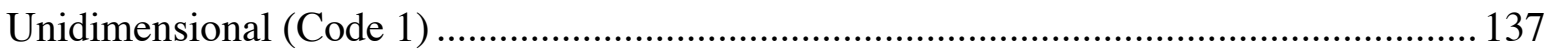

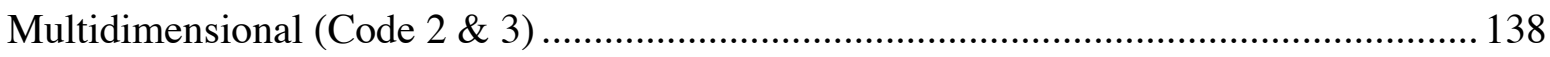

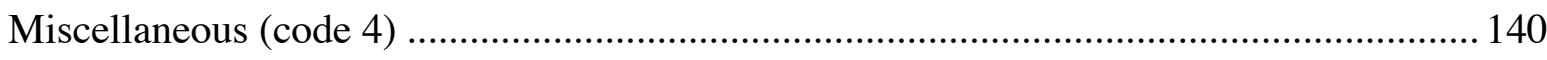

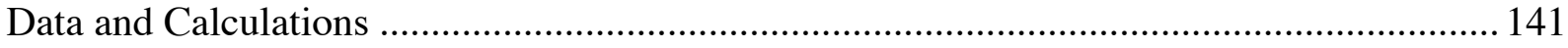

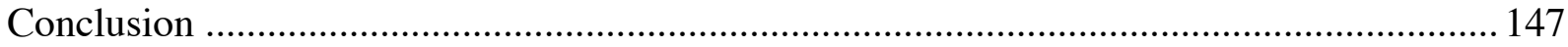

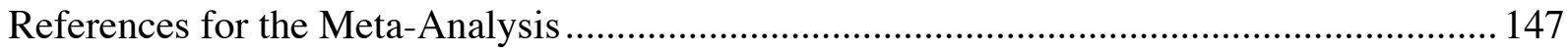

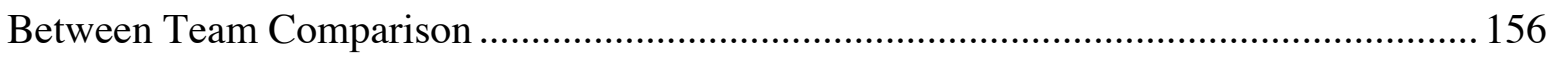

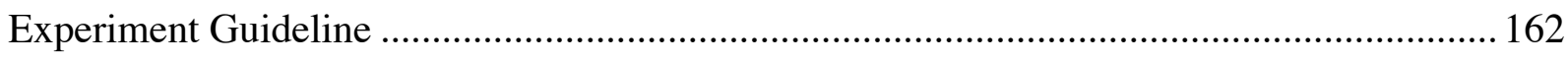

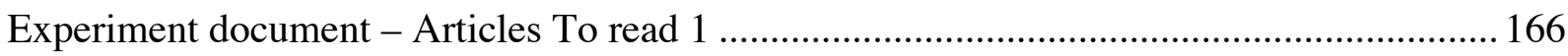

Experiment document - Articles To read 2 .............................................................. 169 
Ph.D. Thesis - Sepandar Sepehr; McMaster University - DeGroote School of Business.

\section{LIST OF FIGURES, TABLES, AND FORMULAS}

\section{Figures}

Figure 1 - Proportions of games within each primary educational content category (Ratan and Ritterfeld 2009)

Figure 2 - Situating Gamification (from Deterding et al. 2011) ………………………............... 16

Figure 3 - Finding the Gap in Literature on Video Gameplay ..................................................... 21

Figure 4 - Finding the Gap in Literature on Video Gameplay (continued) ................................... 22

Figure 5 - Overarching Theoretical Framework...………………………………………….... 25

Figure 6 - The self-determination continuum (source: Ryan \& Deci, 2000) …………….............. 32

Figure 7 - Flow Models: Original Flow Model on the left and Four-State Flow Model on

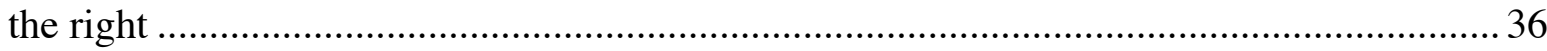

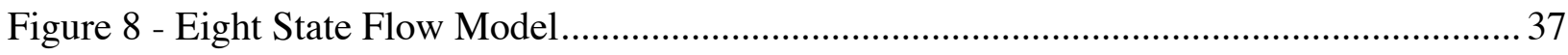

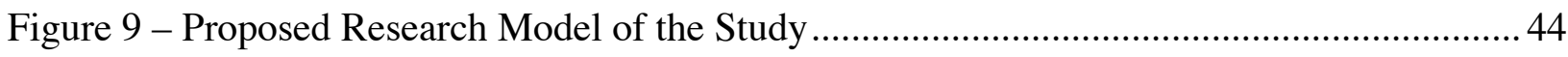

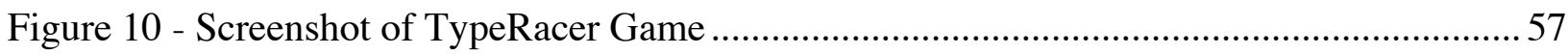

Figure 11 - Result of PLS Analysis of the Proposed Structural Equation Model ......................... 74

Figure 12 - Research Model ............................................................................................... 128

Figure 13 - Variables with Increasing Means ..................................................................... 155

Figure 14 - Variables with no Observable Mean Change ........................................................ 156

Figure 15. Variation of Team's Average Score for the Variables with the Largest Differences from T1 to T3 ........................................................................................ 159

Figure 16. Average Values for Each Team at T1, T2, and T3 Based on Their Rankings .......... 161

\section{Tables}

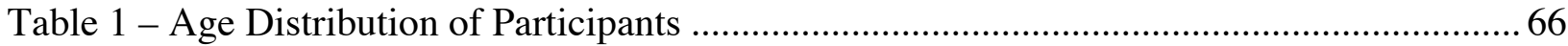

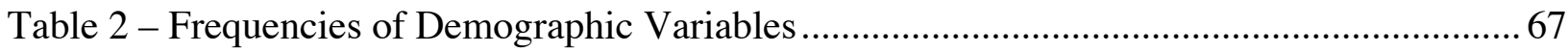

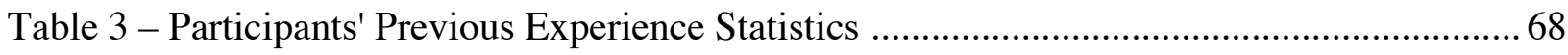

Table 4 - Construct Reliability of the Constructs in the Model ……………………….................. 70

Table 5 - Cross Loadings Matrix for al the First-Order Constructs (significant at 0.001)........... 71 
Ph.D. Thesis - Sepandar Sepehr; McMaster University - DeGroote School of Business.

Table 6 - Discriminant Validity Assessment Table using Construct Correlation Matrix

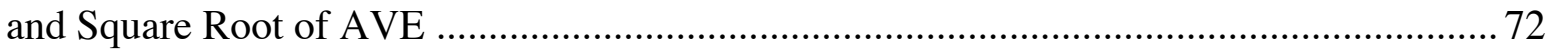

Table 7 - Summary of Findings for Supporting the Proposed Hypotheses .............................. 75

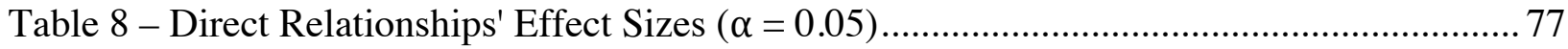

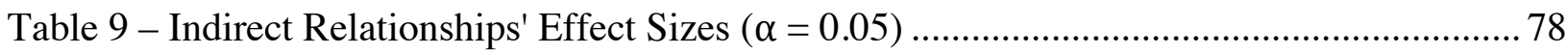

Table 10 - Unmeasured Latent Marker Construct Test Results for Assessing Common

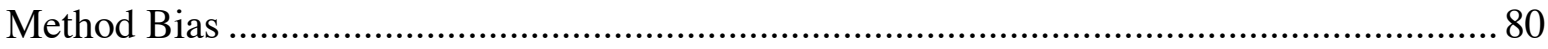

Table 11 - PLS Result for Non-hypothesized Paths in the Saturated Model ............................ 83

Table 12 - Impact of Control Variables on Model's Latent Constructs .................................... 84

Table 13 - Effect Sizes of Control Variables on Endogenous Constructs................................ 85

Table 14 - Total number of studies for each code and each relationship .............................. 135

Table 15 - The results of the meta-analysis after controlling for the moderator

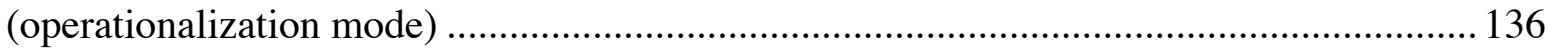

Table 16 - Studies Qualified for the Meta-analysis ...................................................... 141

Table 17 - The extracted data for the studies that were used in the final meta-analysis ............ 143

Table 18 - Calculations for the studies that had correlation between flow and intention .......... 145

Table 19 - Calculations for the studies that had correlation between flow and attitude ........... 146

Table 20. Teams Ranking at each Round ..................................................................... 156

Table 21. Largest Differences Between Teams .............................................................. 158

\section{Formulas}

Equation 1 - Goodness of Fitness Formula (Wetzels et al., 2009) ......................................... 76

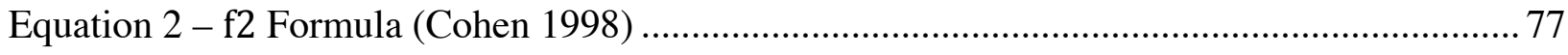


Ph.D. Thesis - Sepandar Sepehr; McMaster University - DeGroote School of Business.

\section{LIST OF ACRONYMS AND SYMBOLS}

\begin{tabular}{|c|c|}
\hline ANOVA & Analysis of Variance \\
\hline AVE & Average Variance Extracted \\
\hline CMV & Common Method Variance \\
\hline EFA & Exploratory Factor Analysis \\
\hline ERP & Enterprise Resource Planning \\
\hline IS & Information Systems \\
\hline IT & Information Technology \\
\hline GoF & Goodness of Fit \\
\hline MIS & Management Information Systems \\
\hline $\mathrm{MMO}(\mathrm{RPG})$ & Massively Multiplayer Online Role-playing Game \\
\hline PLS & Partial Least Squares \\
\hline SDT & Self-Determination Theory \\
\hline TAM & Technology Acceptance Model \\
\hline VIF & Variance Inflation Factor \\
\hline
\end{tabular}


Ph.D. Thesis - Sepandar Sepehr; McMaster University - DeGroote School of Business.

\section{GLOSSARY OF TERMS}

Autonomy

Competence

e-Learning

Edugame

Edutainment

ERPsim

Flow

Game-Based Simulation, Simulations that use video game environments for creating a

Game-Based Simulator, more engaging environment, such as virtual universities
The propensity of people to have control over their actions and see themselves as the locus of causality

Tendency of individuals to feel capable performing a task (sense of self-efficacy).

The use of IT systems in education

Educational Game, aka Game-Based Learning (GBL)

Educational Entertainment, entertaining material that has the purpose of educating users

Game like simulation environment that is used for teaching ERP concepts on SAP ERP

State of optimal holistic experience, capturing deep involvement in an activity 
Ph.D. Thesis - Sepandar Sepehr; McMaster University - DeGroote School of Business.

Simulation Game

Game-Based Model

The games that use a simplified version of real-world models

Game-Based Visualization, The category of systems that use visual technologies and Game Visualization techniques from games to create new forms of visualization and more accessible versions of visualization. These systems allow for higher levels of interactive visualization where user actions might affect resulting visualization

Game-Based Interface, A non-standard but highly symbiotic application interface Game Like Interface, design produced based on the design of a popular game Game-Based UI

Game-Based Production, Use of tools or game/game engines created for videogaming Game-Based Authoring to output some other piece of media.

Game-Based Messaging/Advertising/Mar keting, Advergames

Game-Based Training
A type of Serious Games that are used to transmit a message, advertise a product/service, or market a product
Adding gameplay to enhance motivation to train, or effectiveness of content transfer, behaviour change, or specific goal of training 
Ph.D. Thesis - Sepandar Sepehr; McMaster University - DeGroote School of Business.

Game-Based

Education/Learning

Gamification

SAP ERP

Serious Games
Using gameplay to enhance motivation to learn, engage education, or to enhance effectiveness of content transfer or other specific learning outcome

Using game elements in a non-game system for achieving the engaging power of games

The biggest ERP solution in the market, and the main solution of SAP AG.

Any game that is designed for a purpose that is not pure entertainment. 
Ph.D. Thesis - Sepandar Sepehr; McMaster University - DeGroote School of Business.

\section{CHAPTER 1 - INTRODUCTION}

Since the 1980s, video games have expanded rapidly and established a massive and growing industry (Cucuel, 2011; McGonigal, 2011). Some authors believe that the video games industry is one of the fastest growing in this era (Arnseth, 2006). Video games are pervasive in today's society with reports showing that $67 \%$ of Americans play video games (Entertainment Software Association, 2010). This phenomenon is not restricted to children and teenagers. Statistics show that the average age of video gameplayers is above 30 years old and these adults are expected to play video games for the rest of their lives (Entertainment Software Association, 2010; Williams, Yee, \& Caplan, 2008).

As Millennials ${ }^{1}$-the demographic cohort with birth years from the early 1980 s to the early 2000s - enter the workforce, their mindsets and behaviours in regards to their working environment have become important areas of study. Dr. Jean M. Twenge names this generation, "Generation Me," due to its individualistic attitude and lack of interest in social problems (Twenge, 2006). Millennials, when compared to their predecessors, appreciate extrinsic values more (e.g., money, image, fame) and intrinsic values less (e.g., self-acceptance, affiliation, community), particularly when compared to Generation $\mathrm{X}^{2}$ (Twenge, Campbell, \& Freeman, 2012). It is essential for higher education institutions and employers to understand the differences and mindsets of young students/employees (Twenge, 2006). A significant characteristic of Millennials is the fact that they learn by doing and traditional learning/working environments are boring for them (Twenge, 2006). For this generation, video games are an inseparable communication and learning medium (Edery \& Mollick, 2009).

${ }^{1}$ Also known as Generation Y, Generation N, or the Net Generation

${ }^{2}$ Generation $X$ is referred to the demographic cohort with birth years from the early 1960 s to the early 1980s. 
Ph.D. Thesis - Sepandar Sepehr; McMaster University - DeGroote School of Business.

As Arnseth (2006) explains, "one striking feature of gameplay that seems to be particularly relevant for education is the fact that children and adolescents seem to invest a considerable amount of time and effort in accomplishing tasks that are often very difficult and time consuming." Williams et al. (2008) found that in their sample of 7,000 massively multiplayer online (MMO) gameplayers, users spend on average of close to 30 hours a week playing video games, which is comparable to the amount of time a full-time employee spends at his or her job. Qualitative and quantitative research has shown that time loss among video gameplayers is independent of gender or age (Wood, Griffiths, \& Parke, 2007).

As a consequence of the recent surge of interest in gameplay, schools and workplaces face new challenges to adapt themselves to the gamer generation with its new behaviours and culture (Beck \& Wade, 2004). From a learning perspective, instructors are challenged in finding ways to keep students engaged, attentive, involved and motivated during distinct learning processes at diverse educational levels (Feiertag \& Berge, 2008). These challenges arise due to the fact that Millennials may find traditional school and work environments boring compared to the world they immerse in through playing video games (Collins \& Halverson, 2009). Gee (2003) believes that "schools, workplaces, and families can use games and game technologies to enhance learning" (p. 1).

\subsection{Motivation and Research Objectives}

Some scholars have compared the learning performance of individuals in competitive versus cooperative situations. They tend to agree that cooperative tasks are more effective than competitive tasks, in particular for problem solving (Qin, Johnson, \& Johnson, 1995). However, it should be noted that competition is not the opposite of cooperation (Udvari \& Schneider, 2000), but it is an omnipresent phenomenon in human life, which can motivate students to 
Ph.D. Thesis - Sepandar Sepehr; McMaster University - DeGroote School of Business.

engage deeply in the learning process. An ideal learning atmosphere should have an appropriate level of competition alongside a cooperative environment (Tauer \& Harackiewicz, 2004).

Competition, "the desire to challenge and compete with others" (Yee, 2006, p. 773), is an element that is shared among most existing games. Competition has been shown to be a major motivational factor for playing online video games (Yee, 2006). Reeves and Read (2009) have identified 10 main elements that every great game entails, and among them is "competition under rules that are explicit and enforced" (p. 80), meaning that for competition to be valued by gameplayers, it should be based on predefined rules that players could perceive and follow to see the result of their actions. Otherwise, if the results of a competitive game were random, players would not perceive the consequence of their actions and would not have any measure to improve their skills, which would discourage people from continuing to play. A game's scoring system, which is a simple reward system, enables gamers and learners to compare their performance to their own previous scores and/or to compare it with their peers when the game is in a group, which creates competition (Kelle, Sigurðarson, Westera, \& Specht, 2010). In other words, “good learning in games is a capitalist-driven Darwinian process of selection of the fittest" (Gee, 2003, p. 1). This can also be seen in the perspectives of frequent gamers who believe that "competition is the law of nature" (Beck \& Wade, 2006, p. 81) more than non-frequent gamers.

Recently, various disciplines - in particular operations management and information systems - have employed and studied video games for different purposes, including education (van der Zee, Holkenborg, \& Robinson, 2012). For example, some scholars have studied the motivational factors behind playing video games (H. Chang \& Wang, 2008; Wu, Wang, \& Tsai, 2009), and some have used simulation games for learning (Lewis and Maylor 2007, Léger 2006). However, a review of extant literature shows that previous research studies have not rigorously 
Ph.D. Thesis - Sepandar Sepehr; McMaster University - DeGroote School of Business.

examined the sense of competitiveness as a motivational factor. In particular, what engenders this sense of competitiveness in a gaming environment, and what is the outcome of this perception? Previous studies on video games have mainly focused on either the game design aspects or the psychosocial antecedents of Flow in video gameplay. Flow is a state of optimal experience where one is completely absorbed and immersed in an activity. Flow is an important phenomenon for studying and designing games due to its strength in explaining the state of deep engagement of gameplayers. Based on the literature review discussed in the next chapter, it can be concluded that there is a gap in existing research in understanding the relationship between competition and Flow of video gameplayers.

In sum, this research seeks to examine the concept of competition in video games in order to understand how competition can be used to engage and satisfy students, the psychological state that is greatly desirable for learning ${ }^{3}$. Specifically, the objectives of this research are:

1) To investigate how situational competitiveness of video games impacts antecedents to flow and satisfaction;

2) To study how different modes of competition affect players' perceptions of competitiveness and social presence in video games; and

3) To explore the effect of the personality traits of gameplayers on their perception of competitiveness of video games.

\subsection{Research Outline}

The next chapters of this dissertation are organized as follow:

${ }^{3}$ Learning outcome per se is not the focus of this study. Instead, the focus was on measuring engagement, which can be seen as an intermediately state for enhanced learning. 
Ph.D. Thesis - Sepandar Sepehr; McMaster University - DeGroote School of Business.

Chapter 2 provides a more detailed literature review on games and their various modes. Chapter 3 includes the theoretical framework and research model development. The foundational theories, Flow Theory and Self-Determination Theory, which are used to support the proposed research model of Competitive Video Gameplay, are explained in detail. This leads to the development of a research model and support for its hypothesized relationships

Chapter 4 outlines the research methodology that is utilized for testing the proposed research model of Competitive Video Gameplay.

Chapter 5 describes the results of the analysis for both studies. The proposed model of Competitive Video Gameplay is validated and post-hoc analyses are presented to provide further insights into the results.

Lastly, the discussion, conclusion, and limitations of this research are provided in Chapter 6. Contributions of this research to theory and practice as well as suggestions for future research are also presented. 
Ph.D. Thesis - Sepandar Sepehr; McMaster University - DeGroote School of Business.

\section{CHAPTER 2 - LITERATURE REVIEW}

This chapter first examines various types of video games and their impacts on today's society. Next, an overarching review of extant research on video game experiences is provided in order to illustrate the gap in literature, which this research aims to address.

\subsection{Video Games}

Having outlined the significance of video games in the lifestyle of Millennials and its potential impact for educators and employers, it is necessary to frame the general categories of video games that are related to the workplace and educational environments. In this section, an overview of the main categories of video games that have educational and motivational roles for schools and work environments will be presented. These types of games are referred to as Serious Games, Educational Games, or Gamification. As mentioned in the previous chapter, some individuals spend a significant amount of time every week playing video games. This might raise the concern of negative effects of video games on students and employees performance. Thus, before starting the discussion on the use of video games to gain positive outcomes, it is important to ask: Does the highly engaging aspect of video games make them addictive and result in problematic behaviour?

The fact that people spend a considerable amount of time playing video games does not indicate that it will have a negative effect on their lives. In fact, time spent playing video games does not have a direct correlation with addiction to video games or poor scholastic performance (Skoric, Teo, \& Neo, 2009). In contrast, time loss associated with playing video games can have positive outcomes such as relaxation and escaping from reality (Wood et al., 2007). Some scholars advocate the use of video games in educational and work-related environments to take advantage of their highly engaging characteristics (McGonigal, 2011; Sánchez \& Olivares, 2011; 
Ph.D. Thesis - Sepandar Sepehr; McMaster University - DeGroote School of Business.

Sepehr \& Head, 2011). These Serious Games have received attention from both academics and video game practitioners alike (Crookall, 2011). Consequently, video games can be used for diverse positive outcomes, such as for educational and work-related benefits (Moreno-Ger, Burgos, Martínez-Ortiz, Sierra, \& Fernández-Manjón, 2008)

Many scholars have analyzed the deep involvement of computer users in video games and during Internet use from the addiction standpoint (Acier \& Kern, 2011; Fisher, 1994; Grüsser, Thalemann, \& Griffiths, 2007; Turel, Serenko, \& Giles, 2011). However, we need to be very cautious using terms like 'addiction' when referring to high engagement states. One should be cognizant of the difference between addiction and high engagement in a certain task. Charlton and Danforth (2007) have shown that people who experience high engagement in online video games do not share the same behaviour as addicted online gameplayers. High engagement and addiction share some criteria, but addiction goes beyond high engagement and includes elements of conflict and withdrawal symptoms. The addiction criteria (Charlton \& Danforth, 2007) are as follow:

- Behavioural Salience: the extent to which the activity dominates one's behaviour.

- Relapse and reinstatement: despite trying to quit, continuing the activity the same as before.

- Withdrawal symptoms: having negative emotions and physical effects while not doing the activity.

- Conflict: the extent to which the activity results in conflict with the person's normal life including social relationships and his/her other activities.

Engagement, on the other hand, entails the following criteria (Charlton \& Danforth, 2007): 
Ph.D. Thesis - Sepandar Sepehr; McMaster University - DeGroote School of Business.

- Cognitive Salience: the extent to which the activity dominates one's mental state in life (the person keeps thinking about the activity).

- Euphoria: feeling a 'buzz' or a 'high' from doing the activity.

- Tolerance: having to engage in the activity progressively longer to gain the same 'buzz'. There is evidence in literature that shows the role of dispositional and situational factors that can push a highly engaging task to become addictive, in particular in relation with video games (Sepehr \& Head, 2012b). Moreover, prevalence of video game addiction can be affiliated with less than $10 \%$ of the gameplayers (Sepehr \& Head, 2013b), making it much less common than pure engagement experiences among gameplayers. Empirical evidence shows that "for the vast majority of individuals, online gaming is an enjoyable and harmless activity" (Griffiths, 2010, p. 39).

Overall, it should be clarified that engagement and addiction are separate concepts in video gameplaying. This study aims to investigate competition as an element of games that enables high engagement rather than addiction. Thus, the focus here will not be on the addictive nature of video games. The engagement that is experienced through playing video games can be leveraged to increase the effectiveness of Information Technology (IT) systems and other non-IT based systems in various contexts, including that of education and the workplace.

\subsubsection{Serious Games}

Since the early 1980s, which experienced a boom in computer games, there has been an interest in studying computer games to inform Human-Computer Interaction (HCI) interface design. For example, in his seminal article, Malone (1981) analyzed different aspects of computer games in order to understand why computer games create intense engagement and how this engagement can be used for creating enjoyable learning experiences. Information Systems 
Ph.D. Thesis - Sepandar Sepehr; McMaster University - DeGroote School of Business.

(IS) researchers have also explored such enjoyable experiences during IT use in the workplace and introduced a construct named "playfulness" (Webster \& Martocchio, 1992). The HCI community began taking video games as a domain of research more seriously in the 2000 s. Sweetser and Wyeth's (2005) article is one of many studies that put forward a model for evaluating the enjoyment in playing video games.

While research on video games in the HCI field only dates back one or two decades, games have been used for various purposes for several decades. Particularly, the military has used games significantly for training officers and soldiers (Prensky, 2001). In fact, the term "Serious Games" was first proposed in the 1980s prior to the pervasiveness of video games and the booming video game industry (Abt, 1987). However, as video game audiences and spectrum have expanded broadly since the end of the $20^{\text {th }}$ century, other industries began following the lead of the military to deploy video games to advance their agendas. Today, video games have been applied to various applications in many sectors, such as government, education, corporations, healthcare, and as mentioned above, the military (Susi, Johannesson, \& Backlund, 2007).

As Sawyer and Smith (2008) have remarked, serious games go beyond games that are used only for learning or training. Even though the term "Serious Games" seems to be an oxymoron since games are, by their nature, developed for fun and not serious issues (Newman, 2004), serious games is a term that refers to games (mainly digital) that are "used for purposes other than mere entertainment" (Susi et al., 2007, p. 1). More precisely, serious games can be defined as: 
Ph.D. Thesis - Sepandar Sepehr; McMaster University - DeGroote School of Business.

"Any form of interactive computer-based game software for one or multiple players to be used on any platform and that has been developed with the intention to be more than entertainment" (Ritterfeld, Cody, \& Vorderer, 2009, p. 6).

Based on Sawyer and Smith's (2008) taxonomy, Serious Games can be divided into, but not limited to, the following categories:

- Game-Based Simulations: Also known as Game-Based Simulators or Simulation Games are simulations that use video game environments for creating a more engaging environment, such as virtual universities.

- Game-Based Models: Games that use a simplified version of real-world models, such as building bridges as in Bridge Build ${ }^{\mathrm{TM}}$ or real-world/life simulations as in The Sims.

- Game-Based Visualizations: Also known as Game Visualizations is the category of systems that use visual technologies and techniques from games to create new forms of visualization and more accessible versions of visualization. These systems allow for higher levels of interactive visualization where user actions might affect resulting visualization, such as in the game of Holt Forestry ${ }^{\mathrm{TM}}$.

- Game-Based Interfaces: Also referred to as Game-Like Interfaces or Game-Based UI is a non-standard but highly symbiotic application interface design produced based on the design of a popular game such as Doom ${ }^{\mathrm{TM}}$ in Doom Linux ${ }^{\mathrm{TM}}$.

- Game-Based Productions: Use of tools or game/game engines created for videogaming to output some other piece of media. For example, Electroplankton ${ }^{\mathrm{TM}}$ is a video game in which players use animated planktons to create music. This category of Serious Games could also be referred to as Game-Based Authoring. 
Ph.D. Thesis - Sepandar Sepehr; McMaster University - DeGroote School of Business.

- Game-Based Messaging/Advertising/Marketing: Also known as Advergames are a type of Serious Game that are used to transmit a message, advertise a product/service, or market a product. BMW M3 Challenge£, Johnson \& Johnson ${ }^{\circledR}$ 's Tooth Protectors $^{\mathrm{TM}}$, and GMC ${ }^{\circledR}$ truck's Hit the $\operatorname{Pros}^{\mathrm{TM}}$ are a few examples of this type of games.

- Game-Based Training: Adding gameplay to enhance motivation to train, or effectiveness of content transfer, behaviour change, or another specific goal of training, such as Binary Game ${ }^{\mathrm{TM}}$.

- Game-Based Education/Learning (also known as Edugames): Using gameplay to enhance motivation to learn, engage education, or to enhance effectiveness of content transfer or other specific learning outcome. ERPsim ${ }^{\mathrm{TM}}$, Historia $^{\mathrm{TM}}$, Math Chimp $^{\mathrm{TM}}$, and PhyFun ${ }^{\mathrm{TM}}$ are a few examples of this group of serious games.

One of the key categories of serious games, Game-Based Education/Learning, is the focus of the current investigation and will be discussed in more detail below.

\section{Game-Based Learning (Educational Games)}

The main branch of serious games has always been the application of games in teaching and training, which is referred to as Game-Based Learning (GBL) (Ratan \& Ritterfeld, 2009; Sawyer \& Smith, 2008). The premise of GBL is to "enhance motivation to learn, engage education, or to enhance effectiveness of content transfer or other specific learning outcome" (Sawyer \& Smith, 2008, p. 11). GBL is also known as Game-Based Education, Educational Games, or Learning Games. GBL is closely related to other concepts like e-Learning and edutainment. E-Learning refers to a more general concept, entailing "computer- enhanced learning, computer-based learning, interactive technology, and commonly, distance learning" 
Ph.D. Thesis - Sepandar Sepehr; McMaster University - DeGroote School of Business.

(Susi et al., 2007, p. 2). Edutainment, on the other hand, translates as any entertainment content that is developed with the goal of education rather than pure "fun." Based on these definitions, one can say that GBL is a subset of both e-Learning and edutainment.

Even though some indicate that the US military is "the world's largest spender " on Digital Game-Based Learning (Prensky, 2001, p. 2) ${ }^{4}$, academia (having curriculum-based and extracurricular content) has the biggest consumer base of GBL, representing $63 \%$ of 612 serious games analyzed by Ratan and Ritterfeld (2009). Figure 1 shows the proportions of the analyzed educational games based on their primary content. As depicted in Figure 1, the second most common usage of GBL is for "social change", representing $14 \%$ of the games analyzed. Social change games are related to political issues or social issues such as solving poverty. Next, the most common usage is related to occupational and health-related contents, each with $9 \%$ and $8 \%$ of all the studied games, respectively. Occupational games aim to teach new skills and knowledge related to people's occupation. Finally, health-related games are used to improve one's health or encouraging coping in stressful situations.

Serious games have also been used in business school curricula for more than two decades. One of the most famous games that has been widely used in managerial education is the “role-playing simulation" serious game called the "Beer Game” (Sterman, 1992). The Beer Game allows students to participate in managing a distribution system with the goal of minimizing total costs by controlling the inventories under uncertain situations. Computer-based versions of this game have also been used for many years. By using computers for this game, educators have achieved lower setup and training time, while increasing users' concentration on specific tasks, reducing the number of errors made by players, and enhancing individual

\footnotetext{
${ }^{4}$ The money that was spent in 2005 on military war games and simulation equipment was estimated to be $\$ 4$ billion (Michael \& Chen, 2005).
} 
Ph.D. Thesis - Sepandar Sepehr; McMaster University - DeGroote School of Business.

students' analysis and evaluation of their gameplay results (Coakley, Drexler, Larson, \& Kircher, 1998).

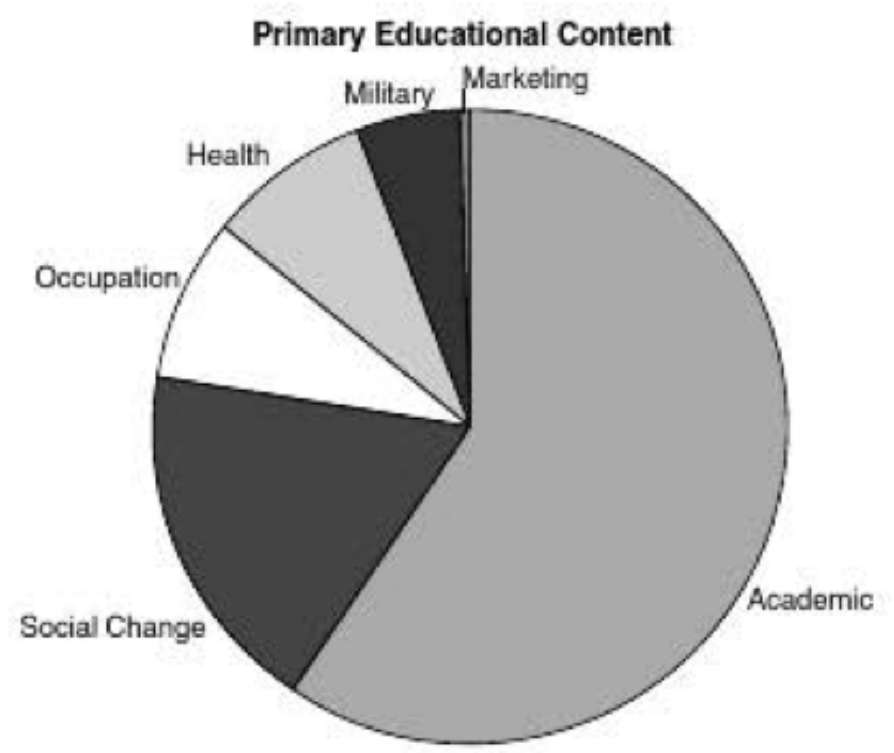

Figure 1 - Proportions of games within each primary educational content category (Ratan and Ritterfeld 2009)

Instructors in the field of IS have increasingly employed video games for teaching students and training employees/managers. Perhaps the most common game used in the IS curricula is the HEC Montreal's ERP (Enterprise Resource Planning) simulation game (also known as ERPsim, Léger, 2006). ERPsim enables instructors to create a hands-on experience similar to the real-world environment working with the SAP ${ }^{\mathrm{TM}}$ ERP system, which is the leading ERP solution available in the market. During this gameplay, students, working in groups, collaborate with group members and compete against other teams, to produce and distribute a series of products in order to achieve the highest income in a virtual market. ERPsim encourages students to take responsibility of different supply chain stages of a simple product production; through this exercise students learn the various functionalities of the SAP ERP system. Due to its gaming structure, ERPsim has been successful in teaching basics of an ERP system despite 
Ph.D. Thesis - Sepandar Sepehr; McMaster University - DeGroote School of Business.

limited knowledge of participants in regards to supply chain and ERP systems in general (Foster \& Hopkins, 2011).

\section{Effectiveness of GBL}

Scholars have found some support for the effectiveness of GBL (Van Eck, 2006).

Sitzmann (2011) has recently conducted a meta-analysis of simulation-based GBL pool of 65 articles and a sample size of 6,476 participants, which have also showed the positive effect of the GBL approach. The results show that "declarative knowledge was $11 \%$ higher for trainees taught with simulation games than a comparison group; procedural knowledge was $14 \%$ higher; retention was 9\% higher; and self-efficacy was 20\% higher" (Sitzmann, 2011, p. 520). However, due to complicated attributed inside video games, it is not practical to design a single GBL experimental design to capture all the goals of video games. In fact, the desired outcome of a game will vary based on its intention to support a specific pedagogy (Young et al., 2012).

Generally, the argument for GBL is that the time spent on video games should not be seen to necessarily be in contradiction with school or work time. In fact, gameplay is "an important component of attention, involvement, and productivity, and it's capable of energizing behaviour of all sorts" (Reeves \& Read, 2009, p. 173). Thus, games are not only about delivering content to the users (in which they are not efficient), but they can also successfully be employed as a mechanism for motivating and engaging individuals in educational settings (Arnseth, 2006; Corti, 2006; Reeves \& Read, 2009). Researchers have shown that when learners are engaged and involved, there is a positive effect on learning outcome (Bandura, 1977; Oncu \& Cakir, 2011; Shin, 2006).

As mentioned in the previous chapter, Millennials have a different mentality, which affects the way they learn. As Feiertag and Berge (2008) put it: 
Ph.D. Thesis - Sepandar Sepehr; McMaster University - DeGroote School of Business.

“Generation N's 'learning style is hands-on and not necessarily linear in fashion. Forget instruction manuals, tech tips and lecture-based lessons; this is a generation that plays to learn. Many of today's video games are based upon trial and error and Gen $N$ sees it as a metaphor for learning” ( $p .458)$.

Furthermore, the focus on "doing" instead of "knowing", when it comes to teaching Millennials, has been advocated due to the higher value of "actions" compared to "accumulation of facts" in the current era (Oblinger, 2003). It is often recommended that teachers focus more on creating interactive and experiential learning environments (Oblinger \& Oblinger, 2005). The significance of engagement in the learning process has been emphasized in the work of the famous educational theorist, Kolb (1984), known as the idea of experiential learning. Other distinguished scholars have also advocated the positive effect of active involvement of students during learning processes (Papert, 1980; Piaget \& Roberts, 1976; Vygotsky, 1978). Therefore, GBL is important as video games have the potential to encompass experiential learning principles (Gee, 2003).

\subsubsection{Beyond Serious Games: Gamification}

"Gamification" $"$ has become a popular term to describe the use of games in nonconventional contexts. Deterding, Dixon, Khaled, \& Nacke (2011) define Gamification as "the use of game design elements in non-game contexts." Foursquare ${ }^{7}$ is perhaps the most successful example of Gamification. Foursquare designers have used game design elements such as points, badges, leaderboard, levels, as well as competition to motivate users to return to continuously

${ }^{5}$ Millennials

${ }^{6}$ Based on Gartner's report in 2011, by 2015 more than $50 \%$ of organizations will gamify their innovative processes (web link: http://www.gartner.com/it/page.jsp?id=1629214)

${ }^{7}$ A location-based social networking website that is widely used by smartphone users: https://foursquare.com/ 
Ph.D. Thesis - Sepandar Sepehr; McMaster University - DeGroote School of Business.

use their service, which has increased their user activity significantly. The main difference between serious games and Gamification is in the level of analysis. Serious games tend to use a complete game in contexts that are beyond mere enjoyment, while in Gamification one aims to use design elements of games in other contexts (e.g. marketing, social networks, sport, and such) without implementing a complete gaming environment. This comparison can be visualized in Figure 2 .

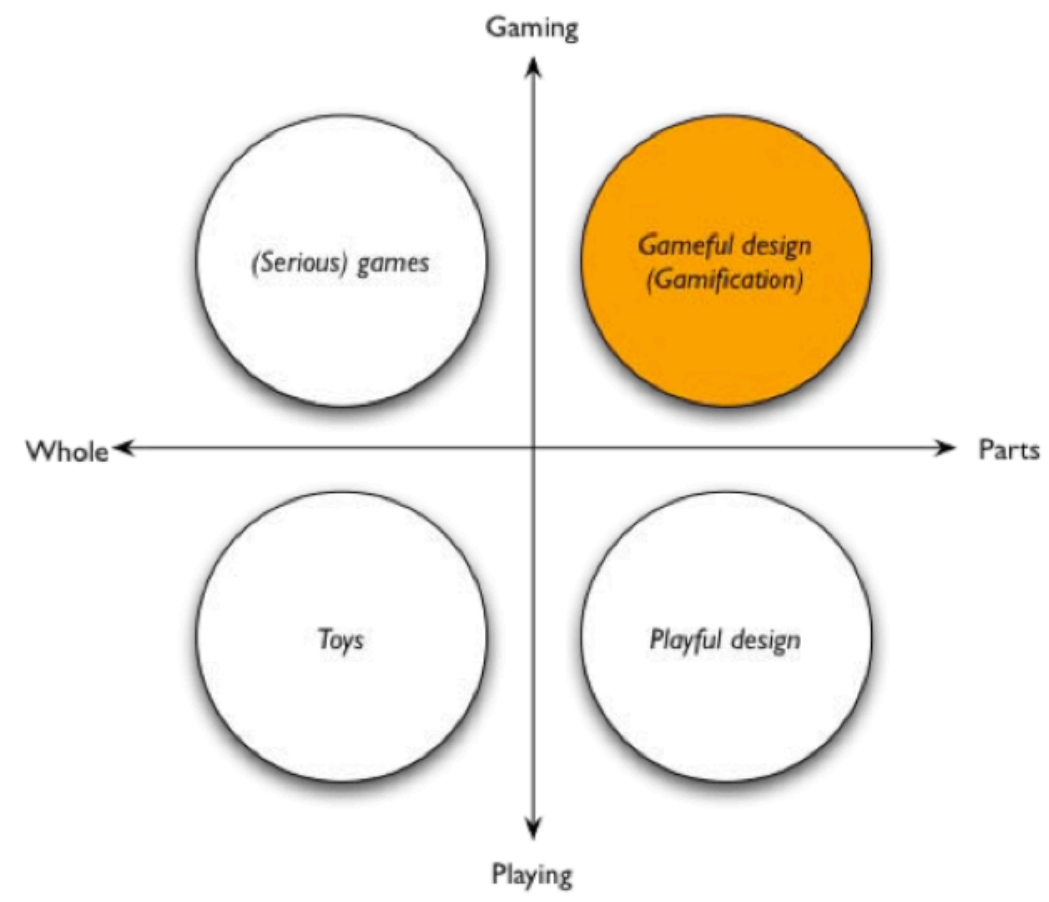

Figure 2 - Situating Gamification (from Deterding et al. 2011)

The dimension that separates games from toys and "playful design", according to Deterding et al. (2011), is the difference between the concepts of play and game. Play is a broader category than games due to its free form and lack of structure (Caillois \& Barash, 2001). Games, unlike play that is also referred to as playfulness, are formal systems that follow a set of explicit rules (Barr, Noble, \& Biddle, 2007). 
Ph.D. Thesis - Sepandar Sepehr; McMaster University - DeGroote School of Business.

\subsection{Extant Literature Review on Video Game Experience}

Through a detailed examination of extant literature, existing gaps in the literature on video game engagement were identified. A graphical summary of this literature review is presented in Figure 3 by visualizing the relationships that other scholars have previously studied. This overarching model also distinguishes the empirical versus non-empirical results by using different relationship lines as validated or proposed relationships. As shown in Figure 3, research on video games and Flow (high engagement) in video games can be divided into two main groups: first, studies that focus on different elements of video gaming systems, in particular competition (left hand side of the figure); and second, studies that evaluate engagement or Flow during video gameplay. The first group of studies are labelled with letters ' $a$ ' to ' $\mathrm{o}$ ', and the second group of studies are labelled with numbers 1 to 18 . The first group of these studies is discussed below. The second group of the studies that focus on the construct of Flow, its antecedents and consequences will be discussed in the next chapter (section 3.2) where details of Flow theory and its various dimensions are presented.

\subsubsection{Studies with the Focus on Competition and Game Elements}

Wu et al. (2009) (paper 'a') studied online games from a Uses and Gratifications (U\&G) perspective, which discusses the usage of media to gratify various users' needs and wants. Based on Uses and Gratification Theory, the authors explore the antecedents (i.e. gratifications and presence) of continuance intention in video games use. Based on 343 completed responses from online gamers in Taiwan it was shown that Gratification (Achievement, Enjoyment, and Social Interaction) is the main predictor of intention to continue playing games in U\&G. Yee (2006) (paper ' $b$ ') also investigated the factors that motivate people to play video games through an empirical study. Through principle component analysis technique of 3,000 MMORPG players 10 
Ph.D. Thesis - Sepandar Sepehr; McMaster University - DeGroote School of Business.

factors were extracted (shown in Figure 3). These 10 factors were organized under three main components of Social, Immersion, and Achievement. Yee (2006) included competition (i.e. Dispositional Competitiveness) as a factor of Achievement.

Some studies explored the effect of competition in more detail. Competition has been hypothesized to have a direct effect on enjoyment of individuals in entertaining media, resulting in higher learning (Vorderer, Klimmt, \& Ritterfeld, 2004) (study 'k'). Reeve and Deci (1996) (paper 'c') studied the role of different elements of a competitive situation (i.e. competitive set, competitive outcome, and interpersonal context) on creating intrinsic motivation among participants who played a puzzle game. The results of this study showed that competitive outcome (i.e.winning vs. losing) and context (i.e.pressured vs. nonpressured) influence intrinsic motivation. The results of their path analysis also showed that winning (compared to losing) increased intrinsic motivation and a pressured (versus nonpressured) context decreased intrinsic motivation.

As Udvari and Schneider (2000) (study 'd') showed, the effects of competition vary in different people in different situations. In this study, the authors investigated how (intellectually) gifted children react to competition. The results of the research supported the claim that gifted children would work harder under competition and achieve higher performance compared to the situations where they do not compete with their classmates. However, these findings are not limited to gifted children. Through a set of studies, Maciejovsky and Budescu (2007) (study 'e') investigated the role of competitive auctions in groups. Their studies showed that competitive situation resulted in higher learning effects, higher knowledge sharing, and higher knowledge transfer to new reasoning problems. Other studies has also shown that gameplayers' motivation 
Ph.D. Thesis - Sepandar Sepehr; McMaster University - DeGroote School of Business.

to compete has a significant effect on the extent to which they perceive the game to be competitive (Vorderer, Hartmann, \& Klimmt, 2003a) (study 'k').

Various situational factors are expected to define competition and reactions of players to competition. Garcia and Tor (2009) (study 'm') introduced the $N$-Effect in competition, which explains that the number of competitors $(N)$ can have a defining role in competitive motivation of players. That is, as the number of competitors increases, it is more likely that the competitive motivation of players will decrease. The results, however, were more significant among individuals who are high in Social Comparison Orientation (SCO). But, SCO became less important as the number of competitors increased. Garcia and Tor (2009) also discussed that the closeness of relationship between competitors affects the social comparison and consequently competitive behaviour of players. The cultural differences among individuals (e.g., individualistic vs. collectivist) have also been shown to have a defining role in how cooperative or competitive individuals react to a group task (Cox, Lobel, \& McLeod, 1991) (study 'n').

Video games may also have negative outcomes. For example, as Skoric et al. (2009) (study 'f') showed, addictive tendencies of children towards video gaming (ages 8 to 12 years) negatively correlates with scholastic performance. Anderson and Brown (1984) (study ' $\mathrm{g}$ ') further studied the role of psychological feelings in creation of problematic behaviours such as gambling. Their findings showed that "arousal and excitement are major mediators of reinforcement and internal cues for gambling behaviour" (p. 406). This study showed that students who participated in the experiment would have higher heart rates when their gambling behaviour increased. Nonetheless, arousal does not only predict problematic behaviour. As Koo and Lee's (2011) study of 406 online consumers (study 'h') showed, arousal increases pleasure and results in higher attention to the activity. This is in line with earlier research on arousal that 
Ph.D. Thesis - Sepandar Sepehr; McMaster University - DeGroote School of Business.

supported the existence of a relationship between arousal and attention and performance in memorizing information (Eysenck, 1976) (study 'o').

Some studies have examined the effect of competition in creating Flow among gameplayers. In particular, Weibel, Wissmath, Habegger, Steiner, and Groner (2008) (study 'i’) conducted a multivariate experiment study that compared playing against a computer-controlled versus playing against a human-controlled opponent. Their findings showed that participants who played against a human-controlled opponent reported higher levels of Flow experience.

It is important to note the research depicted in Figure 3 is not meant to be an exhaustive representation of all extant literature in this domain. However, it does represent the essence of the research from the related fields, through which research gaps can be identified. As Figure 3 shows, there is a gap in extant literature in understanding the relationship between competition and Flow/engagement. Earlier studies have not investigated the process through which competition can influence the level of engagement in video gameplaying. 
Ph.D. Thesis - Sepandar Sepehr; McMaster University - DeGroote School of Business.

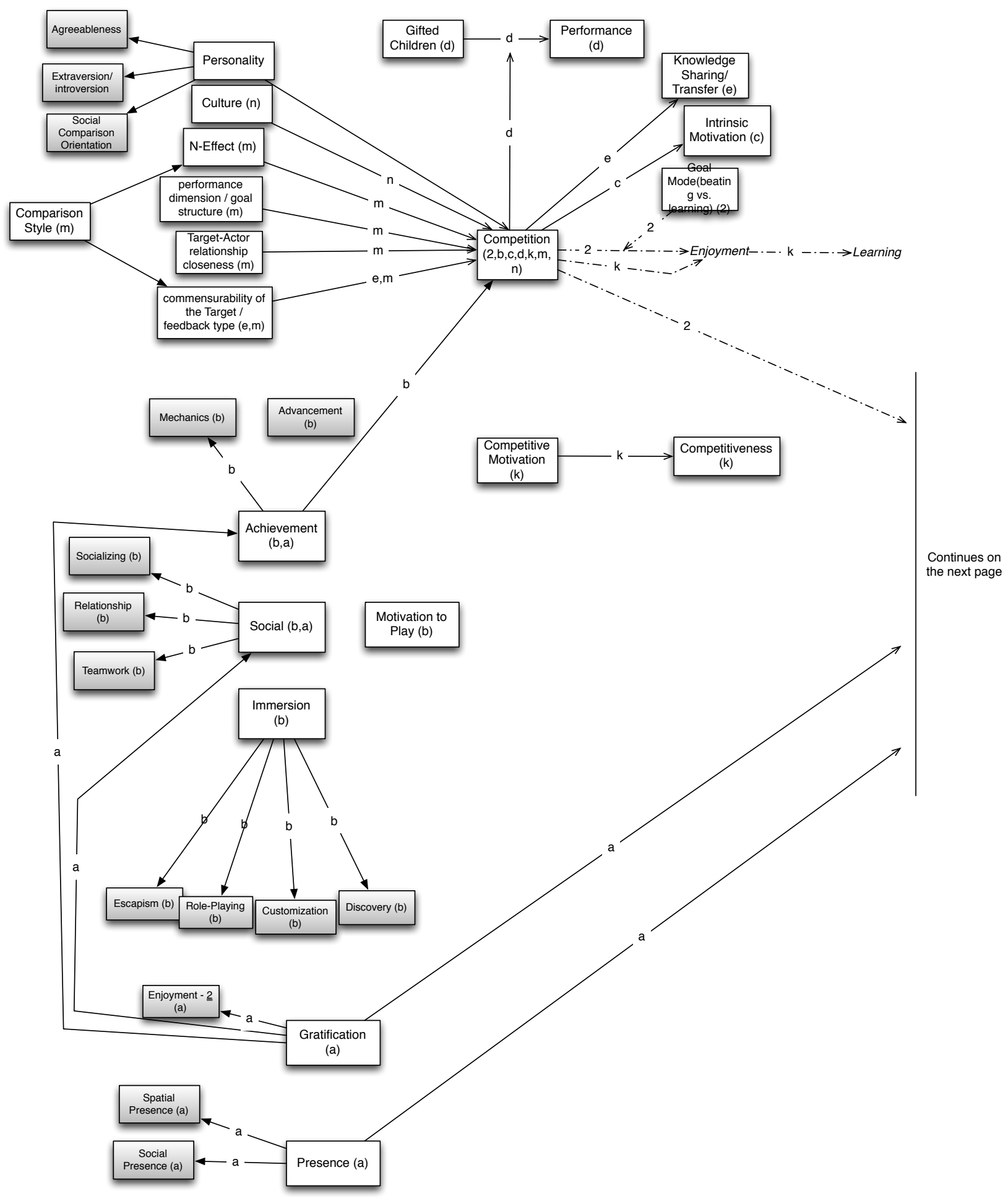

Figure 3 - Finding the Gap in Literature on Video Gameplay 
Ph.D. Thesis - Sepandar Sepehr; McMaster University - DeGroote School of Business.

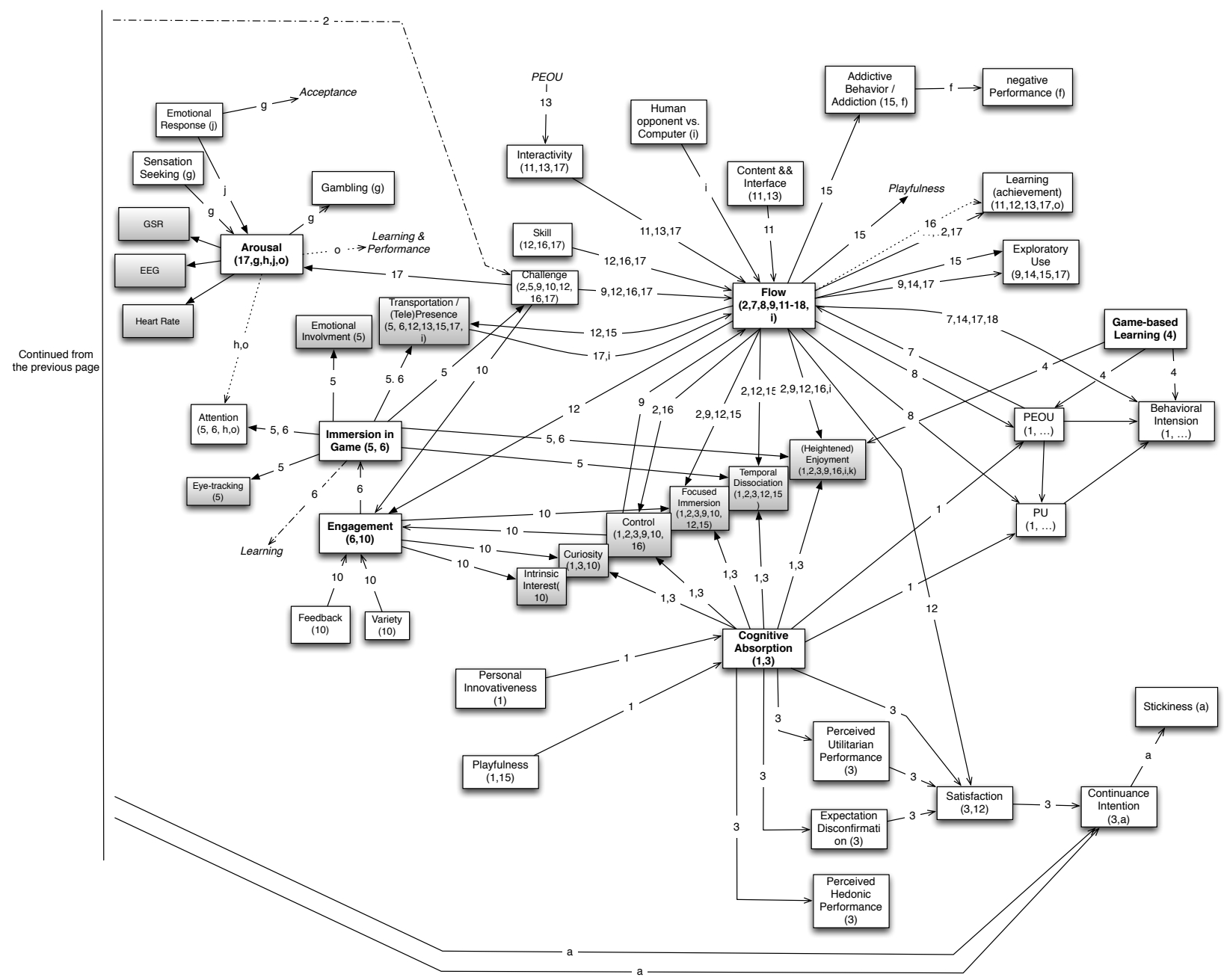

\section{Graph's Legend:}
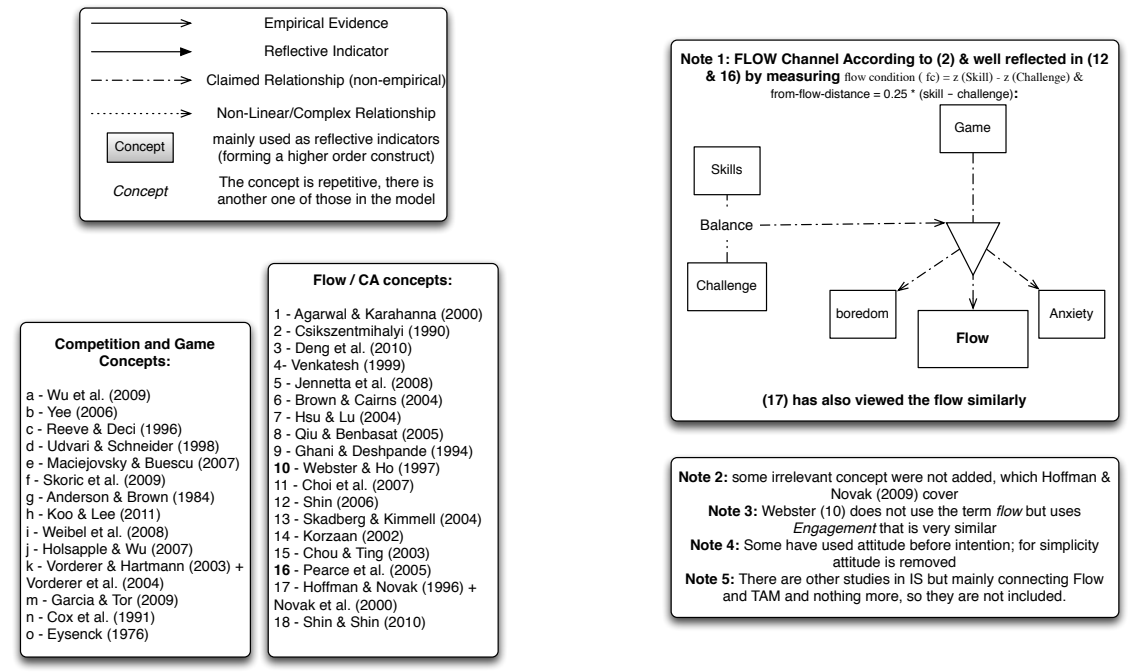

Figure 4 - Finding the Gap in Literature on Video Gameplay (continued) 
Ph.D. Thesis - Sepandar Sepehr; McMaster University - DeGroote School of Business.

In sum, regardless of the category of games (Serious Games or Gamification), competition is one of the design elements that are shared among most of the games that should be further researched regarding its outcomes on gameplayers. Based on the importance of the competition element in video games, this study further investigates the effect of various competition modes and perception of competitiveness during gameplaying. As such, the next chapter will propose a new theoretical model to help answer this study's research questions based on two theories of motivation. 
Ph.D. Thesis - Sepandar Sepehr; McMaster University - DeGroote School of Business.

\section{CHAPTER 3 - THEORETICAL FRAMEWORK AND DEVELOPMENT OF RESEARCH MODEL}

Self-Determination Theory (SDT) (Deci \& Ryan, 1985a) and Flow Theory (Flow) (Csikszentmihalyi, 1975) were chosen as the foundational theories for this study. While these two theories originated in the field of psychology, they have been studied and tested extensively in various disciplines and have been applied to different contexts. Both SDT and Flow are rooted in the investigation of intrinsic motivation among people in their daily activities. As explained below in more detail, both of these theories have a long history of being used to explain the motivational factors in engaging people while they play video games. As such, they are well suited for the current investigation.

The strength of SDT is in its richness and rigour in explaining the psychological aspects of humans in seeking intrinsic motivation. As shown in Figure 5, SDT is able to explain the process through which motivation is distilled for a person, in particular for a video gameplayer. On the other hand, researchers can use Flow for evaluating individuals' state of complete absorption during an activity. Flow Theory was first introduced by Mihaly Csikszentmihalyi in 1975 (Csikszentmihalyi, 1975) and evolved to its most seminal works in 1990s

(Csikszentmihalyi, 1991, 1997). Flow theory explains the state of deep engagement, which is the state that often video gameplayers experience during gameplay. SDT was a theory developed to understand intrinsic motivation based on psychological needs in 1980s (Deci \& Ryan, 1985a) while acknowledging Flow. Since their inception, SDT and Flow have evolved together. Figure 5 presents an overarching theoretical framework, employing and interfusing SDT and Flow theories. As the figure shows, SDT clarifies the procedure through which competition can create motivation, while Flow captures the state of engagement that results from this motivation. The 
Ph.D. Thesis - Sepandar Sepehr; McMaster University - DeGroote School of Business.

final outcome of engagement would be to increase performance/adoption/etc. To establish the connection between SDT and Flow, the two theories are explained in further detail below. The conjunction of these two of theories is also discussed.

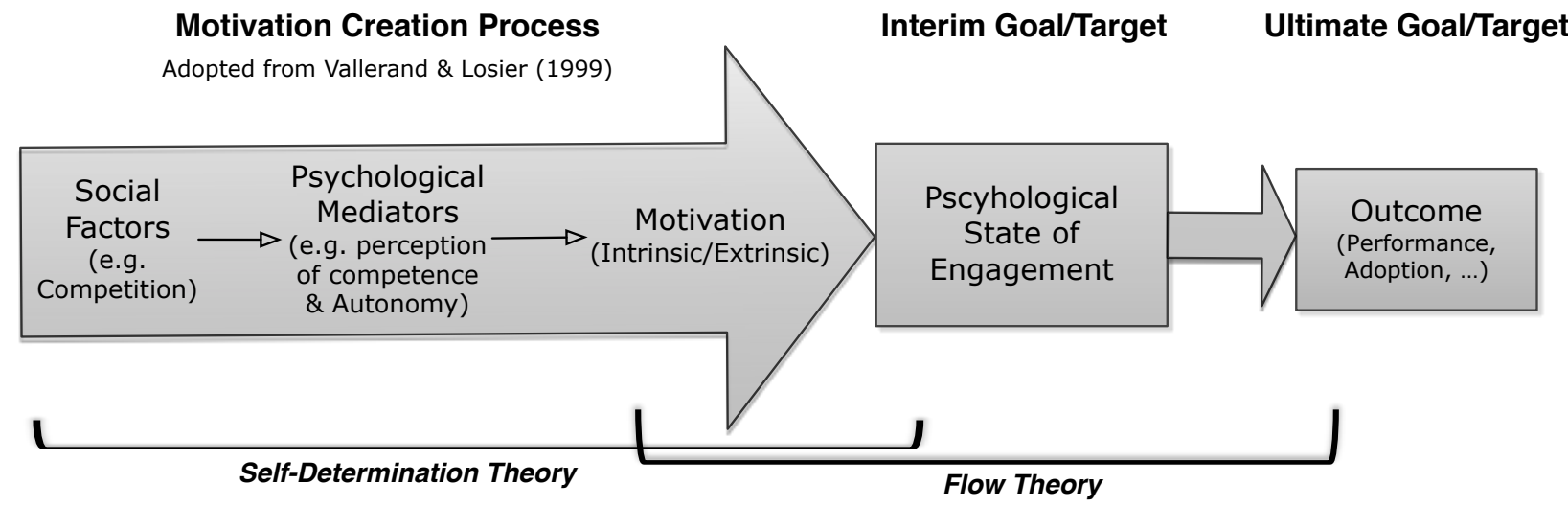

Figure 5 - Overarching Theoretical Framework

\subsection{Self-Determination Theory}

One of the main theories scholars deploy for explaining the formation of individual motivation in various fields is Self-Determination Theory (SDT; Deci \& Ryan, 1985a, 1991). SDT is not a single theory, but is an "organismic meta-theory" that frames five mini-theories on intrinsic and extrinsic motivation and related personality and behaviour (Ryan \& Deci, 2000a). This theory aims to understand the basic psychological needs that are the roots of intrinsic motivation, and consequently, what conditions support or prevent people from satisfying these needs - and as a result intrinsic motivation. These basic innate needs are competence, autonomy, and relatedness (Deci \& Ryan, 1980, 1991, 2000). The need for competence refers to the tendency of individuals to feel capable of performing a task (sense of self-efficacy). Autonomy, on the other hand is the propensity of people to have control over their actions and see themselves as the locus of causality. Autonomy - the feeling of self-initiation of the task - is also 
Ph.D. Thesis - Sepandar Sepehr; McMaster University - DeGroote School of Business.

referred to as perceived self-determination (Deci \& Ryan, 1985b). The last need, relatedness, suggests that people innately demand social connectedness.

SDT aims to understand social conditions and contexts as well as individual differences that enable motivation among humans as "active organisms" (Ryan \& Deci, 2000a). This theory, therefore, explains why and how various forms and levels of motivation are created in people. SDT directed research explain the effects of environment and personality on motivation (Ryan \& Deci, 2000a). The studies that are based on SDT also approach motivation research with the goal of understanding the implications of different forms of motivation. Since SDT's introduction in 1985, it has been employed in research of various fields and domains such as education, healthcare, organizational behaviour, psychotherapy and counselling, sport and physical education, and video games. As such, SDT provides a very strong addition to the theoretical framework of this study for understanding competition as a defining factor of motivation and engagement.

\subsubsection{SDT and Competition}

Various scholars have studied competition based on SDT. Since competition can be seen in sports, games, education, jobs, and basically everywhere, it has been examined by researchers in diverse fields. Researchers have attempted to understand if competition is a source of intrinsic or extrinsic motivation and how it affects individuals to compete (Deci, Betley, Kahle, Abrams, \& Porac, 1981; Vallerand, Gauvin, \& Halliwell, 1986b). Extrinsic motivation is often distinguished from intrinsic motivation based on the source or the reward that provokes the motivation. Specifically, "the reward for extrinsically motivated behaviour is something that is separate from and follows the behaviour" (Deci et al., 1981, p. 71). Deci et al. (1981) have employed a "free-choice time" technique to measure the intrinsic motivation of participants after 
Ph.D. Thesis - Sepandar Sepehr; McMaster University - DeGroote School of Business.

playing with a puzzle game and concluded that competition, regardless of the impact on performance, changes the nature of motivation from intrinsic to extrinsic. Free-choice time has been used by many other scholars to measure intrinsic motivation (e.g. Tauer \& Harackiewicz, 1999; Vallerand et al., 1986), where after the conclusion of experimental tasks, participants are left in the experiment room for a few minutes while being observed to see if they spontaneously continue playing the particular game of the experiment.

In competitive situations, when the focus is on the outcome of a task, the emotion of individuals is defined by the result of competition, namely winning and losing (Weinberg \& Jackson, 1979). As Vallerand, Gauvin, and Halliwell (1986) have shown, participants who lose in competition, perceive their intrinsic motivation lower than their opponents who won. In fact, after losing a competition, people evaluate their performance lower than their expectation for themselves, resulting in a decrease in their perceived competence (Tauer \& Harackiewicz, 1999) that is a requisite for being intrinsically motivated. In other words, if competition is understood as a tool to provide extrinsic reward (such as monetary rewards, deadlines, and prizes), similar to other types of extrinsic rewards it can have a negative effect on intrinsic motivation (Deci, Koestner, \& Ryan, 1999).

Deci and Ryan (1985a), based on Ross and den Haag's (1957) work, present two different forms of competition: direct and indirect. In direct competition, individuals compete against one another, while in indirect competition the focus is on impersonal standards such as performance. The results of previous studies show that direct competition decreases intrinsic motivation (Deci \& Ryan, 1985a). Indirect competition, on the other hand, can enhance competence and consequently intrinsic motivation if the attention is diverged from winning to improving performance. When the focus is on increasing performance, people who are successful (success 
Ph.D. Thesis - Sepandar Sepehr; McMaster University - DeGroote School of Business.

as a subjective measure in contrast to objective measure of winning/losing) in a competitive situation also show higher intrinsic motivation and enjoyment (McAuley \& Tammen, 1989).

Despite the negative effect of losing in competition on intrinsic motivation, the competition context in itself is a rich tool to create engagement through feedback (Tauer \& Harackiewicz, 1999). Much of the research on the motivational aspects of competition has focused on the consequences of losing versus winning a competitive task. Based on the three mini-theories, SDT explains the role of competition in creating motivation to participate in an activity through three principles: (1) The focus on competition's motivational forces should be shifted from the outcome results to the processes of competition regardless of outcomes; (2) Competition should not be seen as a pure extrinsic element; rather, it is best seen as a midpoint of motivation that is valuable in situations where intrinsic motivation does not exist by nature; and (3) Different people have different personality traits; thus, reactions of different people to competition may differ. These arguments will be depicted and the rationale for them will also be provided based on three of SDT mini-theories. These three mini-theories are Cognitive Evaluation Theory, Organismic Integration Theory, and Causality Orientation Theory. Each of these mini-theories have addressed intrinsic/extrinsic motivation, including within competition contexts, forms the basis of this research.

\section{Cognitive Evaluation Theory (CET)}

The first and most important mini-theory of SDT is Cognitive Evaluation Theory (CET). Deci and Ryan (1985a) presented CET to explain how social context can influence intrinsic motivation (positively or negatively). Based on CET, intrinsic motivation is the result of interpersonal events and structures (such as feedback and rewards) that increase the feeling of 
Ph.D. Thesis - Sepandar Sepehr; McMaster University - DeGroote School of Business.

competence, accompanied by satisfaction of the need for autonomy during an action to create intrinsic motivation (Ryan \& Deci, 2000b).

As mentioned before, competition can be direct or indirect. Indirect competition entails two aspects for providing feedback to the competitors: "Informational" and "Controlling" (Deci \& Ryan, 1985a). The Controlling aspect is dominant when competitors put all their effort into winning or feel pressure to beat a standard. This Controlling aspect is similar to other extrinsic reward systems, which decrease intrinsic motivation (Deci et al., 1981). On the other hand, the Informational aspect helps a person to increase his/her competence in the task he/she is competing in through mechanisms such as feedback. Through competition, one is able to assess their performance and build competence. As Vallerand, Gauvin, et al. (1986) explain, "competition constitutes a social event that can provide the individual with competence/incompetence information because social comparison processes are very prominent" (p. 467).

Reeve and Deci (1996) further clarify how external events affect motivation: "External events influence perceived competence via their informational aspect and influence perceived self-determination via their controlling aspect" (p. 24). An "Informational aspect" can have positive or negative influence, having positive effect increases the competence while negative affect decreases the competence of individuals. Therefore, in a competitive environment that supports autonomy of competitors by prohibiting controlling situations, informational feedback can impact intrinsic motivation positively. Moreover, social context of competition is claimed to be motivating by having influence on perception of autonomy and competence of players (Vallerand \& Losier, 1999). 
Ph.D. Thesis - Sepandar Sepehr; McMaster University - DeGroote School of Business.

In video games, non-controlling instructions and giving more options in a competitive situation is one approach to enhance informational feedback "and, in turn, intrinsic motivation" (Ryan, Rigby, \& Przybylski, 2006). Traditionally, the video gaming industry has been very successful at providing a medium for gameplayers in which they can satisfy their basic psychological needs. Clear goal structure and scoring systems have always been the main elements of video games, enabling gamers to evaluate and improve their competence. Recently, video games have become more flexible in their goal structures and have implemented more open and less structured playing environments (Przybylski, Rigby, \& Ryan, 2010). This change has created a gaming environment that supports autonomy of the users more than the classic styles of video games. In more recent years, video games have also improved their support of relatedness need among the gamers by expanding their territory to online virtual worlds (such as in games like World Of Warcraft). However, one can still observe the main element that stays dominant and maintains the attractiveness of video games is their simple scoring and goal structure, being a perfect example of an approach of competence enhancement. Competition has always been one of the main reasons that people play video games, which permits the players to compare their performance and evaluate their competence in gameplay (Sherry, Lucas, Greenberg, \& Lachlan, 2006). In sum, based on CET, competitive environments can be a factor for increasing motivation among players. Given that a video game avoids controlling elements and justifies autonomy of gameplayers, it can use informational feedback to increase competence.

\section{Organismic Integration Theory (OIT):}

The second mini-theory introduced in SDT is Organismic Integration Theory (OIT), which elaborates the concept of extrinsic motivation (Deci \& Ryan, 1985a). Based on OIT, 
Ph.D. Thesis - Sepandar Sepehr; McMaster University - DeGroote School of Business.

extrinsic motivation takes distinct forms based on the locus of causality of tasks and how much people internalize and integrate the motivation of a task. These extrinsic motivation types shape a continuum, ranging from pure extrinsic to pure intrinsic motivations as shown in Figure 6. On the left side of the continuum is the lack of motivation, which results in Amotivation of a person who does not care about the task. On the right side of this continuum, the traditional form of intrinsic motivation is depicted, in which behaviour is merely due to complete innate enjoyment of the self. Externally Regulated motivation can be seen in tasks that are fuelled by external rewards and controlled by an outside factor. This state relates to the classic extrinsic motivation that has been previously discussed.

Rather than having a binary view of extrinsic and intrinsic motivation, OIT differentiates between various forms of extrinsic motivation based on the approach to internalization and integration of the extrinsic motivation. This phenomenon attributes to the fact that often for an individual the source of motivation is not entirely extrinsic. Instead, people tend to receive a value or regulation and transform it into their own in a way that the source of value or regulation is no longer external, but rather internal to some extent. This process is referred to as internalization and integration.

The second form of extrinsic motivation, Introjected Regulation, is the first form of extrinsic motivation that addresses the internalization of an external factor. In this internalization process, people expect the motivation element to be initiated by themselves, but not completely. As a result of this controlled situation, one participates in the act "to avoid guilt or anxiety or to attain ego enhancements such as pride" (Ryan \& Deci, 2000b, p. 62). The next form of extrinsic motivation, Identified Regulation is another form of motivation where the source is more internalized for the actor. In this state, people personally value the factor of motivation and feel 
Ph.D. Thesis - Sepandar Sepehr; McMaster University - DeGroote School of Business.

autonomous in the task. At one end of the spectrum of extrinsic motivations, Integrated Regulation represents the most consciously self-regulated/self-determined type of motivation that is very similar to pure intrinsic motivation, but has an external motivating element.

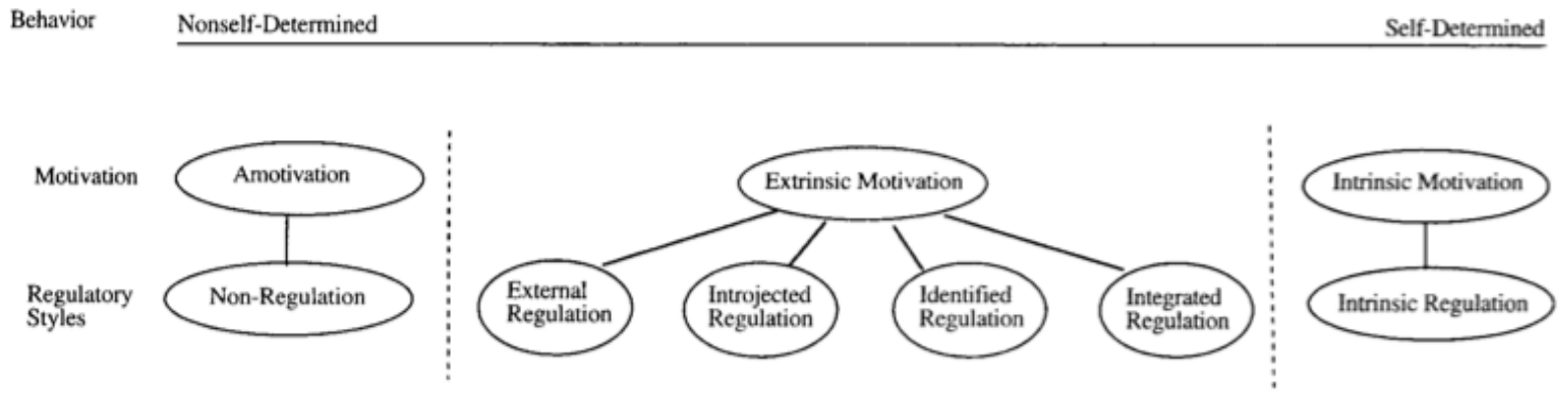

Figure 6 - The self-determination continuum (source: Ryan \& Deci, 2000)

Intrinsic motivation in the purest form is more desirable compared to any of the extrinsic motivation types. However, in the middle of the continuum, there are other types of extrinsic motivation that can be appropriate in situations of low intrinsic interest. There are situations that an individual lacks intrinsic motivation in an activity - e.g. when goal is to have all the students in the class to pay attention to a subject. In these cases, creating other forms of extrinsic motivation that are closer to intrinsic motivation on the spectrum of extrinsic motivation (i.e. Identified Regulation, Integration Regulation, or Introjected Regulation) could be beneficial for engaging people in the task. Video games are occasionally successful in creating various forms of extrinsic motivation based on the expectations of gamers (King \& Delfabbro, 2009). Competition in video games is one of those tools that can help create a moderate form of extrinsic motivation. During competition, people might become ego-involved -aiming to prove their values- as a result of trying to achieve a certain outcome (Vansteenkiste \& Deci, 2003). On the extrinsic motivation continuum, this competitive condition can be characterized as 
Ph.D. Thesis - Sepandar Sepehr; McMaster University - DeGroote School of Business.

Introjected Regulation form of motivation. As the internalization of the motivation to participate in the task increases, the person increases his/her perception of self-regulation and, as a result, experiences a more intrinsic feeling of motivation. This change of autonomy would be dependent on focusing more on the context of competition rather than the outcomes of competition (Tauer \& Harackiewicz, 1999). Increase of autonomy, as mentioned before, is dependent on lack of a controlling and presence of an informative environment. Altogether, a competitive situation can be a desirable tool -in the absence of intrinsic motivation - to create an environment of modest extrinsic motivation, which can eventually enhance the intrinsic motivation among the players.

\section{Causality Orientation Theory (COT):}

The last SDT mini-theory that is used here for background of this study's framework is Causality Orientation Theory (COT), which addresses the differences among people's behaviour regarding their dominant preference for motivation based on the level of causality in interaction with their environment (Deci \& Ryan, 1985a, 1985b). This categorisation of "causality orientation" includes: 1) autonomy orientation, 2) control orientation, and 3) impersonal orientation. In Autonomy Orientation, a person's behaviour sees the locus of causality to be the self (person initiating the behaviour). This group entails behaviours that are rooted in "choices based on an awareness of one's needs, feelings, and integrated goals" (Hodgins, Liebeskind, \& Schwartz, 1996). Control Orientation, on the other hand, is a characteristic of a person who has the tendency to value external factors such as rewards, approval, or achievements for shaping one's behaviour. Lastly, in Impersonal Orientation, behaviour is mainly shaped by feelings of helplessness concerning competence, resulting in a lack of intention to perform the related task. This last group is also referred to as Amotivation Orientation (Deci \& Ryan, 1985b). 
Ph.D. Thesis - Sepandar Sepehr; McMaster University - DeGroote School of Business.

Respectively, it is expected that during a competitive task in video games, people with different tendencies would react to competition differently based on the value they give to the environmental cues. Thus, we would expect the personality of people to be an important factor in the process of engaging in competitive tasks. Previous research has also shown that people with higher orientation towards achievement perceive competition to be more challenging and are more intrinsically motivated (Tauer \& Harackiewicz, 1999). Similar distinction can be noticed between males versus females participating in the same competitive task in such a way that females prefer competition that leads to success while males prefer to achieve domination (Przybylski et al., 2010), and females who are high in achievement orientation enjoy competitive tasks more than males who are high in achievement orientation (Tauer \& Harackiewicz, 1999). These studies have not directly examined the individual dissimilarities in competitive evaluation in the context of video games. However, there is no evidence to suggest that compared to nonvideo games, video games have different influence on the role of personal characteristics regarding orientation towards competition. In contrast, Ryan et al. (2006) have shown that "there is considerable variance between individuals in their overall experience of and motivation for computer games" (p. 354). In sum, based on COT it is expected that individual differences such as personality and gender will influence the process of motivation caused by competition.

\subsection{Flow Theory}

In the past decade there has been increased focus on hedonic systems and how people interact with them in the field of Information Systems (IS) (Lin \& Bhattacherjee, 2010; Van der Heijden, 2004). With this focus on hedonic systems, researchers have developed constructs to measure concepts such as 'enjoyment' and 'playfulness' (Holsapple \& Wu, 2007; Moon, 2001) of hedonic systems use. However, there is a need for the advancement of theories in the field of 
Ph.D. Thesis - Sepandar Sepehr; McMaster University - DeGroote School of Business.

IS to better explain the use of hedonic systems. As Lin and Bhattacherjee (2010) illustrate: "prior models of utilitarian system usage provide a limited understanding of one's usage of hedonic systems, given the motivational differences between using these two types of systems" (p. 163). Aside from the concepts that have been well established in this field, there are some theories that have been regularly used for explaining user interaction with hedonic systems. The theory of 'Flow' is one of those theories (Csikszentmihalyi, 1991), which aim to explain the "optimal holistic experience” (L. Deng, Turner, Gehling, \& Prince, 2010) while performing a task. Flow was initially studied among artists who feel complete involvement in their work (Csikszentmihalyi, 1991). This theory was further expanded to other leisure activities in order to study the engagement of people in what they do (Csikszentmihalyi, 1991). Flow aims to capture the state in which people are highly immersed in their act and feel intensely involved, which is a positive and desirable state for performing any kind of activity (Csikszentmihalyi \& LeFevre, 1989).

According to Flow theory, the balance between challenge and skill in a task results in a deeply engaging experience (Csikszentmihalyi, 1997; Ellis, Voelk1, \& Morris, 1994; Massimini \& Carli, 1988). The original model of Flow was a simple explanation of optimal experience as an equal balance between challenge and skill (Csikszentmihalyi, 1975) that is shown in Figure 7 (Left diagram). According to the original model, people experience the state of Flow while performing a task that has the same level of challenge as the level of skill the actors require to carry out that task. Csikszentmihalyi and Csikszentmihalyi (1988) later modified this model by proposing a four-state model, which "provides us a description of the experiential component of an activity as people's skill develops through repeated exposure to the activity" (Ellis et al., 1994, p. 338). Based on this model, Flow is experienced only when the level of challenge and skill of 
Ph.D. Thesis - Sepandar Sepehr; McMaster University - DeGroote School of Business.

an activity is higher than normal day-to-day life experiences. Thus, low levels of challenge and skills that result in lower extremes of Flow experience would create the feeling of apathy. Deep engagement, arousal, enjoyment, or focused immersion that are characteristics of the state of Flow would not be experienced in the stage of apathy. As it can be seen from both of the models, higher than average level of skills with low levels of challenge in a task causes a person to feel bored or in other words, to be in 'boredom' phase. On the other hand, when people are highly challenged and the level of challenge does not match their potential skills, this would make one anxious or to be in the state that Flow Theory classifies as "anxiety."
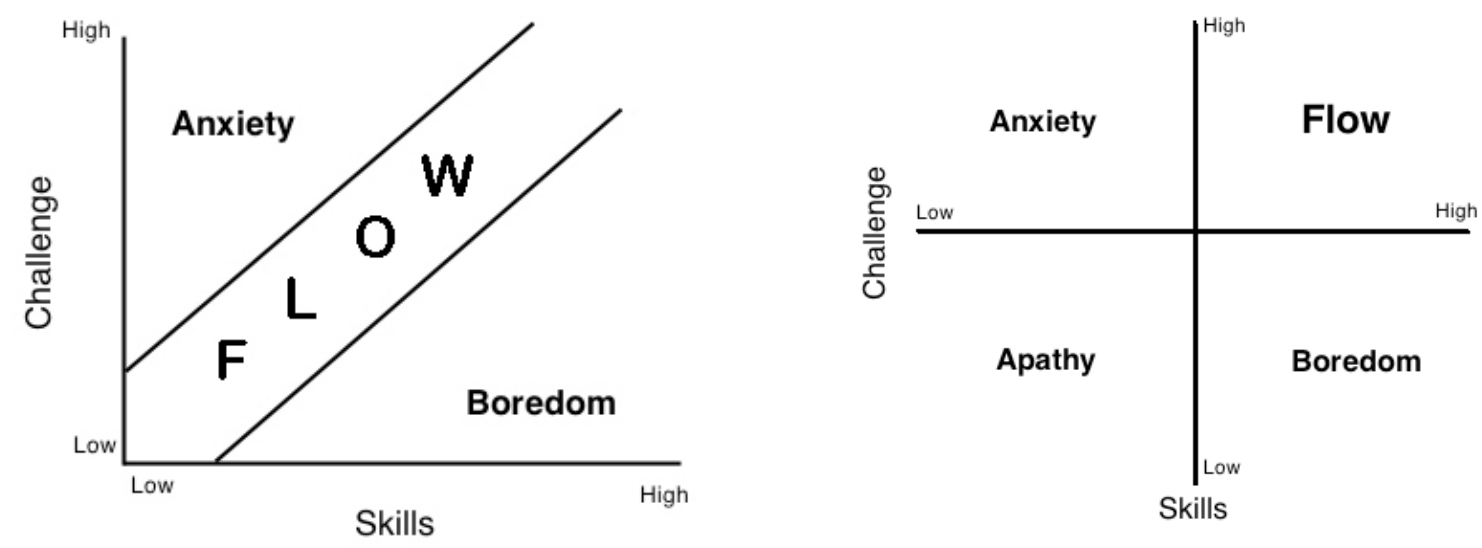

Figure 7 - Flow Models: Original Flow Model on the left and Four-State Flow Model on the right

Since the advent of the original Flow model, there have been some other variations introduced, based on the level of skill and challenge. The most well-known model is the eightstate model (Csikszentmihalyi, 1997; Csikszentmihalyi \& LeFevre, 1989; Massimini \& Carli, 1988; Takatalo, Nyman, \& Laaksonen, 2008) shown in Figure 8, which extends the previous models by adding four new states of Arousal, Control, Worry, and Relaxation that can be seen in the diagram in the respective regions of each state. The eight-state model is a more comprehensive model than the earlier versions and still has more parsimony compared to more complicated models (such as the 16-state model). This model also includes the state of Arousal. 
Ph.D. Thesis - Sepandar Sepehr; McMaster University - DeGroote School of Business.

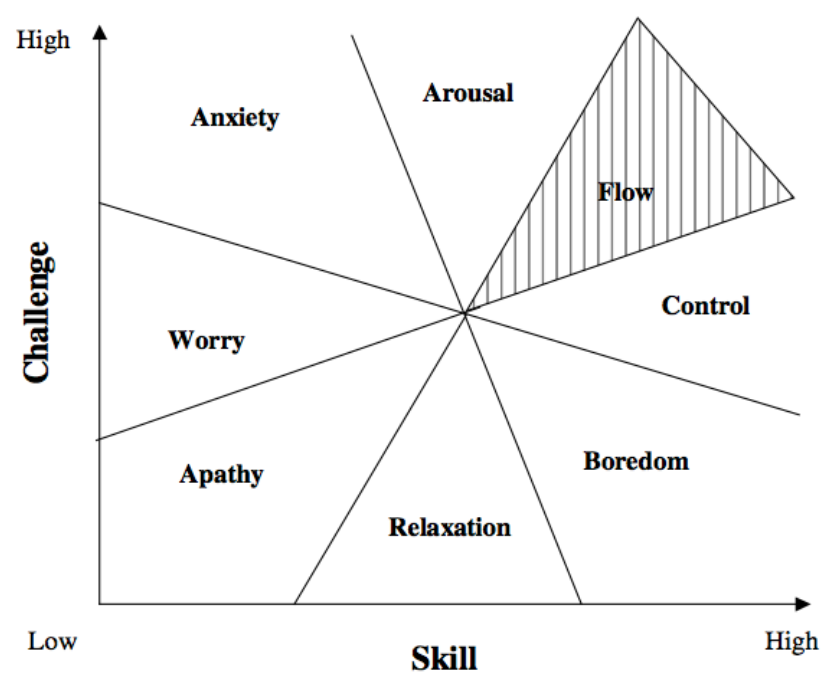

Figure 8 - Eight State Flow Model

Flow Theory has been adapted to the field of IS by Agarwal \& Karahanna (2000), where it is referred to as "Cognitive Absorption" (CA). CA is defined as a multidimensional construct, which reflects the satisfaction of users with IT systems, and consequently, their continuing usage intension (Agarwal \& Karahanna, 2000, p. 665). By incorporating the dimensions of constructs that were previously developed based on Flow, CA encapsulates five dimensions of temporal dissociation, focused immersion, heightened enjoyment, control, and curiosity, overarching Flow and engagement dimensions (Choi et al., 2007; Chou \& Ting, 2003; Korzaan, 2003; Novak, Hoffman, \& Yung, 2000; Shin, 2006; Skadberg \& Kimmel, 2004). Similarly, based on SDT (explained below), competitiveness of video games is hypothesized to be a tool to create the state of Flow (CA).

\subsubsection{Meta-analysis of Flow}

Different scholars have studied the positive effects of being in the state of Flow on various outcomes. These outcomes include positive attitudes and behavioural intentions 
Ph.D. Thesis - Sepandar Sepehr; McMaster University - DeGroote School of Business.

(Agarwal \& Karahanna, 2000; Chin-Lung Hsu \& Lu, 2004; Korzaan, 2003; Koufaris, 2002), learning performance (Choi, Kim, \& Kim, 2007; Xia Skadberg \& Kimmel, 2004), and exploratory behaviour (Chou \& Ting, 2003; Hoffman \& Novak, 1996). However, despite the general agreement on the basic conceptualization of Flow by Csikszentmihalyi (1997), there is no consensus on the instruments that are developed to operationalize Flow. Researchers have argued that this construct is "too broad and ill-defined due to the numerous ways it has been operationalized, tested, and applied" (Choi et al., 2007).

Given the importance of Flow in the current investigation, a meta-analysis was conducted to provide insight into the following Flow-related questions: (1) Among the empirical studies that have examined the positive impacts of Flow for particular hedonic systems, is there a consensus in their findings? (2) Are there any significant differences in the impact of findings between the measurements that are developed for the construct of Flow?

To answer these questions, a meta-analysis was conducted in order to consolidate the findings of previous studies that have used the theory of Flow to investigate hedonic IT use. Meta-analysis is an appropriate research method for answering the research questions mentioned above due to the richness and diversity of previous research in this domain. Details of the metaanalysis study can be found in Appendix 1.

Previous studies have shown that the construct of Flow has a moderate to large effect size on predicting relevant constructs of the Technology Acceptance Model (TAM) in IT usage, namely attitude towards use and intention to use. The number of published studies on the influence of Flow on attitude was not sufficient to draw a certain conclusion about its influence on attitude, despite the proper confidence interval. On the other hand, many empirical studies have been conducted that could be used for performing meta-analysis on the relation of Flow/CA 
Ph.D. Thesis - Sepandar Sepehr; McMaster University - DeGroote School of Business.

on intention to use. These studies support the claim that Flow is a suitable construct to predict the intention to use of IT. Additionally, it was shown that the operationalization approach of Flow plays an important role on the effect size of the relation between this construct and intention to use. This moderation effect indicates that the unidimensional instrument has medium prediction power compared to the high prediction power of multidimensional instruments (CA, engagement, and their variations) on intention to use hedonic systems. The $Q$-test ${ }^{8}$ also showed that the studies used for this meta-analysis were homogeneous in their effect size and the results are stable for this relationship, for both operationalization approaches. It was shown that multidimensional instruments for Flow/CA, to some extent, have similar effect size based on the low $Q$ level in the meta-analysis (high homogeneity, showing high reliability of the general findings).

There are both advantages and disadvantages in using any of the measurements with unidimensional or multidimensional questionnaires. The disadvantage of the multidimensional approach is that it increases the complexity of study, resulting in more complicated analysis and extending the length of questionnaire. However, unidimensional measures may not have the predictability power of multidimensional ones (like CA) and may not reflect the conceptual idea of Flow as well, despite their ease of administration and simplicity. In fact, unidimensional measures fail to include different dimensions of the main concept. In addition, using structural equation modeling (SEM) techniques, evaluation of models with multidimensional constructs would be easier ${ }^{9}$.

${ }^{8}$ Please refer to Appendix 1 for the explanation of the analyses conducted, including the definition of $Q$-test.

${ }^{9}$ For more information on multidimensional constructs and the guidelines for modeling them, one may refer to a recent article by Polites, Roberts, \& Thatcher (2012). 
Ph.D. Thesis - Sepandar Sepehr; McMaster University - DeGroote School of Business.

Hoffman and Novak (2009) recommend that whenever possible, both multidimensional and unidimensional measures should be deployed to strengthen the power of the instrument in a study. In other words, using multiple measurements, "the researcher would be in a position to analyze the data in multiple ways, observe consistencies or inconsistencies, and most importantly, to compare their results with researchers who used different approaches to measuring Flow" (Hoffman \& Novak, 2009, p. 29). Nevertheless, it is not clear how using both measurements can augment the calculations other than a simple comparison of two measurements (while creating a longer questionnaire). One use of gathering both measurements would be to follow the modeling of Guo and Ro (2008), in which one can use unidimensional measure's correlation with different dimensions in order to find the dimensions of the concept of Flow that are relevant to the context; thus, eliminate the dimensions that are not correlating with the unidimensional measure. Yet, using techniques such as PLS outer model loadings it is possible to identify the dimensions that would be proper for measuring Flow (similar to Agarwal and Karahanna, 2000). This approach can be based on a qualitative and/or pilot study and/or literature review to detect the relevant dimensions of Flow in a specific context (e.g. in interaction with recommendation agents or avatars). Hence, it is expected that using multidimensional measurements - whenever possible - to be more comprehensive and create less ambiguity for participants, therefore, to reduce measurement error. It is also possible for researchers to select a subset of the multidimensional construct, based on the relevance to the context and/or outcome of interest in their studies grounded in sound and reasonable theoretical justification (Polites, Roberts, \& Thatcher, 2012). Siekpe (2005) and Lin et al. (2008) are two examples of this approach (selecting a subset of Flow dimensions). 
Ph.D. Thesis - Sepandar Sepehr; McMaster University - DeGroote School of Business.

As the meta-analysis results showed, Flow has positive outcomes on attitude and intention; these outcomes are best captured when Flow is conceptualized in a multidimensional way. Therefore, multidimensional representation of Flow is the recommendation for researchers and what is being followed in the current investigation. For this research, regardless of the ease of instrument administration, it is critical to find the measurement that best represents the concept of Flow to ensure valid and reliable results. As such, in this study, three of the dimensions that were relevant to the context of video game-playing, namely Temporal Dissociation, Focused Immersion, and Heightened Enjoyment, were chosen to measure the concept of Flow. These dimensions will be used in this research and will be further discussed in the methodology section.

\subsection{Combining SDT and Flow}

Many of the studies on SDT and competition have explained the negative effect of competition outcomes on intrinsic motivation, in particular for losers. As a result, it should be mentioned that this study's framework is to evaluate motivation during competition prior to receiving the outcome that can decrease people's competence due to losing the game. Motivation during the game is independent of the outcome and is even more important than after the gameplay (Tauer \& Harackiewicz, 1999). This will allow for understanding the process that creates engagement in gamers. In other words, "effort during competition is not necessarily aligned with post-competition emotional responses" (Liu, Li, \& Santhanam, 2013). Based on SDT, people have tendency to satisfy their basic needs (competence, autonomy, and relatedness). This tendency is stronger specifically prior to receiving the final results (winning or losing). During competition, regardless of the outcome, people engage in the activity in order to achieve competence and autonomy, causing them to be motivated (Tauer \& Harackiewicz, 1999). This 
Ph.D. Thesis - Sepandar Sepehr; McMaster University - DeGroote School of Business.

motivation is not captured in earlier studies through the free-choice period ${ }^{10}$ approach, as this measurement is gathered after the game is over (e.g. in Vallerand et al., 1986b). In fact, rather than evaluating the motivation after the competition is finished and putting emphasis on outcomes, focus should be on the process through which the competitive situation motivates people to pay attention to the task they participate in.

As mentioned earlier, in order to provide a theoretical background for the effect that competition can have in engagement of video games, Flow Theory and SDT are used in conjunction. SDT explains the process in which competition in video games can motivate gamers by focusing on the context of the game and addressing individual differences. However, the goal of this research is not to evaluate pure intrinsic motivation of gamers, as video games can deploy extrinsic elements that highly engage players. One can expect that the competence factor of SDT is captured in the balance of challenge and skill in Flow Theory. Flow Theory also describes that very high competent players who are not challenged can experience boredom. Some authors have mentioned that Flow does not capture all the motivating factors in video games, which can be explained using SDT (Rigby \& Przybylski, 2009). That said, as described above, the focus of this study will not be on capturing all the dimensions of video games, but to understand the process through which competition creates engagement in gamers. Thus, studying competition as a fundamental element of video games, the foundational theories of this research explain that in absence of controlling elements (autonomy diminishing factors), competence becomes the major psychological need to consider (Jang, Reeve, Ryan, \& Kim, 2009). Przybylski et al. (2010) have

${ }^{10}$ Free-choice period the time at the end of an experiment that participants are left alone. Participants are monitored during this period in order to observer whether they continue performing the activity that they had completed during the experiment or not. 
Ph.D. Thesis - Sepandar Sepehr; McMaster University - DeGroote School of Business.

shown that each of the dimensions of SDT have an independent effect on gaming behaviour and perception, which shows the validity of investigating the effect of only one aspect independent of the other.

This research's theoretical framework expresses that SDT predicts motivation of people under the condition that autonomy is preserved (by avoiding the use of controlling feedback in the gaming context, conveying control to players). This motivation will lead to the experience of Flow (balance between challenge and skill), caused by competence evaluation due to informational feedback (explain in $§ 3.1 .1$ ). Deci \& Ryan (1985) have also expressed that Flow state is in "agreement" (p. 332) with their SDT"s concept of intrinsic motivation. In other words, while performing an activity, "when highly intrinsically motivated, organisms will be extremely interested in what they are doing and experience a sense of Flow" (Deci \& Ryan, 1985, p. 29). Flow theory allows us to properly capture the state of high engagement that can be the outcome of competitive feature motivators of video games.

\subsection{Proposed Research model and Hypotheses}

In this section the proposed research model is shown in Figure 9 and an associated ten hypotheses are presented. Hypotheses are explained from right to left (from H1 to H10), starting with the endogenous variable and its antecedent relationships. H1 to H6 aim to address the first research objective in regards to the effect of Situational Competitiveness on the antecedents of Flow and Satisfaction. H7, H8, and H9 are hypothesized in order to answer the questions related to the second research objective of this dissertation in regards to the effect of Competition Mode on Situational Competitiveness. Lastly, H10 addresses the third research objective of this research in regards to the effect of Dispositional Competitiveness on Situational Competitiveness. 
Ph.D. Thesis - Sepandar Sepehr; McMaster University - DeGroote School of Business.

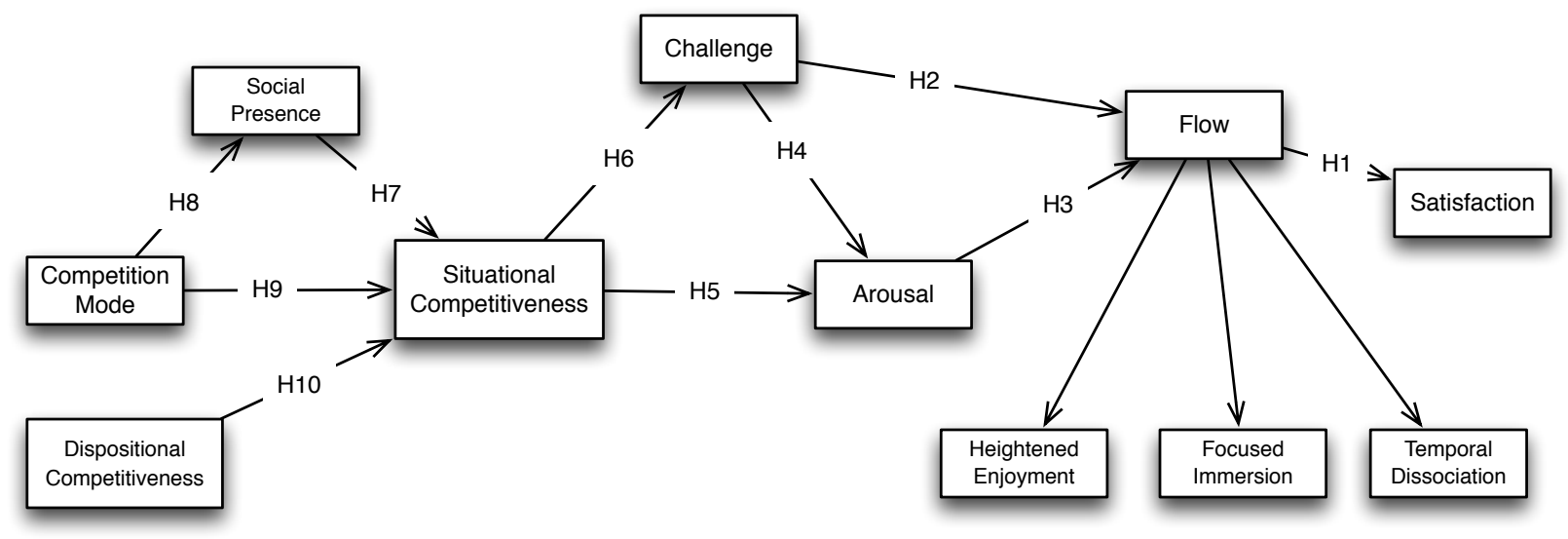

Figure 9 - Proposed Research Model of the Study

Satisfaction has been defined as "a sense of contentment that arises from an actual experience in relation to an expected experience" (Hernon \& Whitman, 2001, p. 32). Satisfaction with an IT system is an important factor due to its effect on attitude, intention, and continued usage of a technology or service (L. Deng et al., 2010; Oliver, 1977). In the current investigation, the game that was chosen as the basis of the empirical study was not one that participants would be likely to use in the future. As such, satisfaction with the game was deemed to be a more appropriate indicator of success with this technology experience and was chosen as the ultimate endogenous construct of the model.

Satisfaction can be attributed to a person's feelings or attitudes toward a variety of factors affecting a particular situation (Wixom \& Todd, 2005). Based on the theory of reasoned action (TRA), object-based attitude, recognized commonly as satisfaction, plays the role of an external variable for behavioural beliefs and attitude (i.e. perceived ease of use and perceived usefulness), which in return affect behavioural attitude and intention (Ajzen \& Fishbein, 1980). Users' satisfaction with a product is an important predictor of their attitude and intention toward that product (Oliver, 1977, 1980). DeLone and McLean's (1992, 2002, 2003) IS success model 
Ph.D. Thesis - Sepandar Sepehr; McMaster University - DeGroote School of Business.

reasons that for measuring the success of an IS product, the satisfaction of users after using the IS product can predict their intention to use, and therefore future usage of that IS product. The positive impact of satisfaction on attitude and intention to use have been shown in various contexts including continued use of online websites (Chia-Lin Hsu, Yu, \& Wu, 2014; Kang \& Lee, 2010), continued usage of Application Service Providers ${ }^{11}$ (Kim, Hong, Min, \& Lee, 2011), customer loyalty (Deng, Lu, Wei, \& Zhang, 2010), and online games (C.-C. Chang, 2013).

Based on the antecedents of satisfaction that DeLone and McLean (1992) introduced, i.e. information and system quality, Wixom and Todd (2005) divided satisfaction into information and system satisfaction. However, information quality is not relevant to the context and research questions of the current investigation. User's system satisfaction or satisfaction from the game, which is the main endogenous construct in this study, is referred to as satisfaction for simplicity.

According to Expectation Confirmation Theory (ECM/; Oliver, 1977, 1980), expectation reflects anticipated behaviour, and when a product or service outperforms our expectations, or creates positive disconfirmation for us, we would have satisfaction from using that product or service. The Flow experience during the video gameplay is the result of disconfirmation. This positive disconfirmation, according to ECM, results in satisfaction of the players from playing the video game. Therefore, in alignment with earlier research (C.-C. Chang, 2013; Chin-Lung Hsu, 2010; Shin, 2006) it is expected to see a direct relationship between Flow and reported Satisfaction of video gameplayers. Thus, it is hypothesized that:

Hypothesis 1: Higher levels of Flow experience of video gameplayers will increase their satisfaction.

${ }^{11}$ Application Service Provider (ASP) delivers application features to multiple customers from a data center across a wide area network (WAN) (Kim et al., 2011). 
Ph.D. Thesis - Sepandar Sepehr; McMaster University - DeGroote School of Business.

As explained earlier, Flow theory indicates that in order to reach the optimal state of flow, an activity should require skills from the performers that are in balance with the challenge that the activity creates. Shin (2006) defines challenge as "the degree to which individuals find it difficult to cope with specific task involved" (p. 706). If the level of Perceived Challenge compared to necessary skills in a computer task is too low, the users will lose interest in performing that task and the task becomes boring (Ghani \& Deshpande, 1994). Therefore, in order to reach the state of Flow, a video gameplayer should perform a task that requires a balance of challenge and skills (Csikszentmihalyi, 1991, 1997). In video games, where players learn the skills required for playing the game, increasing the level of challenge can create the balance between challenge and skill in playing the game, which can result in experiencing Flow.

Preliminary research shows that direct measurement of balance using the construct of Balance of Challenge and Skill, such as Guo and Poole's (2009) two item construct ${ }^{12}$ of Balance, tends to measure only the Skill antecedent of Flow rather than the actual balance between skills and challenges of participants. In fact, Guo and Poole's (2009) results showed that there is an abnormally high correlation between Balance and Skill constructs $(0.82)$, which may be an indication of multicollinearity. The alternative to measuring balance of Challenge and Skill would be to measure both of these constructs separately and develop a new calculated variable that would represent the construct of Balance. An example of this approach is proposed by Shin (2006) to create a new variable called flow condition $(f c)$ by calculating the difference between the (standardized) level of challenge and skill of the participants. However, using the standardized difference between two variables ignores the potential polynomial relationship between the three variables (i.e. Challenge, Skill, and Balance). Therefore, the only valid

${ }^{12}$ The items of Balance construct are: 1) My abilities matched the high challenge of the situation; and 2) I felt I was competent enough to meet the high demands of the situation. 
Ph.D. Thesis - Sepandar Sepehr; McMaster University - DeGroote School of Business.

solution to measure the relationship between Challenge and Skill's balance and Flow would be to use the polynomial regression technique. However, structural equation modelling does not allow the integration of polynomial regressions. As such, this relationship needs to be analyzed in separate analyses.

Generally, "along with individual skills, the challenges presented by an activity are the most important predictors of Flow" (Koufaris, 2002, p. 212). Consistent with Csikszentmihalyi's (1975) discussion on the role of challenge, other scholars have also found Perceived Challenge to have the highest effect on engagement in a computer related activity (Ghani \& Deshpande, 1994; Webster \& Ho, 1997). Thus, in line with extant literature on Flow (Ghani \& Deshpande, 1994; Shin, 2006; Pearce et al., 2005; Hoffman and Novak, 1996; Novak et al., 2000), the effect of Challenge on Flow will be measured independent of Skills in this investigation. This is based on the fact that the setting of the experiment of this research does not include a longitudinal component that would increase the level of Skill of the participants. Given that Skill does not considerably change throughought the experiment, it is expected that only Challenge will be manipulated based on the antecedents of the model. With a constant level of Skill, by increasing Challenge from low levels, it is hypothesized that Challenge will be matching the Skill level of video gameplayers and Flow would increase. As a result, consistent with previous research, we expect to see the same relationship between the perception of challenge in a video game and experiencing Flow by gameplayers.

In summary, it is hypothesized that:

Hypothesis 2: Higher levels of Perceived Challenge reported by the video gameplayers, will lead to a higher levels of Flow. 
Ph.D. Thesis - Sepandar Sepehr; McMaster University - DeGroote School of Business.

In online gaming, feelings similar to arousal have been identified as one main category in the criteria for engagement (Charlton \& Danforth, 2007), which can be associated with the experience of Flow. Neuroscientists have shown that emotional arousal enhances declarative memory, which can be the result of attention due to the arousal (Cahill \& McGaugh, 1998; Coull, 1998). Extant literature supports the effect of arousal on attention (an important dimension of Flow) for various tasks and contexts (Matthews \& Davies, 2001; Robbins, 1997). In the context of gambling, Brown (1986) explains that the increase of arousal in individuals narrows their attention. The theory of Optimum Stimulation Level (Raju, 1980) indicates that people prefer and function better in an optimum level of stimulation (arousal). Similarly, in video games, this sensation seeking behaviour can be seen as the root of the motivational factors for gamers, which influences their intense attention and enjoyment (Brown \& Cairns, 2004) that are other aspects of Flow experience.

Pace's (2004) grounded theory of Flow of web users shows the effect of challenge in information seeking tasks on the focused attention on that activity. In the video game context, it is expected to find the mediating effect of arousal on the relationship between challenge and attention. Moreover, Léger et al. (2010) have shown that arousal is highly correlated with heightened enjoyment. Tauer \& Harackiewicz (1999) found that positive affective responses including arousal- mediate the relationship between competition and task enjoyment. In summary, video gameplayers' arousal during the gameplay affects various dimensions of Flow. Thus, it is hypothesized that:

Hypothesis 3: Higher arousal levels of video gameplayers will increase their Flow experience. 
Ph.D. Thesis - Sepandar Sepehr; McMaster University - DeGroote School of Business.

Competition can be conceptualized as an individual personality trait (outlined below in hypothesis 9) or as a characteristic of the environment that an individual perceives. The latter form of competitiveness is known as "Situational Competitiveness", which explains the behaviour of people in a competitive context (Graziano, Hair, \& Finch, 1997). Individuals can react differently to various contexts - being cooperative in one context and being competitive in another.

Arousal, being a "reported subjective feeling", is the opposite of sleepiness (Russell, Weiss, \& Mendelsohn, 1989). When playing a video game, gamers face various challenges (Jennett et al., 2008), which result in emotional involvement potentially causing physiological alteration (Eysenck, 1976; Graziano, Feldesman, \& Rahe, 1985). According to the theory of Flow (Csikszentmihalyi, 1997), when challenge and skill are well balanced, individuals experience arousal. In fact, challenge is the most important determinant of Flow (ibid). However, higher levels of challenge that are not balanced with the skill level of the person might cause that person to become anxious and frustrated, which create emotional arousal in a person. Thus, it is hypothesized that:

Hypothesis 4: Higher levels of Perceived video game Challenge will increase feelings of Arousal.

Little is known about the mechanism through which competitiveness of a video game impacts one's motivation to play, and potentially to be addicted. Scholars studying addiction have indicated that gamblers experience feelings similar to being "hyped up", which they refer to as arousal (Titz, Andrus, Miller, \& others, 2001). Arousal has been conceptualized by Holsapple \& Wu (2007) as "the state of emotional and mental activation or alertness," (p. 87) which is an emotional response during the use of a hedonic IT product. Similar to gambling (Titz et al., 
Ph.D. Thesis - Sepandar Sepehr; McMaster University - DeGroote School of Business.

2001), it is expected to observe excitement among players of competitive video games due to having expectation in receiving rewards (often intrinsic) upon winning the game. Ravaja et al. (2006) support this claim by expressing that "social-competitive situation" increases arousal. Thus, it is hypothesized that:

Hypothesis 5: Higher Situational Competitiveness of a video game will increase Arousal of the players.

Challenge has been closely connected to competition (Vorderer, Hartmann, \& Klimmt, 2003b), where creating competitive situations is easily manifested through the creation of challenge (Csikszentmihalyi, 1991). Reeve and Deci's (1996) research on the effect of competition on intrinsic motivation showed that when competition provides proper forms of feedback, the task can become more challenging than not only when the task does not involve competition, but it can also be more challenging than when competition involves no feedback. Previous research has also shown that some people tend to search for competitive situations in order to create competition for themselves (Udvari \& Schneider, 2000). Webster \& Ho (1997) have used comparison techniques that motivate competitiveness in order to distill the level of challenge among students. In the context of video games, competition can be used to create challenge. Previous studies have shown that "competitive elements" used in video games provide interactivity and clear and immediate feedback, which enables "active engagement" and a sense of challenge (Vorderer et al., 2003a). Thus, it is hypothesized that:

Hypothesis 6: Higher Situational Competitiveness of a video game will increase Perceived Challenge of the players.

Social presence (the degree to which an individual is aware of another person in a communication interaction) has been studied in various contexts, in particular in website use, 
Ph.D. Thesis - Sepandar Sepehr; McMaster University - DeGroote School of Business.

where scholars have explained the positive effects of different human-centric features such as 'human images' (Cyr, Head, \& Ivanov, 2009; Hassanein \& Head, 2007). Social Facilitation Theory (SFT) (Zajonc, 1965) posits that the presence of others triggers the motivation to compete, and consequently, how people evaluate competitiveness of an environment. Moreover, previous research has shown the presence of others to directly affect people's competitive behaviour (Garcia \& Tor, 2009), indicating a salient effect of social presence on the perception of competitiveness. In other words, "social comparison processes fuel the motivation to compete" (ibid. p. 5). Thus,

Hypothesis 7: Higher perceptions of Social Presence will increase Situational Competitiveness of video game experience.

In video gameplay, players can have various modes of competitive playing. Some games, for example sandbox or open world games, provide immense freedom for players to explore and build new things. In these types of games, players do not have a means for comparison with other individuals, providing no medium for competition. In other types of games, which provide competitive elements, competition can be seen in three forms. In some video games, the game includes intelligent agents that can play sophisticatedly against a human player. Thus, they create a mode of competition against the computer. In other situations where games can be played with multiple users, players can compete against one another. In this case, the mode of competition can be divided into two modes that are defined by the relationship between the players; that is, the mode of competition can be categorized as competition against one's friend or a stranger.

In addition to the four modes mentioned above, one might argue that there exists another mode of competition where game does not include any explicit form of competition, yet the player is involved in competing against him/herself in order to improve his/her performance. 
Ph.D. Thesis - Sepandar Sepehr; McMaster University - DeGroote School of Business.

However, this potential competition mode is subjective in nature and cannot be objectively manipulated in the same fashion as the earlier mentioned modes. In fact, the four modes of competition discussed here can be controlled, whereas competition against one's self can not be controlled and can only be measured through self-report or some psychophysiological measures.

Straub \& Karahanna (1998) propose that the richer the communication medium between people is, the higher the perceptions of social presence. In the context of video games, this communication medium can include competition mode (communicating/competing with no one, with a computer or with a real person). In situations where gamers are aware of playing against a real person, it has been shown that they report higher levels of presence ${ }^{13}$, Flow, and enjoyment (Weibel, Wissmath, Habegger, Steiner, \& Groner, 2008). Similarly, Ravaja et al. (2006) have shown that playing video games with human opponents, compared to computer opponents, causes higher levels of emotional involvement, measured by presence, engagement, and arousal (physiological and self-reported). Ravaja et al. (2006) also found that playing against friends has a deeper level of emotional involvement compared to playing against strangers. Thus, it is hypothesized that:

Hypothesis 8: Different Competition Modes - no competition, competing against computer, competing against human strangers, and competing against human acquaintances/friends - will yield progressively more increased perceived Social Presence in a video games experience.

As previously mentioned (for hypothesis 5), competition can be situational or characterized as a personality trait. Individuals who possess a competitive personality trait or

\footnotetext{
${ }^{13}$ For the context of videogames, social presence, rather than a sense of presence in the environment, is of focus.
} 
Ph.D. Thesis - Sepandar Sepehr; McMaster University - DeGroote School of Business.

attitude are termed Dispositionally Competitive (Graziano et al., 1997). Early research has showed that Dispositionally Competitive people are more likely to perceive other people and situations as competitive and elicit competitive behaviour (Kelley \& Stahelski, 1970).

Individuals with higher orientation towards achievement are more intrinsically motivated through competition (Tauer \& Harackiewicz, 1999). Additionally, how people react to the challenge of an IT task is dependent on their personal characteristics and their condition while performing the computer task (Ghani \& Deshpande, 1994). Among gamblers, personality traits has an important effect in the level of arousal they seek and enjoy (Coventry \& Brown, 1993), which it is expected to be similar among gamers. Williams, Yee, \& Caplan (2008) further explain: "a player seeking to achieve and compete might process stimuli or model behaviours differently than someone interested in role play and immersion" (p. 1008). Previous research has also shown that people's motivation to compete significantly predicts how competitive they perceive a game to be (Vorderer et al., 2003b). On the other hand, situational competitiveness (introduced in $\mathrm{H} 2$ ), is affected by various contextual criteria. Based on Social Comparison Theory (Festinger, 1954), an important contextual criterion is comparison with other people. It is expected that, in a social setting, the closer the relationship among participants in a competitive task is, the greater the comparison and perceptions of competition. Thus:

Hypothesis 9: Different Competition Modes - no competition, competing against computer, competing against human strangers, and competing against human acquaintances/friends - will yield progressively more increased Situational Competitiveness in a video game experience.

Hypothesis 10: Individuals with higher levels of Dispositional Competitiveness will experience higher Situational Competitiveness in a video game environment. 
Ph.D. Thesis - Sepandar Sepehr; McMaster University - DeGroote School of Business.

\section{CHAPTER 4 - RESEARCH METHODOLOGY}

This chapter explains the research methodology that was used to address this study's research objectives and validate the theoretical model that was presented in the previous chapter. Prior to the development of the final model, a preliminary study, composed of one focus group and one longitudinal survey on an educational competitive game, was conducted in order to provide initial support for the proposed theoretical model and inform the full study procedures (discussed in Appendix 2). This preliminary study helped to understand the construct of Flow better and to identify when it is likely to be highest during the process of competition.

The main study was further refined through a pilot study, which provided procedural insights and reaffirmed when Flow is at its highest peak in the context of the specific game used in the main experiment.

\subsubsection{Data Collection Procedure}

An experiment was designed to examine the manipulation of four competition modes: (1) no competition, (2) competition with the computer, (3) competition with a human stranger opponent, and (4) competition with a human friend. Participants were recruited from the student population of a major Canadian university. Students are a suitable sample for this study as they have significant interest and experience in gaming (Beck \& Wade, 2006), and they represent the Millenial generation that is the focus of this research investigation. 114 students were recruited for the experiment, which is more than the required sample size for PLS analysis given the number of constructs and construct items in the model (Gefen, Straub, \& Boudreau, 2000) and provides adequate power for an acceptable effect size that is going to be illustrated in the next chapter (Faul, Erdfelder, Lang, \& Buchner, 2007). As described in the next chapter, post-hoc power analysis also showed that the achieved power for mean differences between the 
Ph.D. Thesis - Sepandar Sepehr; McMaster University - DeGroote School of Business.

independent variable of competition mode (i.e. Social Presence and Situational Competitiveness) were statistically significant, showing that the sample size was appropriate for analyses of this research.

\subsubsection{Pilot Study}

Prior to the main study's data collection, a pilot study was conducted with 19 students. The purpose of the pilot study was to test and refine the measurements that were adapted from extant literature. Additionally, after each interval of gameplay, a mini-survey of challenge, skill, and Flow were given to the participants (shown in Table 1). Through this technique the average timeframe that is proper for evaluating the proposed model during Flow state could be identified and the potential negative consequences of winning/losing predictions could be avoided. It was expected that the learning curve would flatten after a certain number of gameplaying repetitions, where Flow would be at its highest peak. Through the pilot study, however, different intervals were tested to find the best point during the game to give the survey to the participants.

Moreover, the pilot study helped us to resolve potential technical or procedural issues via openended questions.

Table 1 - Mini-Survey for Pilot Study (Adapted from Pearce et al., 2005)

\begin{tabular}{|c|c|}
\hline Construct & Question \\
\hline General Statement & $\begin{array}{c}\text { You have completed one stage of the game. } \\
\text { Before you continue please answer the following: }\end{array}$ \\
\hline Challenge & How challenging did you find this last stage? (5-point Likert scale) \\
\hline Skill & $\begin{array}{c}\text { Were your skills appropriate for performing this last stage? (5-point } \\
\text { Likert scale) }\end{array}$ \\
\hline
\end{tabular}


Ph.D. Thesis - Sepandar Sepehr; McMaster University - DeGroote School of Business.

Do you think you have experienced Flow during this last stage? (5-

Flow point Likert scale, followed by definition of Flow based on Novak et al.'s (2000) questionnaire ${ }^{14}$.

\subsubsection{Data Collection}

Due to the requirement of different competition modes, the challenge of recruiting friends for playing against each other had to be overcome. As such, the study was advertised inside multiple undergraduate classes (more than 1800 students) in person along with emails that were sent to undergraduate and graduate mailing lists. The students were given a small advertisement with the link to a website that they could register for an available time slot to participate in the experiment. The potential participants could choose a time slot and register with one of their friends, or register for any of the other time slots, in which they could be the only person in that time slot and be randomly assigned to one of the two individual modes (competing with computer and no competition) or someone else that they did not know could possibly register for that time slot, which would create the third competition mode of the experiment.

${ }^{14}$ Flow's definition: The word "Flow" is used to describe a state of mind that is sometimes experienced by people who are deeply involved in an activity. One example of flow is the case where a computer gamer is deeply involved in a game and achieves a state of mind where nothing else matters but the game. In other words, he or she is completely and totally immersed in it. Some people report this state of mind when engaging in various activities such as watching movies, reading novels, browsing the Web, or working.

Activities that lead to flow completely captivate a person for some period of time. When one is in flow, time may seem to stand still, and nothing else seems to matter. Flow may not last for a long time on any particular occasion, but it may come and go over time. Flow has been described as an intrinsically enjoyable experience 
Ph.D. Thesis - Sepandar Sepehr; McMaster University - DeGroote School of Business.

During the experiment, participants were asked to play a simple video game with educational content. The video game that was chosen for the experiment was TypeRacer ${ }^{\mathrm{TM}}{ }^{15}$, which is a simple typing game that is used to increase one's typing speed through a simulated multi-player car racing game. TypeRacer ${ }^{\mathrm{TM}}$ provides a simple environment and a simple task (typing) that everyone can relate to. It also enabled the creation of the four manipulation modes that this experiment required. In TypeRacer ${ }^{\mathrm{TM}}$ players have to type a (randomly assigned) text paragraph without any mistakes (refer to Figure 10 for an example of the game). As players advance in the selected text, their racing car advances in the field towards the finish line relative to the length of the text. If the player makes a mistake while typing the text, the car would stop and text would turn red. At any moment the player can see how fast they are typing by reading the quantified number of WPM (words per minute).

Go! Time remaining: $1: 17$

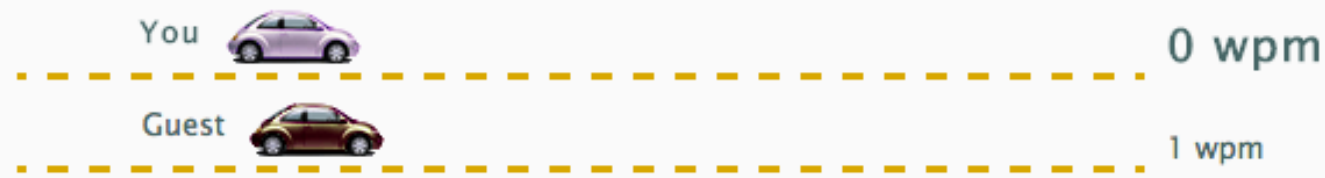

- - - - - - -

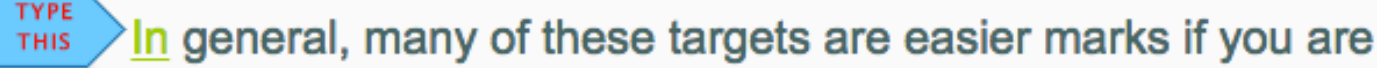
wearing the correct uniform. You should always have one suit or fashionable dress outfit hanging in the closet for the proper heists.

show just one line of text

HERE

1

Figure 10 - Screenshot of TypeRacer Game

For competition against another human (stranger or friend), the participants sat in two separate rooms with one experimental facilitator per room. In order to ensure consistency between both experimental facilitators and across time among all the participants, a dynamic

${ }^{15} \mathrm{http}: / /$ play.typeracer.com/ 
Ph.D. Thesis - Sepandar Sepehr; McMaster University - DeGroote School of Business.

website was designed for giving the instructions to the participants with all the links to the surveys and the game. In addition, a guideline (as shown in Appendix 3) was prepared for the facilitators, which detailed every step to run the experiment. After reading and signing the consent form (Appendix 4), participants were given a personality and general demographics questionnaire before playing the video game. Each participant was then introduced to the environment of the game and had a chance to practice it twice before the experiment began. For the experiment, each participant played 5 rounds of the game and after each round was asked to complete a mini-survey that briefly asked them about their challenge and experience. After completing the third round of the game, the participants were asked to complete a survey based on the measurement items of the proposed model. The third round was chosen for survey administration, as the outcome of the game was still unknown and it would be more likely creating the peak point for Flow based on preliminary studies (Appendix 2) and pilot study' results. As such, players would not bias their responses based on game results but rather focus their responses on the gameplay experience. The survey was implemented using LimeSurvey, which is a free and open-source survey application, on the DeGroote School of Business' server. Prior to any data collection, the McMaster Research Ethics Board approved the experiment's procedure and questionnaire's content.

\subsubsection{Instrument and Model Validation}

All the constructs that were used in this study came from extant literature where their items have been found to be reliable and valid. The constructs that are extracted from the extant literature and adapted to reflect the context of this research, in the order that appeared on the survey, are shown in Table 2. 
Ph.D. Thesis - Sepandar Sepehr; McMaster University - DeGroote School of Business.

Table 2 - Measurement scales for the constructs in the proposed research model

\begin{tabular}{|c|c|c|}
\hline Construct & Reference & Items \\
\hline $\begin{array}{c}\text { Dispositional } \\
\text { Competitiveness } \\
\text { (Personality) }\end{array}$ & $\begin{array}{l}\text { (Spence \& } \\
\text { Helmreich, } \\
\text { 1983) }\end{array}$ & $\begin{array}{l}\text { 1. I enjoy working in situations involving competition } \\
\text { with others. } \\
\text { 2. It is important to me to perform better than others } \\
\text { on a task. } \\
\text { 3. In general, I feel that winning is important. } \\
\text { 4. It annoys me when other people perform better then } \\
\text { I do. } \\
\text { 5. I try harder when I'm in competition with other } \\
\text { people. }\end{array}$ \\
\hline Social Presence & $\begin{array}{c}(\text { Gefen \& } \\
\text { Straub, 2003) }\end{array}$ & $\begin{array}{l}\text { 1. There is a sense of human contact in the game. } \\
\text { 2. There is a sense of personalness in the game. } \\
\text { 3. There is a sense of sociability in the game. } \\
\text { 4. There is a sense of human warmth in the game. } \\
\text { 5. There is a sense of human sensitivity in the game. }\end{array}$ \\
\hline $\begin{array}{c}\text { Situational } \\
\text { Competitiveness }\end{array}$ & $\begin{array}{c}\text { (C. a. Anderson } \\
\text { \& Carnagey } \\
\text { 2009) }\end{array}$ & $\begin{array}{l}\text { 1. To what extent did you feel like you were } \\
\text { competing with someone else. } \\
\text { 2. How hard were you trying to win the game. } \\
\text { 3. How competitive was this video game } \\
\text { 4. To what extent did this video game involve } \\
\text { competition. }\end{array}$ \\
\hline Arousal & $\begin{array}{c}\text { (Koo \& Lee } \\
\text { 2011) }\end{array}$ & $\begin{array}{l}\text { When I was playing the game, I felt (acted) } \\
\text { 1. Active } \\
\text { 2. Energetic } \\
\text { 3. Vigorous } \\
\text { 4. Sleepy (R) } \\
\text { 5. Excited }\end{array}$ \\
\hline
\end{tabular}


Ph.D. Thesis - Sepandar Sepehr; McMaster University - DeGroote School of Business.

\begin{tabular}{|c|c|c|}
\hline Challenge & $\begin{array}{c}\text { (Novak, } \\
\text { Hoffman, \& } \\
\text { Yung, 2000) }\end{array}$ & $\begin{array}{l}\text { 1. Playing the TypeRacer game challenges me to } \\
\text { perform to the best of my ability. } \\
\text { 2. Playing the TypeRacer game provides a good test of } \\
\text { my skills. } \\
\text { 3. I find that playing the TypeRacer game stretches my } \\
\text { capabilities to my limits. }\end{array}$ \\
\hline $\begin{array}{l}\text { Flow: Focused } \\
\text { Immersion }\end{array}$ & & $\begin{array}{l}\text { 1. While playing the game, I am able to block out most } \\
\text { other distractions. } \\
\text { 2. While playing the game, I am absorbed in what I am } \\
\text { doing. } \\
\text { 3. While playing the game, I am immersed in the task I } \\
\text { am performing. } \\
\text { 4. When playing the game, I get distracted by other } \\
\text { attentions very easily. } \\
\text { 5. While playing the game, my attention does not get } \\
\text { diverted very easily. }\end{array}$ \\
\hline $\begin{array}{c}\text { Flow: Heightened } \\
\text { Enjoyment }\end{array}$ & $\begin{array}{c}\text { (Agarwal \& } \\
\text { Karahanna, } \\
\text { 2000) }\end{array}$ & $\begin{array}{l}\text { 1. I have fun playing the game. } \\
\text { 2. Playing the game provides me with a lot of } \\
\text { enjoyment. } \\
\text { 3. I enjoy playing the game. } \\
\text { 4. Playing the game bores me. (R) }\end{array}$ \\
\hline $\begin{array}{l}\text { Flow: Temporal } \\
\text { Dissociation }\end{array}$ & & $\begin{array}{l}\text { 1. Time appears to go by very quickly when I am } \\
\text { playing the game. } \\
\text { 2. Sometimes I lose track of time when I am playing } \\
\text { the game. } \\
\text { 3. Time flies when I am playing the game. } \\
\text { 4. Most times when I play video games, I end up } \\
\text { spending more time that I had planned. } \\
\text { 5. I often spend more time playing video games than I }\end{array}$ \\
\hline
\end{tabular}


Ph.D. Thesis - Sepandar Sepehr; McMaster University - DeGroote School of Business.

\begin{tabular}{|c|c|c|}
\hline & & had intended. \\
\hline Satisfaction & & $\begin{array}{l}\text { 1. All things considered, I am very satisfied with the } \\
\text { (Wixom \& } \\
\text { Todd, 2005) }\end{array}$ \\
& $\begin{array}{l}\text { TypeRacer Game. } \\
\text { 2. Overall, my interaction with the TypeRacer game is } \\
\text { very satisfying. }\end{array}$ \\
\hline
\end{tabular}

\subsection{Manipulation Check}

The manipulated treatment in the main study is the competition mode of the gameplay (no competition; competing against a computer, against human strangers, and against acquaintances/friends). The participants answered the following series of questions following the gameplay in order to assess their awareness of the competition mode for validation of the treatments (Boudreau, Gefen, \& Straub, 2001):

What was the gaming mode you played in the last sets of game? (mark the proper answer)

\begin{tabular}{|l|l|}
\hline $\begin{array}{l}\text { No Competition / } \\
\text { Against Myself }\end{array}$ & \\
\hline $\begin{array}{l}\text { Competing Against } \\
\text { Computer }\end{array}$ & \\
\hline $\begin{array}{l}\text { Competing Against a } \\
\text { Human }\end{array}$ & \\
\hline
\end{tabular}

If you think the game's mode was competing against a human, how close do you evaluate your relationship with your opponent?

\begin{tabular}{|c|c|c|c|c|}
\hline $\begin{array}{l}\text { Completely } \\
\text { Unfamiliar }\end{array}$ & $\begin{array}{l}\text { Somewhat } \\
\text { Unfamiliar }\end{array}$ & Acquaintance & $\begin{array}{l}\text { Somewhat } \\
\text { Close }\end{array}$ & $\begin{array}{l}\text { Very } \\
\text { Close }\end{array}$ \\
\hline 1 & 2 & 3 & 4 & 5 \\
\hline
\end{tabular}


Ph.D. Thesis - Sepandar Sepehr; McMaster University - DeGroote School of Business.

During the last set of games, how many rounds of the game did you play?

During the last set of games, how many rounds did you win? 
Ph.D. Thesis - Sepandar Sepehr; McMaster University - DeGroote School of Business.

\section{CHAPTER 5 - DATA ANALYSIS AND RESULTS}

This chapter outlines the data analysis and results for validating the proposed Research Model of Competitive Video Gameplay (which included a pilot study). As mentioned in the methodology chapter, prior to testing the research model that answers the key research questions, a pilot study was conducted to help us finalize the design of the experiment's procedure and content of this research.

\subsubsection{Pilot Study}

A pilot study was conducted with 19 students from the DeGroote School of Business in order to resolve technical and procedural issues and to identify any problems with survey content. The survey included open-ended questions in order to receive feedback for resolving any issue with the design of the experiment as well as the survey questions. The pilot study also helped in designing the main experiment by reaffirming the best point (midway) in the experiment to hand out the complete questionnaire in the specific context of the TypeRacer game. The data collection procedure of the pilot study was slightly different than the main study's procedure (please refer to Appendix 5 for the explanation of the experiment's procedure). The duration of the experiment was the main difference between the pilot study and the main study. In the pilot study a partially repeated measures design was implemented by assigning each participant to two out of four modes of the game. With the assignment of two modes of the game, each experiment took more than one hour, resulting in some participants' frustration. As such, it was decided that participants in the main study should only be assigned one mode of gameplay.

The other take away of the pilot study relates to the timing of the complete survey. In the pilot study, each participant would play five rounds of the game, similar to the main experiment. 
Ph.D. Thesis - Sepandar Sepehr; McMaster University - DeGroote School of Business.

However, the complete survey was given to the participants in a random fashion. Based on the mini-surveys that were given to the participants during the pilot study, the end of the third round of the game to administer the complete survey was selected. This choice was based on changes in perceived engagement of participants (level of Flow experience) after each round of the game. The results of this study's analyses showed that before the third round there is a learning curve that effects the engagement of participants and after the third round engagement flattens. Rounds four and five would not be appropriate since as the preliminary study (Appendix 2) and pilot study showed that getting closer to the end of the competition might influence participants' engagement and satisfaction if they are certain to win or lose.

In the pilot study participants were not given a chance to practice with the game before starting the experiment. Pilot participants expressed that this was frustrating and that they wished they could play the game for one or two rounds in order to get used to its environment before starting the competition. As a result, for the main study, two rounds of practice prior to the main part of their experiment were added (one of the four modes of the game).

\subsubsection{Full Study}

\section{Data Screening}

The collected data was screened for normality of distributions, missing data, and outliers. The details of these analyses are examined below.

\section{Frequencies, Distributions, and Missing Data}

Using SPSS v22 various statistics such as mean, minimum, maximum, standard deviation, skewedness, kurtosis, and histogram charts were inspected for all the measured variables and composite variables. All the variables fell within acceptable thresholds. The 
Ph.D. Thesis - Sepandar Sepehr; McMaster University - DeGroote School of Business.

histograms were also inspected to identify clear anomalies in the distributions. The distributions tend to follow the normal curve's distribution and no clear anomaly was identified. There was however some bias towards higher or lower values for some variables such as bias towards higher values for temporal dissociation dimension of Flow, which could be expected due to the engaging nature of the experiment due its employing a video game. It is evident that using a video game made the experiment more exciting than what participants would expect from an experiment. This was also expressed in the open-ended answers. None of the construct variables had missing data, which may be attributed to the controlled laboratory design of this experiment.

\section{Outliers}

To identify outliers, a univariate outlier test was conducted by performing a z-test for extreme values of each variable. Any variable that had a case with z-score of higher than the critical value of 3.29 was investigated (Tabachnick \& Fidell, 2001). From all the variables, only Arousal and Heightened Enjoyment (HE) had one outlier case, namely case 32 with Arousal value of -3.91 and case 22 with $\mathrm{HE}$ value of -3.96 . Both of these cases were further examined for any other problematic behaviour in their responses. No problematic behaviour was observed with these cases and their results for Arousal and HE seem to be genuine responses. Therefore, these cases were kept in the dataset.

In order to check multivariate outliers, Mahalanobis distance (Meyers, Gamst, \& Guarino, 2006) was used. Mahalanobis distance "measures the multivariate "distance" between each case and the group multivariate mean” (Meyers et al., 2006, p. 67). A case could be considered an outlier based on this analysis if its Mahalanobis distance was equal or above the critical threshold of 21.67. This threshold is calculated based on the Chi-square value for 9 degrees of freedom at alpha level of $p<.001$. Again, the two cases of 22 and 32 were identified 
Ph.D. Thesis - Sepandar Sepehr; McMaster University - DeGroote School of Business.

as outliers with Mahalanobis distance of 28.16 and 31.54 respectively. However, as mentioned before, after inspecting their responses, no evidence of problematic behaviour was found. Their low score of enjoyment and arousal was attributed to participating in the no competition mode. These two participants were not excited by the game when no competition was involved.

In sum, the data was kept intact with no missing variable data.

\subsubsection{Participant Demographics and Control Variables}

In addition to the variables in the proposed model, general demographic information was gathered from participants. Out of the 114 participants, $65(57 \%)$ were female and $49(43 \%)$ were male. The average age of the participants was $20.66(\mathrm{SD}=4.74)$ with the distribution as shown in Table 1. Minimum and maximum ages of participants in the sample were 17 and 46 respectively. The sample is skewed towards younger population, which is the main target of this research.

Table 1 - Age Distribution of Participants

\begin{tabular}{|c|c|c|}
\hline Age Group & Frequency & Percent \\
\hline $17-22$ & 93 & $82 \%$ \\
\hline $23-29$ & 14 & $12 \%$ \\
\hline $30+$ & 7 & $6 \%$ \\
\hline
\end{tabular}

Some other questions regarding control variables (education, ethnicity, and first language) were asked from the participants, the results of which are shows in Table 2 . The majority of the participants finished high school since most were recruited from undergraduate classes at a large Canadian university. Most of the participants were white or Asian/Pacific Islanders. With respect to the first language of participants, even though the majority spoke 
Ph.D. Thesis - Sepandar Sepehr; McMaster University - DeGroote School of Business.

English as their first language, $37 \%$ of participants spoke English as their second language.

These demographic variables were examined for any potential influence on the proposed research model.

Table 2 - Frequencies of Demographic Variables

\begin{tabular}{|c|c|c|c|}
\hline Variable & Category & Frequency & Percentage \\
\hline \multirow[t]{3}{*}{ Education } & High School & 89 & $78 \%$ \\
\hline & $\begin{array}{l}\text { Bachelor's or } \\
\text { College Degree }\end{array}$ & 12 & $11 \%$ \\
\hline & Master's Degree & 12 & $11 \%$ \\
\hline \multirow[t]{7}{*}{ Ethnicity } & White & 40 & $36 \%$ \\
\hline & Hispanic or Latino & 1 & $1 \%$ \\
\hline & $\begin{array}{c}\text { Black or African } \\
\text { American }\end{array}$ & 2 & $2 \%$ \\
\hline & $\begin{array}{l}\text { Asian/Pacific } \\
\text { Islander }\end{array}$ & 54 & $49 \%$ \\
\hline & Middle Eastern & 11 & $10 \%$ \\
\hline & Aboriginal & 1 & $1 \%$ \\
\hline & South Asian & 2 & $2 \%$ \\
\hline \multirow[t]{2}{*}{ Language } & $\begin{array}{l}\text { English as First } \\
\text { Language }\end{array}$ & 72 & $63 \%$ \\
\hline & $\begin{array}{c}\text { English as Second } \\
\text { Language }\end{array}$ & 42 & $37 \%$ \\
\hline
\end{tabular}

Additionally, participants were asked about their previous experiences with computers, the Internet, and video games. As Table 3 shows, participants were comfortable with using computers and the Internet. Moreover, video gaming experience was normally distributed around average levels. The majority of participants were not serious video gameplayers or competitors. 
Ph.D. Thesis - Sepandar Sepehr; McMaster University - DeGroote School of Business.

Thus, it can be concluded that the majority of the participants would not have an advantage due to their gaming experience.

Table 3 - Participants' Previous Experience Statistics

\begin{tabular}{|c|c|c|c|}
\hline Variable & Category & Frequency & Category \\
\hline \multirow{7}{*}{$\begin{array}{l}\text { Computer } \\
\text { Experience }\end{array}$} & Not at all & 0 & $0 \%$ \\
\hline & To a little extent & 1 & $1 \%$ \\
\hline & To some extent & 4 & $4 \%$ \\
\hline & To a great extent & 41 & $36 \%$ \\
\hline & $\begin{array}{c}\text { To a very great } \\
\text { extent }\end{array}$ & 68 & $59 \%$ \\
\hline & Mean & \multicolumn{2}{|c|}{4.54} \\
\hline & $\begin{array}{l}\text { Standard } \\
\text { Deviation }\end{array}$ & \multicolumn{2}{|c|}{0.61} \\
\hline \multirow{7}{*}{$\begin{array}{c}\text { Internet } \\
\text { Experience }\end{array}$} & Not at all & 0 & $0 \%$ \\
\hline & To a little extent & 0 & $0 \%$ \\
\hline & To some extent & 2 & $2 \%$ \\
\hline & To a great extent & 41 & $36 \%$ \\
\hline & $\begin{array}{c}\text { To a very great } \\
\text { extent }\end{array}$ & 71 & $62 \%$ \\
\hline & Mean & \multicolumn{2}{|c|}{4.61} \\
\hline & $\begin{array}{l}\text { Standard } \\
\text { Deviation }\end{array}$ & \multicolumn{2}{|c|}{0.53} \\
\hline \multirow{5}{*}{$\begin{array}{c}\text { Gaming } \\
\text { Experience }\end{array}$} & Not at all & 13 & $11 \%$ \\
\hline & To a little extent & 23 & $20 \%$ \\
\hline & To some extent & 44 & $39 \%$ \\
\hline & To a great extent & 23 & $20 \%$ \\
\hline & To a very great & 11 & $10 \%$ \\
\hline
\end{tabular}


Ph.D. Thesis - Sepandar Sepehr; McMaster University - DeGroote School of Business.

\begin{tabular}{|c|c|c|}
\hline \multirow{2}{*}{} & extent & 3.00 \\
\cline { 2 - 3 } & Mean & 1.12 \\
\cline { 2 - 3 } & $\begin{array}{c}\text { Standard } \\
\text { Deviation }\end{array}$ & \\
\hline
\end{tabular}

\subsubsection{Research Model Validation}

The proposed research model was measured and validated through a couple of steps.

First, standard tests were employed to assess construct reliability and convergent and discriminant validity. Then, to validate the proposed model, Structural Equation Modeling (SEM) was used. Since the model includes a second-order construct (Flow), Partial Least Squares (PLS), in particular SmartPLS software was used. PLS also allows for both exploratory and confirmatory assessments and inclusion of second order constructs.

All the constructs that are used in the model are reflective constructs. In order to test the construct reliability of the deployed constructs, Cronbach Alpha, composite reliability, and Average Variance Extracted (AVE) were calculated. The only item out of the 43 measured items that was problematic was the reversed coded item in Focused Immersion (i.e. "While playing the game, I was able to block out most other distractions") that lowered the reliability of this construct significantly. Therefore, for the rest of the analysis this item was removed, making Focused Immersion a two-item construct. As shown in Table 4, all of the constructs have higher than the suggested critical value of 0.7 for Cronbach Alpha (Nunnally \& Bernstein, 1994). In addition, Composite Reliability and AVE are higher than 0.8 and 0.5 , respectively, as recommended by previous scholars (Chin, 1998; Fornell \& Larcker, 1981; Nunnally \& Bernstein, 1994). The only construct that has a slightly lower AVE is Flow, which is a secondorder construct where it was not expected to see similar behaviour to the first-order constructs 
Ph.D. Thesis - Sepandar Sepehr; McMaster University - DeGroote School of Business.

(Mackenzie, Podsakoff, \& Podsakoff, 2011). In fact, the AVE for a second-order construct can be calculated "by averaging the squared multiple correlations for the first-order sub-dimensions (or averaging the square of each sub-dimension's completely standardized loading on the second-order construct)" (Mackenzie et al., 2011, p. 313). As such, the AVE of Flow construct equals 0.56 with the given dataset, showing that the majority of variance in the second-order latent construct is shared with its first-order dimensions.

Table 4 - Construct Reliability of the Constructs in the Model

\begin{tabular}{|c|c|c|c|c|}
\hline Construct & $\begin{array}{c}\text { Number of } \\
\text { items }\end{array}$ & AVE & $\begin{array}{c}\text { Composite } \\
\text { Reliability }\end{array}$ & $\begin{array}{c}\text { Cronbach } \\
\text { Alpha }\end{array}$ \\
\hline Mode & 1 & 1.000 & 1.000 & 1.000 \\
\hline $\begin{array}{c}\text { Dispositional } \\
\text { Competitiveness }\end{array}$ & 5 & 0.541 & 0.853 & 0.805 \\
\hline Social Presence & 5 & 0.617 & 0.889 & 0.848 \\
\hline $\begin{array}{c}\text { Situational } \\
\text { (Perceived) } \\
\text { Competitiveness }\end{array}$ & 4 & 0.734 & 0.917 & 0.879 \\
\hline $\begin{array}{c}\text { Challenge } \\
\text { Arousal }\end{array}$ & 3 & 0.735 & 0.892 & 0.826 \\
\hline Flow & 9 & 0.470 & 0.869 & 0.825 \\
\hline $\begin{array}{c}\text { Focused } \\
\text { Immersion }\end{array}$ & 2 & 0.767 & 0.868 & 0.698 \\
\hline $\begin{array}{c}\text { Heightened } \\
\text { Enjoyment }\end{array}$ & 4 & 0.667 & 0.870 & 0.783 \\
\hline $\begin{array}{c}\text { Temporal } \\
\text { Dissociation }\end{array}$ & 3 & 0.700 & 0.875 & 0.792 \\
\hline \begin{tabular}{c} 
Satisfaction \\
\hline
\end{tabular} & 2 & 0.919 & 0.958 & 0.912 \\
\hline
\end{tabular}


Ph.D. Thesis - Sepandar Sepehr; McMaster University - DeGroote School of Business.

Fornell \& Larcker (1981) explain that if a construct meets these requirements for reliability, it can be concluded that the construct has convergent validity. Therefore, it can be said that each of the items in the proposed model loads on its own latent construct strongly, indicating high convergent validity.

Discriminant validity enables us to check whether the items of a construct are only related to that construct and no other construct in the model. In order to test the discriminant validity of the evaluated constructs, a confirmatory factor analysis (CFA) was conducted to generate a matrix of loadings and cross loadings. Each item was carefully examined and confirmed to load on its corresponding construct stronger than other constructs as per the Gefen and Straub's (2005) guideline of testing for CFA. The only item that seems to be problematic is Heightened Enjoyment 1 (HE1: "Playing the game bored me"), which had to be removed from the rest of the analysis as its loading on the HE construct was not at least one order of magnitude larger than its cross-loading on other constructs.

Table 5 - Cross Loadings Matrix for al the First-Order Constructs (significant at 0.001)

\begin{tabular}{|c|c|c|c|c|c|c|c|c|c|}
\hline & DCompt & SP & SCompt & Ch & AR & FI & HE & TD & SA \\
\hline DCompt1 & $\mathbf{0 . 5 8 3}$ & 0.052 & 0.181 & 0.054 & 0.167 & 0.066 & 0.142 & 0.084 & 0.249 \\
\hline DCompt2 & $\mathbf{0 . 8 2 3}$ & 0.089 & 0.243 & 0.140 & 0.166 & 0.049 & 0.223 & 0.060 & 0.111 \\
\hline DCompt3 & $\mathbf{0 . 7 1 7}$ & 0.146 & 0.154 & 0.066 & 0.112 & 0.039 & 0.127 & 0.076 & -0.043 \\
\hline DCompt4 & $\mathbf{0 . 6 6 9}$ & 0.034 & 0.097 & 0.094 & 0.066 & 0.029 & 0.259 & 0.046 & 0.058 \\
\hline DCompt5 & $\mathbf{0 . 8 5 2}$ & 0.105 & 0.402 & 0.267 & 0.112 & 0.072 & 0.144 & 0.059 & 0.158 \\
\hline SP1 & 0.104 & $\mathbf{0 . 8 1 6}$ & 0.415 & 0.168 & 0.185 & -0.055 & 0.270 & 0.326 & 0.209 \\
\hline SP2 & 0.082 & $\mathbf{0 . 7 3 1}$ & 0.307 & 0.203 & 0.126 & -0.073 & 0.140 & 0.131 & 0.146 \\
\hline SP3 & -0.004 & $\mathbf{0 . 7 8 3}$ & 0.375 & 0.152 & 0.185 & 0.023 & 0.186 & 0.224 & 0.124 \\
\hline SP4 & 0.179 & $\mathbf{0 . 7 8 8}$ & 0.281 & 0.137 & 0.148 & -0.101 & 0.147 & 0.206 & 0.131 \\
\hline SP5 & 0.154 & $\mathbf{0 . 7 5 7}$ & 0.260 & 0.074 & 0.048 & -0.199 & 0.076 & 0.200 & 0.083 \\
\hline SCompt1 & 0.305 & 0.478 & $\mathbf{0 . 8 6 9}$ & 0.363 & 0.330 & 0.084 & 0.337 & 0.270 & 0.350 \\
\hline SCompt2 & 0.349 & 0.297 & $\mathbf{0 . 8 3 6}$ & 0.402 & 0.387 & 0.084 & 0.363 & 0.317 & 0.405 \\
\hline SCompt3 & 0.279 & 0.369 & $\mathbf{0 . 8 4 7}$ & 0.464 & 0.359 & 0.021 & 0.259 & 0.201 & 0.280 \\
\hline SCompt4 & 0.268 & 0.350 & $\mathbf{0 . 8 8 7}$ & 0.468 & 0.359 & 0.090 & 0.292 & 0.194 & 0.272 \\
\hline
\end{tabular}


Ph.D. Thesis - Sepandar Sepehr; McMaster University - DeGroote School of Business.

\begin{tabular}{|l|l|l|l|l|l|l|l|l|l|} 
CH1 & 0.217 & 0.160 & 0.526 & $\mathbf{0 . 9 0 1}$ & 0.440 & 0.273 & 0.329 & 0.301 & 0.490 \\
\hline CH2 & 0.156 & 0.146 & 0.351 & $\mathbf{0 . 8 3 9}$ & 0.197 & 0.166 & 0.162 & 0.150 & 0.326 \\
\hline CH3 & 0.142 & 0.201 & 0.343 & $\mathbf{0 . 8 3 9}$ & 0.280 & 0.136 & 0.253 & 0.261 & 0.402 \\
\hline AR1 & 0.156 & 0.161 & 0.297 & 0.305 & $\mathbf{0 . 7 8 6}$ & 0.290 & 0.493 & 0.267 & 0.487 \\
\hline AR2 & 0.123 & 0.154 & 0.319 & 0.313 & $\mathbf{0 . 8 9 6}$ & 0.359 & 0.614 & 0.397 & 0.573 \\
\hline AR3 & 0.088 & 0.150 & 0.347 & 0.340 & $\mathbf{0 . 8 5 1}$ & 0.318 & 0.565 & 0.337 & 0.580 \\
\hline AR4 & 0.115 & 0.051 & 0.272 & 0.254 & $\mathbf{0 . 5 0 0}$ & 0.194 & 0.281 & 0.250 & 0.358 \\
\hline AR5 & 0.177 & 0.193 & 0.370 & 0.266 & $\mathbf{0 . 7 7 3}$ & 0.240 & 0.593 & 0.331 & 0.457 \\
\hline FI1 & 0.054 & -0.056 & 0.085 & 0.158 & 0.321 & $\mathbf{0 . 9 0 0}$ & 0.331 & 0.236 & 0.264 \\
\hline FI3 & 0.081 & -0.103 & 0.058 & 0.267 & 0.331 & $\mathbf{0 . 8 6 8}$ & 0.219 & 0.258 & 0.325 \\
\hline HE1 & 0.116 & -0.032 & -0.121 & -0.163 & 0.048 & 0.134 & $\mathbf{0 . 2 0 6}$ & -0.022 & -0.021 \\
\hline HE2 & 0.233 & 0.257 & 0.425 & 0.321 & 0.690 & 0.253 & $\mathbf{0 . 9 1 9}$ & 0.445 & 0.667 \\
\hline HE3 & 0.213 & 0.168 & 0.329 & 0.305 & 0.608 & 0.324 & $\mathbf{0 . 9 5 1}$ & 0.439 & 0.639 \\
\hline HE4 & 0.167 & 0.225 & 0.295 & 0.261 & 0.614 & 0.295 & $\mathbf{0 . 9 4 0}$ & 0.454 & 0.603 \\
\hline TD1 & 0.097 & 0.230 & 0.178 & 0.172 & 0.450 & 0.370 & 0.546 & $\mathbf{0 . 8 5 1}$ & 0.404 \\
\hline TD2 & 0.005 & 0.238 & 0.302 & 0.251 & 0.176 & 0.123 & 0.200 & $\mathbf{0 . 7 9 7}$ & 0.196 \\
\hline TD3 & 0.091 & 0.274 & 0.269 & 0.330 & 0.357 & 0.151 & 0.362 & $\mathbf{0 . 8 7 3}$ & 0.315 \\
\hline SA1 & 0.139 & 0.160 & 0.347 & 0.473 & 0.576 & 0.299 & 0.646 & 0.363 & $\mathbf{0 . 9 5 8}$ \\
\hline SA2 & 0.175 & 0.197 & 0.378 & 0.460 & 0.655 & 0.335 & 0.642 & 0.367 & $\mathbf{0 . 9 5 9}$ \\
\hline
\end{tabular}

An additional test for discriminant validity was conducted whereby a correlation matrix was generated with square root of AVE values of each construct on the diagonal cells. It can be seen in Table 6 that square root of AVE for all constructs is significantly higher than the correlations with the other constructs (numbers in their corresponding row and column). As a result, and since all AVEs are higher than 0.5 it can be concluded that the proposed model's constructs demonstrated discriminant validity (Chin, 1998).

Table 6 - Discriminant Validity Assessment Table using Construct Correlation Matrix and Square Root of AVE

\begin{tabular}{|c|c|c|c|c|c|c|c|c|c|c|}
\hline & Mode & DCompt & SP & SCompt & CH & AR & FI & HE & TD & SA \\
\hline Mode & $\mathbf{1 . 0 0 0}$ & & & & & & & & & \\
\hline DCompt & 0.016 & $\mathbf{0 . 7 3 6}$ & & & & & & & & \\
\hline SP & 0.365 & 0.072 & $\mathbf{0 . 7 8 5}$ & & & & & & & \\
\hline
\end{tabular}


Ph.D. Thesis - Sepandar Sepehr; McMaster University - DeGroote School of Business.

\begin{tabular}{|c|c|c|c|c|c|c|c|c|c|c|}
\hline sCompt & 0.531 & 0.306 & 0.436 & 0.857 & & & & & & \\
\hline $\mathbf{C H}$ & 0.123 & 0.235 & 0.163 & 0.459 & 0.857 & & & & & \\
\hline AR & -0.002 & 0.177 & 0.172 & 0.398 & 0.384 & 0.771 & & & & \\
\hline FI & -0.004 & 0.068 & $\begin{array}{c}- \\
0.063\end{array}$ & 0.077 & 0.228 & 0.362 & 0.876 & & & \\
\hline HE & 0.086 & 0.205 & 0.213 & 0.372 & 0.307 & 0.671 & 0.304 & 0.938 & & \\
\hline TD & 0.177 & 0.069 & 0.265 & 0.291 & 0.274 & 0.404 & 0.262 & 0.482 & 0.837 & \\
\hline SA & 0.019 & 0.171 & 0.145 & 0.367 & 0.481 & 0.636 & 0.304 & 0.672 & 0.385 & 0.959 \\
\hline
\end{tabular}

Lastly, the variables in the model should have no multicollinearity, which arises from having exogenous variables in the model that are highly correlated. Multicollinearity shows that two variables are "highly confounded with one another" and simply they measure the same phenomenon, or it becomes impossible to identify the effect of one versus the other (Meyers et al., 2006). Existence of multicollinearity is a problem in SEM due to the increase in the effect of independent variables on one another, making the interpretation of the variate in the model and identifying the effect of a single variable more complicated (Hair, Black, Babin, \& Anderson, 2009). To check for multicollinearity, three tests were conducted: 1) test of the correlation matrix, 2) test of the condition index, and 3) test of the Variance Inflation Factor (VIF). First, checking the correlation table matrix (Table 6), it is evident that none of the constructs is highly correlated with another one as the correlations are all well below the 0.8 critical value (Tabachnick \& Fidell, 2001). Second, in SPSS, a simple multiple regression was conducted with all the variables in the model except satisfaction as independent variables and satisfaction as the dependent variable. The results of multicollinearity test in SPSS show that all condition indices were below the 30 critical value (Pedhazur, 1997), except the last dimension, which had variance of more than 0.5 for only one variable (constant value). This further shows the lack of 
Ph.D. Thesis - Sepandar Sepehr; McMaster University - DeGroote School of Business.

multicollinearity as criteria for diagnosing multicollinearity is to have condition index of higher than 30 for one dimension "coupled with variance proportions greater than .50 for at least two different variables" (Tabachnick \& Fidell, 2001, p. 91). Finally, to test multicollinearity, VIF and Tolerance values of the multiple regression conducted in the previous test were evaluated.

Scholars define 0.1 and lower for tolerance values and 10 or greater for VIF values as signs of multicollinearity issue (Stevens, 2012; Tabachnick \& Fidell, 2001). All of the model's tolerance values are well above 0.1 and VIFs are all smaller than 3 (well below 10 critical value), also showing that the variables have no multicollinearity problem.

\subsubsection{The Structural Model Evaluation}

SmartPLS was used to test the structural equation model using the cross-sectional data gathered throughout experiments. The results of the PLS analysis is presented in Figure 11. The level of significance for each relationship is calculated based on the t-statistics of bootstrapping process with 500 resampling cases.

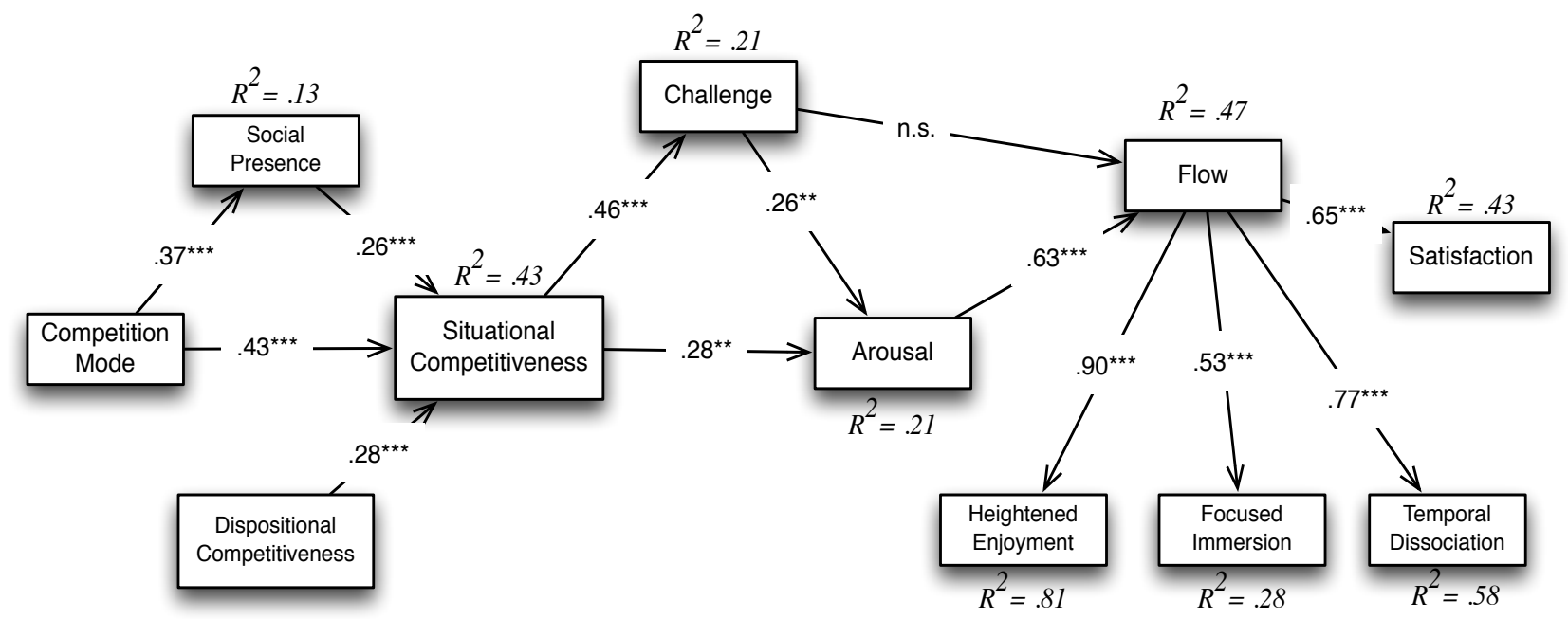

Figure 11 - Result of PLS Analysis of the Proposed Structural Equation Model

$$
\begin{aligned}
& * *_{*}^{*}: \text { significant at } \mathrm{p}<.001 \\
& { }^{* *}: \text { significant at } \mathrm{p}<.01 \\
& \quad * \text { significant at } \mathrm{p}<.05
\end{aligned}
$$


Ph.D. Thesis - Sepandar Sepehr; McMaster University - DeGroote School of Business.

All the relationships in the model were significant, except the relationship between Challenge and Flow. This may be due to the fact that Arousal mediates the relationship between Challenge and Flow (further explained below). In addition, the variance explained for the endogenous variables is all above $10 \%$ as per Falk \& Miller's (1992) recommendation. The variance explained of the last endogenous construct (Satisfaction) is $R^{2}=0.43$ further supporting the validity of the proposed model. A summary of the hypothesis findings is provided in Table 7.

Table 7 - Summary of Findings for Supporting the Proposed Hypotheses

\begin{tabular}{|c|c|c|c|c|c|}
\hline Hypothesis & Path & $\begin{array}{c}\text { Path } \\
\text { Coefficient }\end{array}$ & t-Statistic & Sig. Level & Validation \\
\hline H1 & Flow $\rightarrow$ SA & .65 & 9.93 & .000 & Supported \\
\hline H2 & CH $\rightarrow$ Flow & .12 & 1.23 & .104 & Not Supported \\
\hline H3 & AR $\rightarrow$ Flow & .63 & 6.66 & .000 & Supported \\
\hline H4 & CH $\rightarrow$ AR & .26 & 2.69 & .003 & Supported \\
\hline H5 & SCompt $\rightarrow$ AR & .28 & 2.44 & .008 & Supported \\
\hline H6 & SCompt $\rightarrow$ CH & .46 & 6.71 & .000 & Supported \\
\hline H7 & SP $\rightarrow$ SCompt & .26 & 3.30 & .000 & Supported \\
\hline H8 & Mode $\rightarrow$ SP & .37 & 4.06 & .000 & Supported \\
\hline H9 & Mode $\rightarrow$ SCompt & .43 & 5.55 & .000 & Supported \\
\hline H10 & DCompt $\rightarrow$ SCompt & .28 & 3.63 & .000 & Supported \\
\hline
\end{tabular}

\section{Mediation Test (Challenge $\rightarrow$ Arousal $\rightarrow$ Flow)}

Based on the theory of Flow, it was expected that there would be a significant relationship between Challenge and Flow. However, the only non-significant relationship in the model was for the hypothesis of the effect of Challenge on Flow. As such, it is likely that 
Ph.D. Thesis - Sepandar Sepehr; McMaster University - DeGroote School of Business.

Arousal is fully mediating the relationship between Challenge and Flow. In order to test for mediation effect of Arousal on the relationship between Challenge and Flow further analysis was conducted. These steps were taken to check the mediation effect:

1. Flow was regressed on Challenge

2. Arousal was regressed on Challenge

3. Flow was regressed on Arousal and Challenge at the same time

The result of both step 1 and 2 were significant at $p<.01$ with standardized coefficient (Beta) value of .275 and $p<.001$ with Beta value of .357 respectively. Step 3 showed that when both variables are used together in multiple regression on Flow, the effect of Arousal on Flow is high and significant $(B=.562$ for $p<.001)$ while the effect of Challenge on Flow is 0 and not significant at any level. This shows that despite the effect of Challenge on Flow, Arousal fully mediates the relationship between these two variables.

\section{Goodness of Fit}

SmartPLS, unlike covariance-based SEM tools such as LISREL, AMOS, and Mplus does not provide a Goodness of Fitness (GoF) index. However, it is possible to calculate a GoF based on the results of SEM in SmartPLS in order to assess the fit of the model. Here Wetzels, Odekerken-Schroder, \& Van Oppen's (2009) approach was used (Equation 1) for measuring GoF of a variance-based SEM such as PLS.

Equation 1 - Goodness of Fitness Formula (Wetzels et al., 2009)

$$
\begin{aligned}
\text { GoF }=\sqrt{\frac{\sum_{n} A V E_{n}}{n} \times \frac{\sum_{m} R_{m}^{2}}{m}} \quad \text { Where } \mathrm{n} & =\text { number of total constructs } \\
\mathrm{m} & =\text { number of endogenous constructs }
\end{aligned}
$$


Ph.D. Thesis - Sepandar Sepehr; McMaster University - DeGroote School of Business.

Based on the above formula, the GoF for the proposed model is 0.52 , which is significantly higher than the recommended threshold of 0.36 (Wetzels et al., 2009). This result also supports the validity of the proposed model and show that the collected data fits the proposed model very well.

\subsubsection{Effect Sizes}

Effect size can be used to identify the impact of an independent variable on a dependent variable. PLS uses Cohen's (1998) $f^{2}$ formula (Equation 2), which calculates the effect size based on the $R^{2}$ of a dependent variable once with the independent variable in the model and once without the independent variable in the model.

$$
f^{2}=\frac{R_{\text {included }}^{2}-R_{\text {excluded }}^{2}}{1-R_{\text {excluded }}^{2}}
$$

Equation $2-\boldsymbol{f}^{2}$ Formula (Cohen 1998)

The direct effect sizes of independent variables on dependent variables can be seen in Table 8. Based on Cohen's (1988) criteria, six out of ten effect sizes can be considered large (above 0.35 ) and the other four are of medium size (above 0.15 ).

Table 8 - Direct Relationships' Effect Sizes $(\boldsymbol{\alpha}=0.05)$

\begin{tabular}{|c|c|c|c|c|c|c|}
\hline & SP & SCompt & AR & CH & Flow & SA \\
\hline DCompt & & 0.281 & & & & \\
\hline SP & & 0.257 & & & & \\
\hline SCompt & & & 0.398 & 0.459 & & \\
\hline AR & & & & & 0.630 & \\
\hline
\end{tabular}


Ph.D. Thesis - Sepandar Sepehr; McMaster University - DeGroote School of Business.

\begin{tabular}{|c|l|l|l|l|l|l|}
\hline $\mathrm{CH}$ & & & 0.256 & & 0.277 & \\
\hline Flow & & & & & & 0.653 \\
\hline Mode & 0.365 & 0.527 & & & & \\
\hline
\end{tabular}

Table 9 also shows the indirect effect sizes in the model for the latent constructs that do not have direct relationship.

Table 9 - Indirect Relationships' Effect Sizes $(\boldsymbol{\alpha}=0.05)$

\begin{tabular}{|c|c|c|c|c|c|c|}
\hline & SP & SCompt & AR & CH & Flow & SA \\
\hline DCompt & & & 0.111 & 0.129 & 0.085 & 0.198 \\
\hline SP & & & 0.102 & 0.118 & 0.078 & 0.051 \\
\hline SCompt & & & & & 0.304 & 0.198 \\
\hline AR & & & & & & 0.411 \\
\hline CH & & & & & & 0.181 \\
\hline Flow & & & & & & \\
\hline Mode & & & 0.210 & 0.242 & 0.160 & 0.105 \\
\hline
\end{tabular}

\subsubsection{Post-hoc Analyses}

In addition to testing the proposed model by analyzing the collected data, four post-hoc analyses were conducted in search of other insights that could be extracted from data. These analyses are: 1) testing the model for common method bias, 2) examining the saturated model, 3) testing the effect of control variables, and 4) analyzing answers to the open-ended questions. 
Ph.D. Thesis - Sepandar Sepehr; McMaster University - DeGroote School of Business.

\section{Common Method Bias (CMB)}

Cross-sectional study with self-reported data poses a threat to biases due to various factors such as social desirability and bias due to the method of the experiment. As such, common method bias should be tested in order to make sure that such biases do not exist or are not severe in the collected data. Thus, two tests were conducted for evaluating the severity of common method bias if it exits. These two techniques are Harman's one factor test (Podsakoff \& Organ, 1986) and unmeasured latent market construct (Podsakoff, MacKenzie, Lee, \& Podsakoff, 2003).

\section{Harman's One Factor Test}

Harman's One Factor Test (Podsakoff \& Organ, 1986) explains that in order to test whether all the items in the model tend to load on a shared variable one should perform an exploratory factor analysis with all the items in the model. Therefore, an un-rotated principal components analysis (PCA) was conducted with all the items in the model. The results show how many factors can be extracted from the PCA. Harman's One Factor Test indicates that if all the items load on a single factor or one factor explains more than half of the variance of all the items then it can be suspected that $\mathrm{CMB}$ exists.

The results of PCA in the proposed model show that nine factors were extracted from the items of the model based on the survey data. These factors together explained less than $26 \%$ of the variance in the dataset and no one factor can explain the majority of variance in data, indicating that $\mathrm{CMB}$ is not likely present in this dataset. In fact, all of the predictive variances were below the threshold of $34 \%$ that has been proposed in previous studies (Wakefield \& Whitten, 2006). Moreover, all of the nine extracted factors had eigenvalues of greater than one, which further supports the independence of these factors from one another. 
Ph.D. Thesis - Sepandar Sepehr; McMaster University - DeGroote School of Business.

\section{Unmeasured Latent Marker Construct Test}

Unmeasured latent marker technique is the second test for evaluating the possibility of having CMB in the collected data. Based on the earlier approach introduced by Podsakoff et al. (2003) for covariance-based SEM models (e.g. LISREL and AMOS), Liang, Saraf, Hu, \& Xue (2007) proposed a technique for using PLS for running unmeasured latent market test ${ }^{16}$.

Unmeasured latent marker construct technique requires adding a latent method factor in the structural model that determines the indicators of all the constructs in the model. That is, each indicator (item) in the model is defined by its corresponding principal construct, the method factor, and measurement error. However, PLS does not include random errors in the model nor does it allow having two constructs for one indicator. To avoid identification problem due to limitations of PLS modeling, the new approach recommends converting all the indicators to a single-indicator construct. The new model was implemented using this system by adding a new method factor, which predicts all the newly defined single-item constructs in the model. That is, all the constructs in the model will be second-order constructs. Using this technique, the loadings for each indicator as well as their R-squares can be measured. Table 10 shows the comparison of factor loadings and R-squares for principal factors versus method factor loadings and R-squares.

Table 10 - Unmeasured Latent Marker Construct Test Results for Assessing Common Method Bias

\begin{tabular}{|c|c|c|c|c|c|c|}
\hline Indicator & $\begin{array}{c}\text { Principal } \\
\text { Factor } \\
\text { Loading }\end{array}$ & $\begin{array}{c}\text { Significant } \\
\text { Level at } \\
P<\end{array}$ & $R l^{2}$ & $\begin{array}{c}\text { Method } \\
\text { Factor } \\
\text { Loading }\end{array}$ & $\begin{array}{c}\text { Significant } \\
\text { Level at } \\
P<\end{array}$ & $R 2^{2}$ \\
\hline AR1 & 0.874 & 0.001 & 0.874 & -0.104 & n.s. & -0.053 \\
\hline AR2 & 0.935 & 0.001 & 0.935 & -0.048 & n.s. & 0.007 \\
\hline
\end{tabular}

${ }^{16}$ Method being discounted by Chin et al. (2012), but used as a second method to detect $\mathrm{CMB}$ as it is still commonly used by IS researchers and no alternatives have been proposed yet. 
Ph.D. Thesis - Sepandar Sepehr; McMaster University - DeGroote School of Business.

\begin{tabular}{|c|c|c|c|c|c|c|}
\hline AR3 & 0.848 & 0.001 & 0.848 & -0.001 & n.s. & 0.048 \\
\hline AR4 & 0.434 & 0.050 & 0.434 & 0.074 & n.s. & 0.099 \\
\hline AR5 & 0.674 & 0.001 & 0.674 & 0.113 & n.s. & 0.152 \\
\hline $\mathrm{CH} 1$ & 0.759 & 0.001 & 0.759 & 0.165 & 0.010 & 0.214 \\
\hline $\mathrm{CH} 2$ & 0.962 & 0.001 & 0.962 & -0.150 & 0.010 & -0.087 \\
\hline $\mathrm{CH} 3$ & 0.869 & 0.001 & 0.869 & -0.025 & n.s. & 0.031 \\
\hline DCompt1 & 0.484 & 0.001 & 0.484 & 0.077 & n.s. & 0.077 \\
\hline DCompt2 & 0.877 & 0.001 & 0.877 & 0.003 & n.s. & 0.003 \\
\hline DCompt 3 & 0.861 & 0.001 & 0.861 & -0.082 & n.s. & -0.082 \\
\hline DCompt4 & 0.798 & 0.001 & 0.798 & -0.057 & n.s. & -0.057 \\
\hline DCompt5 & 0.702 & 0.001 & 0.702 & 0.095 & n.s. & 0.095 \\
\hline FI1 & 0.877 & 0.001 & 0.877 & 0.009 & n.s. & 0.029 \\
\hline FI3 & 0.876 & 0.001 & 0.876 & -0.009 & n.s. & 0.011 \\
\hline HE2 & 0.768 & 0.001 & 0.768 & 0.189 & 0.010 & 0.219 \\
\hline HE3 & 0.977 & 0.001 & 0.977 & -0.036 & n.s. & 0.003 \\
\hline HE4 & 0.984 & 0.001 & 0.984 & -0.058 & n.s. & -0.019 \\
\hline Mode & 1.000 & 0.001 & 1.000 & 0.274 & 0.010 & 0.274 \\
\hline SCompt 1 & 0.851 & 0.001 & 0.851 & 0.012 & n.s. & 0.138 \\
\hline SCompt 2 & 0.753 & 0.001 & 0.753 & 0.105 & n.s. & 0.215 \\
\hline SCompt3 & 0.894 & 0.001 & 0.894 & -0.057 & n.s. & 0.074 \\
\hline SCompt4 & 0.924 & 0.001 & 0.924 & -0.053 & n.s. & 0.083 \\
\hline SA1 & 0.996 & 0.001 & 0.996 & -0.050 & n.s. & -0.021 \\
\hline SA2 & 0.921 & 0.001 & 0.921 & 0.050 & n.s. & 0.077 \\
\hline SP1 & 0.738 & 0.001 & 0.738 & 0.114 & n.s. & 0.184 \\
\hline SP2 & 0.753 & 0.001 & 0.753 & -0.011 & n.s. & 0.060 \\
\hline
\end{tabular}


Ph.D. Thesis - Sepandar Sepehr; McMaster University - DeGroote School of Business.

\begin{tabular}{|c|c|c|c|c|c|c|}
\hline SP3 & 0.742 & 0.001 & 0.742 & 0.042 & n.s. & 0.112 \\
\hline SP4 & 0.845 & 0.001 & 0.845 & -0.027 & n.s. & 0.052 \\
\hline SP5 & 0.863 & 0.001 & 0.863 & -0.117 & 0.050 & -0.036 \\
\hline TD1 & 0.707 & 0.001 & 0.707 & 0.147 & n.s. & 0.170 \\
\hline TD2 & 0.926 & 0.001 & 0.926 & -0.154 & 0.010 & -0.124 \\
\hline TD3 & 0.892 & 0.001 & 0.892 & 0.001 & n.s. & 0.031 \\
\hline Average & $\mathbf{0 . 8 2 1}$ & & $\mathbf{0 . 8 2 1}$ & $\mathbf{0 . 0 0 0}$ & & $\mathbf{0 . 0 4 6}$ \\
\hline
\end{tabular}

As the results show, all the constructs of the model have very high loadings on their own items (indicators) (i.e. principal factor loadings), while method factor's loadings are very low. On average, principal factor loadings are 0.821 and method factor's loadings are zero. Moreover, the predictive power of principal factors is on average $17.8(0.821 \div 0.046)$ times greater than the predictive power of the method factor added in this model. Furthermore, the majority of the factor loadings of the method factor are not significant. Considering this comparison, it can be concluded that it is very unlikely that common method bias issues exist with the dataset used to evaluate this model.

\section{Saturated Model Analysis}

In order to test whether there are any non-hypothesized relationships in the model that could have a significant effect in the model, an alternative saturated model was evaluated using SmartPLS. In the saturated model, all the constructs were linked to one another. Using the bootstrapping approach (with 500 samples), the significance of each path was evaluated. The results of this analysis is shown in Table 11. 
Ph.D. Thesis - Sepandar Sepehr; McMaster University - DeGroote School of Business.

Table 11 - PLS Result for Non-hypothesized Paths in the Saturated Model

\begin{tabular}{|c|c|c|c|}
\hline & $\begin{array}{c}\text { Path } \\
\text { Coefficient }\end{array}$ & $\begin{array}{c}\mathrm{T} \\
\text { Statistics }\end{array}$ & $\begin{array}{c}\text { Significant } \\
\text { Level }\end{array}$ \\
\hline $\mathrm{AR} \rightarrow \mathrm{SA}$ & 0.270 & 2.049 & $p<0.05$ \\
\hline $\mathrm{CH} \rightarrow \mathrm{SA}$ & 0.221 & 2.512 & $p<0.01$ \\
\hline Mode $\rightarrow$ AR & -0.270 & 2.711 & $p<0.01$ \\
\hline Mode $\rightarrow \mathrm{CH}$ & -0.147 & 1.339 & n.s. \\
\hline Mode -> Flow & 0.095 & 0.883 & n.s. \\
\hline Mode -> DCompt & -0.033 & 0.238 & n.s. \\
\hline Mode $->$ SA & -0.088 & 0.971 & n.s. \\
\hline SCompt $->$ Flow & -0.011 & 0.092 & n.s. \\
\hline SCompt $->$ SA & 0.082 & 0.725 & n.s. \\
\hline DCompt $->$ AR & 0.011 & 0.098 & n.s. \\
\hline DCompt $->\mathrm{CH}$ & 0.070 & 0.658 & n.s. \\
\hline DCompt $->$ Flow & 0.050 & 0.512 & n.s. \\
\hline DCompt $->$ SA & -0.017 & 0.180 & n.s. \\
\hline $\mathrm{SP} \rightarrow \mathrm{AR}$ & 0.056 & 0.580 & n.s. \\
\hline $\mathrm{SP} \rightarrow \mathrm{CH}$ & -0.012 & 0.133 & n.s. \\
\hline SP -> Flow & 0.074 & 0.757 & n.s. \\
\hline SP $->$ DCompt & 0.080 & 0.571 & n.s. \\
\hline $\mathrm{SP} \rightarrow \mathrm{SA}$ & -0.026 & 0.306 & n.s. \\
\hline
\end{tabular}

Footnote 1 - AR: Arousal, SA: Satisfaction, CH: Challenge, Mode: Competition Mode, DCompt:

Dispositional Competitiveness, SCompt: Situational Competitiveness, SP: Social Precense

As the results of saturated model analysis show, the only non-hypothesized relationships that were significant were the path between Arousal and Satisfaction, Challenge and Satisfaction, 
Ph.D. Thesis - Sepandar Sepehr; McMaster University - DeGroote School of Business.

and Mode and Arousal. However, none of these relationships can be theoretically justified, nor was any evidence found to support them in the literature. It is evident that the Flow construct was not able to fully mediate the relationship between Challenge and Satisfaction or Arousal and Satisfaction. Due to the significance of these relationships, they should be considered for further analyses and are thus included in guidance for future research in the next chapter.

\section{Control Variables Effects}

As mentioned earlier in this chapter, some demographics, individual characteristics and control variables information was gathered from participants. In order to test the effects of these variables on the model, the effect of each of them individually on all the latent constructs in the model was evaluated using SmartPLS.

Table 12 - Impact of Control Variables on Model's Latent Constructs

\begin{tabular}{|c|c|c|c|c|c|c|c|c|}
\hline & & DCompt & SP & SCompt & $\mathrm{CH}$ & $\mathrm{AR}$ & Flow & SA \\
\hline \multirow{2}{*}{ Age } & $\beta$ & & & & 0.22 & 0.213 & & \\
\hline & $\mathrm{p}<$ & n.s. & n.s. & n.s. & 0.05 & 0.01 & n.s. & n.s. \\
\hline \multirow{2}{*}{ Gender } & $\beta$ & & & & & & & \\
\hline & $\mathrm{p}<$ & n.s. & n.s. & n.s. & n.s. & n.s. & n.s. & n.s. \\
\hline \multirow{2}{*}{ Education } & $\beta$ & & & & 0.198 & 0.211 & -0.13 & \\
\hline & $\mathrm{p}<$ & n.s. & n.s. & n.s. & 0.01 & 0.01 & 0.05 & n.s. \\
\hline \multirow{2}{*}{ Ethnicity } & $\beta$ & & & & & & & \\
\hline & $\mathrm{p}<$ & n.s. & n.s. & n.s. & n.s. & n.s. & n.s. & n.s. \\
\hline \multirow{2}{*}{$\begin{array}{c}\text { Language } \\
\text { (1=English, } \\
\text { 2=Not } \\
\text { English) }\end{array}$} & $\beta$ & & & -0.15 & & & -0.184 & \\
\hline & $\mathrm{p}<$ & n.s. & n.s. & 0.05 & n.s. & n.s. & 0.05 & n.s. \\
\hline Computer & $\beta$ & & & & & & 0.14 & \\
\hline
\end{tabular}


Ph.D. Thesis - Sepandar Sepehr; McMaster University - DeGroote School of Business.

\begin{tabular}{|c|c|c|c|c|c|c|c|c|}
\hline Experience & $\mathrm{p}<$ & n.s. & n.s. & n.s. & n.s. & n.s. & 0.05 & n.s. \\
\hline \multirow{2}{*}{$\begin{array}{c}\text { Internet } \\
\text { Experience }\end{array}$} & $\beta$ & & & & & & 0.162 & \\
\hline & $\mathrm{p}<$ & n.s. & n.s. & n.s. & n.s. & n.s. & 0.05 & n.s. \\
\hline \multirow{2}{*}{$\begin{array}{c}\text { Gaming } \\
\text { Experience }\end{array}$} & $\beta$ & & -0.173 & & -0.211 & & -0.042 & \\
\hline & $\mathrm{p}<$ & n.s. & 0.05 & n.s. & 0.01 & n.s. & 0.05 & n.s. \\
\hline
\end{tabular}

As Table 12 shows, 12 out of the 42 relationships were significant. In order to test the effect of control variables on the model, one PLS model was developed for each variable, having relationships with all the latent constructs in the model. To test the variables' effect, first the level of significance of each relationship of the control variable with other latent constructs was tested. In order to further test the predictive power of the control variables, statistical power of their relationships can be measured through their effect sizes (Hair et al., 2009). To calculate effect sizes of the significant relationships (with endogenous constructs),

Equation 2 was used. The effect size $\left(f^{2}\right)$ of control variables on endogenous constructs that they have significant relationship, which can be seen in Table 13.

Table 13 - Effect Sizes of Control Variables on Endogenous Constructs (Bold: Small Effect; * : Medium Effect)

\begin{tabular}{|c|c|c|c|c|c|}
\hline & SP & SCompt & CH & AR & Flow \\
\hline No Control & 0.13 & 0.43 & 0.21 & 0.21 & 0.47 \\
\hline Age & & & $\mathbf{0 . 0 2 1}$ & $\mathbf{0 . 2 1 3}^{*}$ & \\
\hline Education & & 0.018 & $\mathbf{0 . 2 1 1}$ & 0.015 \\
\hline Language & $\mathbf{0 . 0 2 3}$ & & & $\mathbf{0 . 0 3 7}$ \\
\hline $\begin{array}{c}\text { Computer } \\
\text { Experience }\end{array}$ & & & & & 0.018 \\
\hline $\begin{array}{c}\text { Internet } \\
\text { Experience }\end{array}$ & 0.010 & & $\mathbf{0 . 0 2 1}$ & & -0.002 \\
\hline $\begin{array}{c}\text { Gaming } \\
\text { Experience }\end{array}$ & & & & & \\
\hline
\end{tabular}


Ph.D. Thesis - Sepandar Sepehr; McMaster University - DeGroote School of Business.

In Table 13 the effect sizes that are considerable (>.02) based on Cohen's (1988) critical values are marked with bold numbers. Two of the seven considerable effect sizes can be considered as having medium size effect $(>.15)$, which are marked with an asterisk. The results show that Age has a significant effect on the level of Challenge and Arousal. That is, older participants reported being more challenged, and more significantly aroused and excited. Education also had a considerable effect on the level of arousal of the participants, which can be correlated with the age of the more educated population.

The participants who did not speak English as their first language were more likely to perceive the experiment as competitive. They also reported their level of Flow experience to be higher compared to the participants who spoke English as their first language. These perceptions could be attributed to cultural differences rather than a language barrier since no considerable effect on Challenge was observed as a result of language difference. Moreover, higher Internet Experience could affect being in a Flow state. This relationship can be a result of having more experience with similar online environments, and therefore reducing the distracting factors of a new environment, making it easier for the participants with more experience to focus on the game tasks and engage better. In addition, higher level of Gaming Experience affected participants' perceptions of challenge. Video gameplayers can be more interested in playing games and more easily get challenged and motivated to win a video game.

\section{Open-ended Questions Analysis}

In addition to the survey questionnaire, two open-ended questions were asked of participants who participated in competition modes (i.e. competing against friends, non-friend human, and computer) and one open-ended question was asked of the participants in the noncompetition mode. In the competition modes, one question addressed opponent matching of the 
Ph.D. Thesis - Sepandar Sepehr; McMaster University - DeGroote School of Business.

experiment. The other question was a general question about the design of the survey and the study itself. The two questions for competition mode participants were:

- How did you find your opponent? Do you find the matching fair?

- If you have any comments about this study or the surveys please write your comments here.

The open-ended question for the no-competition mode participants was the same as the second question in the competition mode. These questions provide some qualitative and exploratory insight into this research that can be interpreted for future research and provide insights into the findings of this study's experiments.

Regarding the fairness of the matching for competitive experiments, a great number of the participants ( 87 out of 92) answered the first question, despite it being optional. From 87 answers, 59 of the answers indicated that their matching was fair and only 28 said they did not find the competition to be fair. This is despite the fact that participants were randomly assigned to the experiments, except for the participants who competed against their friends. The setting of a completely randomized setup, which would require knowing the friend network of all the potential participants, would be overly complicated and, as the McMaster Research Ethics Board pointed out, would be unethical. Therefore, participants had to self-register for that mode of competition (competing against their friends). Despite this randomization limitation, no evidence exists that would show that participants who registered with one of their friends had chosen the friend to participate with based on her/his level of typing skills. In fact, one of the participants who indicated that matching was not fair was competing with his/her friend. This participant indicated: 
Ph.D. Thesis - Sepandar Sepehr; McMaster University - DeGroote School of Business.

"My opponent is too weak for me. The matching was not fair. Maybe rather than compete with our friend, we should compete with someone we do not know, and with similar skills.”

Overall, the participants were satisfied with the matching and it cannot be said that losing the game affected their perception towards the fairness of the game. Even though some people lost the competition, some were positive about the matching. One of the participants stated:

"They were a faster typing opponent than myself, still fair considering I don't know the person."

One key finding from this open-ended question was related to the adaptability of the computer mode. When the computer would change its speed to adapt to the speed of its opponent, participants would find the task more challenging and engaging. Unlike human opponents, the computer opponent is capable of changing its skill to adjust based on the player's skill level, making sure the challenge and skill of the video game stay in par, resulting in higher levels of Flow. One of the participants mentioned:

"It adjusted the AI very well to my skill, ramping up WPM as it went along."

Moreover, one of the participants added that competition of two opposite genders could create more challenge and motivate the player to try harder to win the game, making the game more competitive and engaging. Even though the gender gap between men and women video gameplayers is disappearing (Entertainment Software Association, 2010), however, men and women tend to play different types of games. As such, in particular for a male player, playing against a female player proposed a new set of challenges as opposed to playing against a male player. For instance, below is the response from a male participant: 
Ph.D. Thesis - Sepandar Sepehr; McMaster University - DeGroote School of Business.

"I found out that my opponent was a female. I think that further enhanced my competitive spirit. The matching was ideal."

Through the second open-ended question, participants mostly expressed their overall satisfaction with the study. In particular, the use of a video game for the experiment made it much more exciting than a typical lab experiment for students, who perhaps have participated in other lab experiments in university. Below are some of the positive responses:

"I felt very relaxed and comfortable during the surveys and the game was fun to play."

"This was a lot of fun!"

"Good job!( have too much to say....)"

"It is a good test of my abilities under pressure."

"It sounds like a really interesting study, and I'm glad $i$ was offered the chance to participate."

"Study bring in a lot excitement, feels like I am playing a video game like I normally would."

"The typewriter game was interesting and fun to play."

Even the participants who participated in the non-competitive group (playing by themselves) enjoyed the experiment. One participant said:

"It was fun, and I would do it again to improve my typing skills. I experienced flow so much, I repeatedly almost forgot to click my sensor!”

However, some participants expressed some concerns about the design of the study. Two of the participants indicated that they preferred typing with their own keyboard as the keyboard that was provided during the experiment was different from their own, in particular if they were 
Ph.D. Thesis - Sepandar Sepehr; McMaster University - DeGroote School of Business.

using a different type of computer (i.e. MacBook). More specifically, the comments were as follow:

"I am not sure to what extent is past typing experience being considered. For example, I use a MacBook. If the competition was held in an Apple computer keyboard, I think I might have done better. This is just my perception.”

"Different people are more comfortable with other keyboards. The option should be given, whether it is a laptop keyboard or a typical keyboard."

"In studies or surveys that require the use of a keyboard and mouse, I would suggest allowing participants the choice of hardware that better matches the hardware they use most often in their everyday lives. In this way, they are more familiar with the environment, and may provide more accurate results regarding their computer use."

One other concern that was raised by a participant was regarding the duration of experience and feelings of Flow. This participant mentioned that the duration of experiment is perhaps not long enough for a person to understand if they have felt Flow or not. The participant said:

"Perhaps longer typing tests- Hard to note "flow" without having a longer time period to experience it in." 
Ph.D. Thesis - Sepandar Sepehr; McMaster University - DeGroote School of Business.

\section{CHAPTER 6 - DISCUSSION AND CONCLUSION}

This chapter discusses and answers the research questions posed in chapter 1, based on results of the experiments outlined in chapters 4 and 5 . Contributions to both practice and academia are presented and an agenda for future research and conclusions of this doctoral dissertation are outlined.

\subsection{Research Findings}

Recall from section 1.1 that, the overall objective of this research was to understand the role of competition in engaging video gameplayers and, specifically:

1) To investigate how situational competitiveness of video games impacts antecedents of Flow and satisfaction;

2) To study how different modes of competition affect players' perception of competitiveness and social presence in video games; and

3) To explore the effect of the personality traits of gameplayers on their perception of competitiveness of video games.

\subsubsection{Research Objective 1: The Effect of Situational Competitiveness on Flow}

The data analysis of this investigation's research model showed that Situational Competitiveness had a significant indirect effect on Flow experience and Satisfaction of video games. Flow had a high positive effect on Satisfaction, which in turn was predicted by the Arousal level of players. Situational Competitiveness and Challenge, in turn, were determined to predict Arousal.

The results supported the expectation confirmation theory in this context regarding the role of satisfaction of video gameplayers (H1, Flow $\rightarrow$ Satisfaction with a t-statistic value of 
Ph.D. Thesis - Sepandar Sepehr; McMaster University - DeGroote School of Business.

9.93, significant at $p<.001)$. That is, experiencing Flow confirms or positively disconfirms players' expectations and creates a sense of satisfaction from playing the video game. In the validated research model, Flow was the only antecedent modelled to impact Satisfaction and accounted for $43 \%$ of the explained variance of this endogenous variable. Individuals who experienced Flow state more often, reported being more satisfied with the system than participants who did not experience Flow. Thus, Flow was found to be a strong predictor of Satisfaction. This finding is in line with extant literature on Flow, which have reported Flow to have a significant effect on Satisfaction (e.g. C.-C. Chang, 2013; Chin-Lung Hsu, 2010; Shin, 2006).

Flow was proposed to be impacted by Situational Competitiveness via the mediating variables of Challenge and Arousal. Flow theory explains that the state of optimal experience can be achieved through any task that enables the person to practice their skills by challenging them to the extent that they have the required skills for performing well in the activity. That is, the balance of skill and challenge in a task makes it more engaging, creating the state of Flow. It was expected that this study's experiment would create this balance of challenge and skill for players by increasing challenge of an activity (i.e. learning to type faster) that is not inherently challenging. However, it was found that Challenge did not have a significant effect on Flow (H2, Challenge $\rightarrow$ Flow with a t-statistic value of 1.23).

There are two possible explanations for the lack of significance in the relationship between Challenge and Flow in results. The first could be attributed to the mediating role of Arousal in the context of video gameplaying. A review of extant literature showed that no other study has tested Arousal, Challenge, and Flow in one structural model. As mentioned in Chapter 3, Tauer \& Harackiewicz (1999) showed that Arousal mediates the relationship between 
Ph.D. Thesis - Sepandar Sepehr; McMaster University - DeGroote School of Business.

competition and some of the dimensions of Flow, but, these authors did not included the construct of Challenge in their model. Thus, it is possible that Arousal fully mediated the relationship between Challenge and Flow. That is, when players are challenged, they experience Arousal, which, in turn, helped them enjoy the game more and become involved more deeply. The results of the mediation test further supported this claim, showing that Challenge does not have a direct effect on Flow in the model, but its effect through Arousal on Flow is highly significant.

Another potential explanation for the lack of significance in the relationship between perception of Challenge and experiencing Flow could be attributed to the fact that the participants of the main experiment were not skilful enough at the game task. This could arise from the heavy reliance on autocorrect when typing for younger individuals, which slowed advancement in the game due to making typing mistakes and not fixing them. As such, they would lose their balance of Challenge and Skill. This would create anxiety that results in the lack of enjoyment, immersion, and Flow. However, Challenge had significant (medium size) effect on all the dimensions of Flow (i.e. Focused Immersion, Temporal Dissociation, and Heightened Enjoyment) as well as the second order construct of Flow itself. Therefore, it is unlikely that the lack of skills in the experiment's typing game was the result of having a non-significant path between Challenge and Flow. These results show that in the absence of Arousal, Challenge would be a significant predictor of Flow as the theory of Flow explains.

As expected, Arousal appeared to be an important mediator for the relationship between Situational Competitiveness and Flow (H3, Arousal $\rightarrow$ Flow with a t-statistic value of 6.66, significant at $p<.001)$. Emotional Arousal influences how much individuals pay attention to an activity, making them more engaged and experience Flow during that activity. Even though 
Ph.D. Thesis - Sepandar Sepehr; McMaster University - DeGroote School of Business.

extant literature mainly supports the effect of Arousal on the attention dimension of Flow state, the correlation values of the main study showed that in addition to the Focused Immersion dimension, Arousal significantly affects Temporal Dissociation and Heightened Enjoyment. In fact, the effect of Arousal on these two dimensions was stronger than its effect on Focused Immersion. These results show that being emotionally aroused - as a result of increased challenge during gameplay - makes the video game more enjoyable for participants, who also lose track of time. Overall, the results strongly supported the hypothesis that Arousal predicts Flow and mediates the relationships of Challenge and Situational Competitiveness with Flow.

As hypothesized, Arousal was predicted by the level of Perceived Challenge (H4 with tstatistic value of 2.69 , significant at $p<.01)$. As Flow theory explains, being emotionally excited and aroused is a positive consequence of having balance between the level of Challenge and skill (Csikszentmihalyi, 1997). In fact, in the context of educational video gameplaying, in which participants lack challenge to be engaged in the learning process, increasing the level of Challenge as perceived by the learners results in the balance of Challenge and skill that is required for being engaged in the task and experiencing the state of Flow. As expected, Arousal was a very good candidate for mediating this relationship, explaining the emotional process through which individuals experience Flow as a result of the increase in Challenge. The physiological reactions to new challenges, which were also perceived by participants with subjective reports of Arousal, explains why they would be able to be more engaged in a challenging activity, in particular a video game, compared to the situation that the participant is not challenged to perform better in that activity.

The main hypotheses to address the first research objective were regarding the effect of Situational Competitiveness on Challenge and Arousal. These two hypotheses (H5: Situational 
Ph.D. Thesis - Sepandar Sepehr; McMaster University - DeGroote School of Business.

Competitiveness $\rightarrow$ Arousal; and H6: Situational Competitiveness $\rightarrow$ Challenge) were both supported (with t-statistic value of 2.44, significant at $p<.01$ for H5 and t-statistic value of 6.71, significant at $p<.001$ for H6). Participants who perceived the video games to be more competitive were more excited about the game and reported their emotional Arousal level to be higher. Based on SDT, intrinsic rewards create motivation by making a task more exciting for a person. It is speculated that video gameplayers of more competitive modes were directed towards the goal of receiving rewards from winning the game. This reward was implicit in achieving higher ego-based satisfaction due to the feeling of having performed better than someone else. This kind of goal can increase the sense of competence that is at the center of SDT. This sense of competence makes the game more exciting and, as a result, participants report higher levels of Arousal. In addition, more competitive situations challenge players to perform better in order to achieve the goal of winning and receiving self-directed rewards in an intrinsically motivating environment. In more competitive situations, players wish to avoid the negative feelings associated with losing and reach positive effects that are linked to winning the game.

\subsubsection{Research Objective 2: The Role of Competition Mode on the Level of Situational}

\section{Competitiveness and Social Presence}

Perception of Social Presence was hypothesized to have an important role in the relationship between the mode of competition and the extent to which players perceive the video game to be competitive. This was supported in empirical findings of this research, where the relationships between Social Presence and Situational Competitiveness (H7) and Competition Mode and Social Presence (H8) were highly significant (with t-statistic value of 3.30 for H7 and with t-statistic value of 4.06 for $\mathrm{H} 8$, both significant at $p<.001$ ). The perception of other individual's presence triggers the motivation to compete and the feeling that the environment 
Ph.D. Thesis - Sepandar Sepehr; McMaster University - DeGroote School of Business.

engenders competition. People tend to compare themselves to one another, which is more noticeable when they are in the presence of other people, even through an IT medium such as a video game. Moreover, the mode of competition in a video game has a defining role in the reported level of Social Presence. Playing against a person who is familiar to the player creates the highest level of Social Presence. This mode of the game can provide the feeling of having a richer communication medium, thus, experiencing higher Social Presence compared to the situation in which one plays against a stranger or a computer. As predicted, competing against a computer resulted in the lowest levels of Social Presence. In line with extant literature (Ravaja et al., 2006; David Weibel et al., 2008), playing against a stranger, playing against computer, and no competition modes had progressively lower effect on the level of Social Presence.

Different modes of competition were also shown to have a significant direct effect on the level of Situational Competitiveness during video gameplaying (H9, Mode $\rightarrow$ Situational Competiveness with $\mathrm{t}$-statistic of 5.55, significant at $p<.001)$. As hypothesized, the mode of competition in a video game is a situational variable that can be manipulated to influence the perception of competition among video gameplayers. As Social Comparison Theory (Festinger, 1954) explains, comparison is a strong contextual criterion, which the results of this research have shown to be influenced by the conditions of the competition (i.e. playing against a human being or computer). Playing against a friend has an increased effect on this comparison by furthering the perception of competitiveness.

\subsubsection{Research Objective 3: The Effect of Personality Traits on Situational}

\section{Competitiveness}

The last tested hypothesis in the proposed model addressed the other type of competition that can be associated with individual personality traits. This study's findings show that 
Ph.D. Thesis - Sepandar Sepehr; McMaster University - DeGroote School of Business.

Dispositional Competitiveness has a significant effect on Situational Competitiveness (H10 with t-statistic value of 3.63 , significant a $p<.001)$. This indicates that the reactions of video gameplayers are a function of both situational factors (offering of various competition modes) as well as individual personality (the innate competitiveness of the individual). Participants who reported higher levels of Dispositional Competitiveness - for example they indicated that they enjoy working in situations involving competition or it is important for them to perform better than others - perceived the game to be more competitive compared to the individuals who had low Dispositional Competitiveness. In alignment with extant literature (Graziano et al., 1997; Kelley \& Stahelski, 1970; Tauer \& Harackiewicz, 1999), the higher Dispositionally competitive persons showed to be more intrinsically motivated during the video gameplay - regardless of the mode of the game - and perceived the video game to be more competitive.

In addition, other control variables related to participants' demographics - namely Age, Gender, Education, Ethnicity, Language, Computer Experience, Internet Experience, and Gaming Experience - were included in the model. Age and Education were the only variables that had a medium effect on Arousal. That is, older people (who had higher education due to having a university sample) reported higher levels of Arousal compared to the younger participants. Age also had a small effect on the perception of Challenge. Speaking English as the first language showed to have a small effect on Situational Competitiveness and the experience of Flow in this research, showing that language can be a barrier to designing games for the purpose of learning and training. If the game is focused on an aspect of language, such as TypeRacer that requires reading and typing English text, people who speak English as a second language tend to experience less Flow and perceive the environment to be less competitive. Moreover, higher Internet Experience had a small effect on experiencing Flow and higher 
Ph.D. Thesis - Sepandar Sepehr; McMaster University - DeGroote School of Business.

Gaming Experience had a small effect on Challenge, showing the effect of previous experiences on current experience of video games.

\subsection{Contributions}

\subsubsection{Contributions to Theory}

This research contributes to both theory and practice. From a theoretical perspective, this research contributes to the IS body of literature by incorporating various theoretical lenses from different disciplines such as psychology, marketing, and education. This research provides a framework for integrating two well-known theories of motivation (i.e. SDT and Flow Theory) together. Various studies have utilized the explanatory power of these theories separately within the video game engagement context. This integration opens the door for researchers to achieve greater synergies by bringing together the findings of studies that are based on these two theories in answering new research questions. Additionally, this research furthers our understanding of the impact that a particular social context has on experiences of users. As such, competition modes that vary in social context - playing alone, against a stranger or against a friend - have a direct impact on players' perceptions of competition, which, in turn, impacts their sense of Flow and overall satisfaction.

Recent studies have touched on the role of competition in video games (Liu et al., 2013; Song, Kim, Tenzek, \& Lee, 2013). However, to the best of my knowledge, the current investigation provides the first theoretical model for explaining how Situational and Dispositional Competitiveness can contribute to the experience of Flow and Satisfaction of video games. As Graziano et al. (1997) discussed, competitiveness should be analyzed based on various levels of personality, perception and behaviour. This research enabled this analysis by 
Ph.D. Thesis - Sepandar Sepehr; McMaster University - DeGroote School of Business.

showing the relation of the two aspects of competitiveness that have not been investigated together in the context of video gaming before.

By employing the emotional construct of Arousal, and by investigating the connection between Situational Competitiveness and Flow, this research illustrates some processes through which competition impacts the use of competitive video games. This contributes to the IS literature in the area of usability, adoption, and HCI by incorporating the constructs of Situational Competitiveness and Arousal into the IS literature. The findings of this research help advance the knowledge of continuing usage of hedonic systems. Moreover, the usage of video games for learning and working has not been extensively investigated. This dissertation introduces new areas that IS researchers can probe into in future studies. As this study's results show, the Competitive Video Gaming Model provides a strong power in predicting Satisfaction of users of hedonic systems, specifically that of video games. As such, this research also helps to support the usability literature through a better understanding of the ways that people experience satisfaction and deep engagement through usage of information system.

In addition to the core objectives of the main study mentioned earlier, this research examined how the construct of Flow could be modeled as a second-order reflective construct. As earlier research suggests, Flow is a second order construct and should be modeled as a reflective construct that includes a subset of original Flow theory dimensions, which are relevant to the context that it is being used in (Sepehr \& Head, 2012a). Based on the findings of the first study and the extant literature, the three dimensions of Focused Immersion, Temporal Dissociation, and Heightened Enjoyment were considered as the most relevant dimensions in the context of video gaming. The result of the main study supported this selection as the Flow construct shared a high variance with all three dimensions in the model. The SEM analysis also provided 
Ph.D. Thesis - Sepandar Sepehr; McMaster University - DeGroote School of Business.

nomological validity for the operationalization of Flow as described since all except one of the supported hypotheses regarding the antecedents and consequences of Flow were supported through the main study's experiment. These findings provide researchers further guidance on how to operationalize this complex concept.

\subsubsection{Contributions to Practice}

From a practitioner's perspective, designers of educational video games for organizations and schools can benefit by obtaining a richer understanding of the factors that can lead to deep involvement of learners or employees. Previously scholars have noted that an ideal learning atmosphere should have an appropriate level of competition alongside a cooperative environment (Johnson \& Johnson, 1991). This research showed that competition can enhance existing systems and create the Flow experience for learners. As the preliminary studies (Appendix 2) showed, in classes where students participate in a competitive task, in particular in a group for reaching a shared goal, the level of attention and enjoyment is highly significant. It is important for the designers of such systems to limit the effect of extrinsic rewards in order to avoid the creation of excessive extrinsic motivation thus limiting the intrinsic interest of students and employees to succeed in the competitive activity. As earlier research has shown, if the effect of extrinsic rewards, such as financial or promotional incentives increases, the intrinsic value of video games that creates Flow and Satisfaction would decrease (Deci et al., 1981).

Moreover, by investigating various manipulation modes, this research showed that by manipulating the mode of competition in educational video games and Gamified work-related systems, practitioners can create more Situational Competitiveness, excitement, and ultimately more Flow experience and Satisfaction. The findings of this research showed that the element of competition can be more effective if the mode of competition is designed in such a way that 
Ph.D. Thesis - Sepandar Sepehr; McMaster University - DeGroote School of Business.

players can compare their performance to their friends and colleagues, and therefore, compete with them. Alternatively, competing with strangers can provide high excitement compared to a non-competitive situation or when players have to compete against just the computer. Moreover, the open-ended questions revealed that even though playing against a computer does not create the same level of excitement and Flow as competing against a human, it can create an adaptive system that increases the Challenge as the player develops new sets of skills. In conjunction with human-operated opponents, these adaptive systems can be used for training and practicing, which can be used prior to matching players to compete with one another.

These findings may also be of relevance to developers of other hedonic systems (e.g. electronic training systems or Internet websites that are designed for the purpose of enjoyment and entertainment) where various forms of competition may enhance the experience with the system. Similarly, these systems can follow the guidelines outlined for educational video game designers to increase the effectiveness of their hedonic systems through engagement of users. These guidelines could result in higher adoption and continuing usage of hedonic systems.

\subsection{Research Limitations}

As with most empirical studies, some limitations for this research are acknowledged. First, the data collection of both studies used self-reported surveys for testing the hypotheses and structural model. Common method variance test was conducted to eliminate the potentiality of any bias as a result of the cross-sectional design of the research. Even though the results of the common method variance analysis indicated that there was no likely potential bias, it is advisable to use alternative and complementary approaches to measure the constructs and triangulate with the self-reported data. For example, Arousal can also be measured through physiological measures such as EEG (Electroencephalogram), GSR (Galvanic Skin Response), or measuring 
Ph.D. Thesis - Sepandar Sepehr; McMaster University - DeGroote School of Business.

heart rate. Challenge could also be manipulated by researchers rather than using a self-report measure, similar to Abuhamdeh and Csikszentmihalyi's (2012) research design. Engagement can be measured in a longitudinal study where the continuing usage of players is observed throughout a period of time.

Second, the study was conducted among North American students, which limits the generalizability of the results to other countries. The majority of the participants were undergraduate students aged between 17 and 23. Despite the fact that students represent an appropriate sample for this context since they represent Millenials (who are the focus of using video games for learning and working), in order to generalize the findings of this study's results, non-Canadians, non-students and diverse age groups should be investigated.

Third, a direct measurement of learning outcomes was not assessed in this study. As such, inferences from the video game context to the learning context will have to be based on the outcomes of satisfaction, rather than on more direct learning outcomes such as performance. However, there is strong evidence in the extant literature to suggest that emotions such as satisfaction can result in positive learning outcomes, such as improved learning performance (e.g. Bandura, 1977; Oncu \& Cakir, 2011; Shin, 2006).

Fourth, knowing and identifying possible networks of friends among students in the experiment design would not be ethically acceptable. Therefore, randomization of participants was dependent on participants choosing the mode of the game. It was not possible to control which participant chose to participate in the experiment with their friend. Nevertheless, participants were not familiar with the exact procedure of the experiment beforehand. The participants only had the option of choosing a time from available timeslots to attend either by himself or herself or with a friend. In order to eliminate self-selection bias regarding the mode of 
Ph.D. Thesis - Sepandar Sepehr; McMaster University - DeGroote School of Business.

the game, more timeslots were provided for individuals who could bring a friend in order to encourage them to sign up with a friend from the beginning. However, this resulted in having more participants in the competition against friend mode than other modes. This could endanger the findings with bias towards certain modes. Nevertheless, as discussed in Chapter 5, no evidence was identified that support the claim that participants had chosen their friends based on their skill levels or any bias existed in this regard.

Last, a minor issue that became evident in open-ended questions was the use of a nonfamiliar keyboard. Two of the participants mentioned that they were not familiar with the keyboard that was used in the main study's experiment. The keyboard that was used for the experiment was a Windows keyboard and it can be possible that participants who are Mac users would not be as comfortable with the keyboard. One of the participants mentioned that he or she would be more skilled if he or she had his or her keyboard rather than the generic keyboard. However, allowing the participants to use their own system would not be an option due to setup requirement of the experiment with the lab's computer.

\subsection{Future Research Agenda}

Throughout the studies conducted in this work, several interesting research questions emerged that could be further pursued in future research within the domain of video game engagement. Some of these potential research areas were discovered through the analysis of open-ended questions. A number of participants identified that they lacked time in order to experience Flow. These participants mentioned that in order to properly experience Flow throughout an activity, one has to have ongoing interaction with the technology and report their involvement over a longer period of time. As such, future studies can deploy longitudinal survey designs, in particular Experience Sampling Method (ESM) that was originally proposed by 
Ph.D. Thesis - Sepandar Sepehr; McMaster University - DeGroote School of Business.

Csikszentmihalyi and Larson (1987). ESM is a technique that is suitable for studies that aim to investigate frequency, pattern, and intensity of variables throughout daily activities, such as emotional, cognitive, and conative dimensions of experience. By using ESM for measuring Flow, scholars will be able to examine "the magnitude, duration, and sequences of states, as well as an investigation of correlations between the occurrences of different experiences" (Csikszentmihalyi \& Larson, 1987, p. 533).

Future studies can also investigate the role of Information Quality in engagement and satisfaction, in particular in educational and work related video games. Recall from Chapter 3 , as DeLone and McLean (1992) have proposed, antecedents of Satisfaction can be attributed to Information and System Quality. In this investigation, however, only the aspect of System Quality was addressed through analyzing the role of competition (as an element of system) in video game engagement and satisfaction. To better understand how competition within the context of video games, can be used to improve engagement in work and learning, the effect of learning and work-related material and its content (Information Quality) can be investigated in detail.

In addition to information quality, future research could take a more granular approach to measuring the satisfaction construct. In the current research, satisfaction was measured with two general questions that came from extant literature. Future research could employ a more detailed measurement of satisfaction such as a formative second-order construct that entails more specific aspects of the game experience like satisfaction with the learning outcomes, the results of competition, game controllers, or the game dynamics per se.

The saturated model analysis revealed that three of the non-hypothesized relationships were significant. Arousal had a significant effect on Satisfaction; Challenge had a significant 
Ph.D. Thesis - Sepandar Sepehr; McMaster University - DeGroote School of Business.

effect on Satisfaction; and Competition Mode had a negative significant effect on Arousal. Future studies can investigate if Flow plays a major role as a mediator of the relationship between Challenge and Satisfaction, as well as between Arousal and Satisfaction. The results showed that Flow only partially mediates these relationships, despite the fact that the construct of Challenge was extracted directly from the theory of Flow. Extant literature revealed no theoretical justification for these direct relationships. Future research could seek to further investigate and explain these anomalies and provide grounding in appropriate theory. Additionally, the direct effect of Competition Mode on Arousal suggests that Situational Competitiveness does not thoroughly explain the effect of various modes of gameplay on players' excitement. Future research can seek to probe further into the antecedents of emotional Arousal during video gameplay.

Computer Adaptability is another potential area for future research. As the analysis of this study's open-ended questions revealed, playing against the computer provides the advantage of being able to adapt the challenge and skill of the opponent with player's skill levels. Participants indicated that they enjoyed having this feature in playing against the computer. Therefore, future studies can investigate various design approaches of computer opponents to increase motivation among students and employees during a serious game or a gamified system.

The analysis of control variables also showed that previous experiences, first gaming experience as well as education and age play an important role in how much people perceive a video game to be challenging or exciting or how much they engage in the game. As such, future research can investigate the role of different variables that were only control variables in this research. Moreover, open-ended questions showed that how fair participants perceived the game to be could influence their perception of Challenge in the game and even how much they 
Ph.D. Thesis - Sepandar Sepehr; McMaster University - DeGroote School of Business.

engaged in playing. Therefore, the perception of fairness is an important aspect of a competitive video game, and perhaps non-video game competitive systems that researchers can address.

Moreover, in the current investigation, engagement and addiction were treated as separate concepts. Video game addiction was not investigated in this research. However, despite the evidence that engagement and addiction are separate constructs (Charlton \& Danforth, 2007) recent studies have shown that engagement could be a stepping stone for addiction (Seok \& DaCosta, 2014). Future studies should examine in depth the dual perspective of engagement/addiction, in the context of video games. It is important to understand how various elements, such as competition, can play a role in engaging or enabling problematic behaviour among video gameplayers. Various environmental and personal factors, such as the ones proposed in other works (Sepehr \& Head, 2012b) could be included in such studies.

Lastly, Social Presence was shown to mediate the relationship between competition mode and Situational Competitiveness. Future research can be focused on analyzing the role of various Social Presence elements in competitiveness of video games. Similar to the experimental studies of Cyr et al. (2009) and Hassanein and Head (2007), other video games settings can be used to study the effect of system elements related to Social Presence. For example, researchers could examine the difference between the effect of a video game that entails human elements versus another game, such as TypeRacer, that does not include human elements when players are competing against the computer only.

\subsection{Conclusion}

The main objective of this dissertation research was to study the role of competition in video games, which could be used for engaging students and employees for learning and work related outcomes. As younger generations are playing more video games every day, it becomes 
Ph.D. Thesis - Sepandar Sepehr; McMaster University - DeGroote School of Business.

increasingly important for schools and workplaces to harness this technology to help achieve positive outcomes. The preliminary study of this research (Appendix 2) validated the importance of competition element in engaging students in an educational video game. The second study further tested this claim by validating the proposed model of competitive video gameplaying through an extensive laboratory experiment with 104 participants. The findings of the main study supported the significant effect of competition on experiencing Flow and feeling satisfied from the video gameplaying experience through increasing perception of competitiveness of the video game. Situational Competitiveness increased the chance of being in a state of Flow by influencing the level of Challenge of the video game and Arousal or excitement during the game. This research also aimed to analyze the various effects of situational and personal differences on the level of Situational Competitiveness. The experiment's data supported the hypotheses that various levels of Dispositional Competitiveness and various modes of Competition (i.e. no competition, competing against computer, competing against a stranger, and competing against a familiar person in increasing order) have increasing positive effects on Situational Competitiveness of a video game. Social Presence also mediated the relationship between competition mode and Situational Competitiveness.

Overall, this research showed the importance of competition as a driver of video game engagement and satisfaction. This work offered some insights for other hedonic IS and provided guidelines and possible avenues for future IS research in this area. Even though the process through which competition enables video gameplayers to experience Flow was critically examined and accounted for, there is much more to discover in the increasingly relevant area of educational and work-related video games. 
Ph.D. Thesis - Sepandar Sepehr; McMaster University - DeGroote School of Business.

\section{REFERENCES}

Abt, C. C. (1987). Serious games. University Press of America.

Abuhamdeh, S., \& Csikszentmihalyi, M. (2012). The importance of challenge for the enjoyment of intrinsically motivated, goal-directed activities. Personality \& Social Psychology Bulletin, 38(3), 317-30. doi:10.1177/0146167211427147

Acier, D., \& Kern, L. (2011). Problematic Internet use: Perceptions of addiction counsellors. Computers \& Education, 56(4), 983-989. doi:10.1016/j.compedu.2010.11.016

Agarwal, R., \& Karahanna, E. (2000). Time flies when you're having fun: cognitive absorption and beliefs about information technology usage 1. MIS Quarterly, 24(4), 665-694. doi: $10.2307 / 3250951$

Ajzen, I., \& Fishbein, M. (1980). Understanding attitudes and predicting social behaviour.

Anderson, C. a., \& Carnagey, N. L. (2009). Causal effects of violent sports video games on aggression: Is it competitiveness or violent content? Journal of Experimental Social Psychology, 45(4), 731-739. doi:10.1016/j.jesp.2009.04.019

Anderson, G., \& Brown, R. I. (1984). Real and laboratory gambling, sensation-seeking and arousal. British Journal of Psychology (London, England: 1953), 75 ( Pt 3)(1984), 401-10. Retrieved from http://www.ncbi.nlm.nih.gov/pubmed/6487928

Arnseth, H. (2006). Learning to Play or Playing to Learn. A Critical Account of the Models of Communication Informing Educational Research on Computer Gameplay. Game Studies. Retrieved from http:/gamestudies.org/0601/articles/arnseth

Bandura, A. (1977). Social learning theory. Prentice Hall. Retrieved from http://books.google.ca/books?id=IXvuAAAAMAAJ

Barr, P., Noble, J., \& Biddle, R. (2007). Video game values: Human--computer interaction and games. Interacting with Computers, 19(2), 180-195.

Beck, J. C., \& Wade, M. (2004). Got game: How the gamer generation is reshaping business forever. Harvard Business Press.

Beck, J. C., \& Wade, M. (2006). The kids are alright: How the gamer generation is changing the workplace. Harvard Business Press.

Boudreau, M. C., Gefen, D., \& Straub, D. W. (2001). Validation in information systems research: A state-of-the-art assessment. Mis Quarterly, 25(1), 1-16. Retrieved from http://www.jstor.org/stable/3250956 
Ph.D. Thesis - Sepandar Sepehr; McMaster University - DeGroote School of Business.

Brown, E., \& Cairns, P. (2004). A grounded investigation of game immersion. Extended Abstracts of the 2004 Conference on Human Factors and Computing Systems - CHI'04, 1297. doi:10.1145/985921.986048

Brown, R. I. (1986). Arousal and sensation-seeking components in the general explanation of gambling and gambling addictions. The International Journal of the Addictions, 21(9-10), 1001-16. Retrieved from http://www.ncbi.nlm.nih.gov/pubmed/3793306

Cahill, L., \& McGaugh, J. L. (1998). Mechanisms of emotional arousal and lasting declarative memory. Trends in Neurosciences, 21(7), 294-9. Retrieved from http://www.ncbi.nlm.nih.gov/pubmed/9683321

Caillois, R., \& Barash, M. (2001). Man, play, and games. Univ of Illinois Pr.

Chang, C.-C. (2013). Examining users' intention to continue using social network games: A flow experience perspective. Telematics and Informatics, 30(4), 311-321. doi:10.1016/j.tele.2012.10.006

Chang, H., \& Wang, I. (2008). An investigation of user communication behavior in computer mediated environments. Computers in Human Behavior, 24(5), 2336-2356.

doi:10.1016/j.chb.2008.01.001

Charlton, J., \& Danforth, I. (2007). Distinguishing addiction and high engagement in the context of online game playing. Computers in Human Behavior, 23(3), 1531-1548. doi:10.1016/j.chb.2005.07.002

Chin, W. W. (1998). The partial least squares approach to structural equation modeling. Modern Methods for Business Research, 295(2), 295-336.

Choi, D., Kim, J., \& Kim, S. (2007). ERP training with a web-based electronic learning system: The flow theory perspective. International Journal of Human-Computer Studies, 65(3), 223-243. doi:10.1016/j.ijhcs.2006.10.002

Chou, T.-J., \& Ting, C.-C. (2003). The role of flow experience in cyber-game addiction. Cyberpsychology \& Behavior : The Impact of the Internet, Multimedia and Virtual Reality on Behavior and Society, 6(6), 663-75. doi:10.1089/109493103322725469

Coakley, J. R., Drexler, J. a., Larson, E. W., \& Kircher, a. E. (1998). Using a Computer-Based Version of the Beer Game: Lessons Learned. Journal of Management Education, 22(3), 416-424. doi:10.1177/105256299802200311

Cohen, J. (1988). Statistical power analysis for the behavioral sciences. Lawrence Erlbaum.

Collins, A., \& Halverson, R. (2009). Rethinking education in the age of technology: The digital revolution and the schools. New York: Teachers College. 
Ph.D. Thesis - Sepandar Sepehr; McMaster University - DeGroote School of Business.

Corti, K. (2006). Games-based Learning; a serious business application. Informe de PixelLearning, 1-20. Retrieved from http://pixelearning.com/docs/seriousgamesbusinessapplications.pdf

Coull, J. T. (1998). Neural correlates of attention and arousal: insights from electrophysiology, functional neuroimaging and psychopharmacology. Progress in Neurobiology, 55(4), 343 61. Retrieved from http://www.ncbi.nlm.nih.gov/pubmed/9654384

Coventry, K. R., \& Brown, R. I. (1993). Sensation seeking, gambling and gambling addictions. Addiction (Abingdon, England), 88(4), 541-54. Retrieved from http://www.ncbi.nlm.nih.gov/pubmed/8485432

Cox, T. H., Lobel, S. a., \& McLeod, P. L. (1991). Effects of Ethnic Group Cultural Differences on Cooperative and Competitive Behavior on a Group Task. Academy of Management Journal, 34(4), 827-847. doi:10.2307/256391

Crookall, D. (2011). Serious Games, Debriefing, and Simulation/Gaming as a Discipline. Simulation \& Gaming, 41(6), 898-920. doi:10.1177/1046878110390784

Csikszentmihalyi, M. (1975). Beyond boredom and anxiety. Jossey-Bass Publishers San Francisco, CA.

Csikszentmihalyi, M. (1991). Flow: The psychology of optimal experience: Steps toward enhancing the quality of life. Harper Collins Publishers.

Csikszentmihalyi, M. (1997). Finding flow: The psychology of engagement with everyday life. Basic Books.

Csikszentmihalyi, M., \& Larson, R. (1987). Validity and reliability of the Experience-Sampling Method. The Journal of Nervous and Mental Disease, 175(9), 526-36. Retrieved from http://www.ncbi.nlm.nih.gov/pubmed/3655778

Csikszentmihalyi, M., \& LeFevre, J. (1989). Optimal experience in work and leisure. Journal of Personality and Social Psychology, 56(5), 815-22. Retrieved from http://www.ncbi.nlm.nih.gov/pubmed/2724069

Cucuel, Q. (2011). The Video Game Industry : Explaining the Emergence of New Markets. Otago Management Graduate Review, 9, 1-23.

Cyr, D., Head, M., \& Ivanov, A. (2009). Perceived interactivity leading to e-loyalty: Development of a model for cognitive-affective user responses. International Journal of Human-Computer Studies, 67(10), 850-869.

Deci, E. L., Betley, G., Kahle, J., Abrams, L., \& Porac, J. (1981). When Trying To Win: Competition and Intrinsic Motivation. Personality and Social Psychology Bulletin, 7(1), 79-83. 
Ph.D. Thesis - Sepandar Sepehr; McMaster University - DeGroote School of Business.

Deci, E. L., Koestner, R., \& Ryan, R. M. (1999). A meta-analytic review of experiments examining the effects of extrinsic rewards on intrinsic motivation. Psychological Bulletin, 125(6), 627-68; discussion 692-700. Retrieved from http://www.ncbi.nlm.nih.gov/pubmed/10589297

Deci, E. L., \& Ryan, R. M. (1980). The empirical exploration of intrinsic motivational processes. Advances in Experimental Social Psychology, 13, 39-80.

Deci, E. L., \& Ryan, R. M. (1985a). Intrinsic motivation and self-determination in human behavior. Springer.

Deci, E. L., \& Ryan, R. M. (1985b). The general causality orientations scale: Self-determination in personality. Journal of Research in Personality, 19(2), 109-134. doi:10.1016/00926566(85)90023-6

Deci, E. L., \& Ryan, R. M. (1991). A motivational approach to self: Integration in personality. In Nebraska symposium on motivation (Vol. 38, pp. 237-288).

Deci, E. L., \& Ryan, R. M. (2000). The "What" and "Why " of Goal Pursuits : Human Needs and the Self-Determination of Behavior. Psychological Inquiry, 11(4), 227-268.

DeLone, W., \& McLean, E. (1992). Information systems success: the quest for the dependent variable. Information Systems Research, 3(1), 60-95. Retrieved from http://pubsonline.informs.org/doi/abs/10.1287/isre.3.1.60

DeLone, W., \& McLean, E. (2002). Information Systems Success Revisited, O0(c), 1-11.

DeLone, W., \& McLean, E. (2003). The DeLone and McLean model of information systems success: a ten-year update. Journal of Management Information Systems, 19(4), 9-30. Retrieved from http://mesharpe.metapress.com/index/PEQDJK46VY52V4Q6.pdf

Deng, L., Turner, D. E., Gehling, R., \& Prince, B. (2010). User experience, satisfaction, and continual usage intention of IT. European Journal of Information Systems, 19(1), 60-75. doi:10.1057/ejis.2009.50

Deng, Z., Lu, Y., Wei, K. K., \& Zhang, J. (2010). Understanding customer satisfaction and loyalty: An empirical study of mobile instant messages in China. International Journal of Information Management, 30(4), 289-300. doi:10.1016/j.ijinfomgt.2009.10.001

Deterding, S., Dixon, D., Khaled, R., \& Nacke, L. (2011). From game design elements to gamefulness: defining "Gamification." Proceedings of the 15th International Academic MindTrek Conference: Envisioning Future Media Environments. Retrieved from http://dl.acm.org/citation.cfm?id=2181040

Edery, D., \& Mollick, E. (2009). Changing the game: How video games are transforming the future of business. Ft Pr. 
Ph.D. Thesis - Sepandar Sepehr; McMaster University - DeGroote School of Business.

Entertainment Software Association. (2010). Essential Facts About the Computer and Video Game Industry: 2010 Sales, Demographic and Usage Data. Retrieved from http://www.theesa.com/facts/pdfs/ESA_Essential_Facts_2010.PDF

Eysenck, M. W. (1976). Arousal, learning, and memory. Psychological Bulletin, 83(3), 389-404. Retrieved from http://www.ncbi.nlm.nih.gov/pubmed/778883

Falk, R. F., \& Miller, N. B. (1992). A primer for soft modeling. University of Akron Press.

Faul, F., Erdfelder, E., Lang, A.-G., \& Buchner, A. (2007). G*Power 3: a flexible statistical power analysis program for the social, behavioral, and biomedical sciences. Behavior Research Methods, 39(2), 175-91. Retrieved from http://www.ncbi.nlm.nih.gov/pubmed/17695343

Feiertag, J., \& Berge, Z. L. (2008). Training Generation N: how educators should approach the Net Generation. Education + Training , 50(6), 457-464. doi:10.1108/00400910810901782

Festinger, L. (1954). A theory of social comparison processes. Human Relations, 7(2), 117-140. Retrieved from http://www.soc.ucsb.edu/faculty/friedkin/Syllabi/Soc147/A Theory of Social Comparison Processes.pdf

Fisher, S. (1994). Identifying video game addiction in children and adolescents. Addictive Behaviors, 4603(5), 545-553. Retrieved from http://www.sciencedirect.com/science/article/pii/0306460394900108

Fornell, C., \& Larcker, D. F. (1981). Evaluating structural equation models with unobservable variables and measurement error. Journal of Marketing Research, 39-50.

Foster, S., \& Hopkins, J. (2011). ERP Simulation Game: Establishng Engagement, Collaboration And Learning. PACIS 2011 Proceedings. Retrieved from http://www.pacisnet.org/file/2011/PACIS2011-052.pdf

Garcia, S. M., \& Tor, A. (2009). The N-Effect: More Competitiors, Less Competition. Psychological Science, 20(7), 871-877. Retrieved from http://onlinelibrary.wiley.com/doi/10.1111/j.1467-9280.2009.02385.x/full

Gee, J. P. (2003). What video games have to teach us about learning and literacy. Computers in Entertainment, 1(1), 20. doi:10.1145/950566.950595

Gefen, D., \& Straub, D. (2005). A practical guide to factorial validity using PLS-Graph: Tutorial and annotated example. Communications of the Association for Information Systems, 16(1), 5 .

Gefen, D., \& Straub, D. W. (2003). Managing User Trust in B2C e-Services. E-Service Journal, 2(2), 7-24. doi:10.1353/esj.2003.0011 
Ph.D. Thesis - Sepandar Sepehr; McMaster University - DeGroote School of Business.

Gefen, D., Straub, D. W., \& Boudreau, M. C. (2000). Structural equation modeling and regression: Guidelines for research practice. Communications of the Association for Information Systems, 4(1), 7.

Ghani, J. A., \& Deshpande, S. P. (1994). Task Characteristics and the Experience of Optimal Flow in Human -Computer Interaction. The Journal of Psychology, 128(4), 381-391. Retrieved from http://www.tandfonline.com/doi/abs/10.1080/00223980.1994.9712742

Graziano, W. G., Feldesman, A. B., \& Rahe, D. F. (1985). Extraversion, social cognition, and the salience of aversiveness in social encounters. Journal of Personality and Social Psychology, 49(4), 971-980. doi:10.1037//0022-3514.49.4.971

Graziano, W. G., Hair, E. C., \& Finch, J. F. (1997). Competitiveness Mediates the Link Between Personality and Group Performance. Journal of Personality and Social Psychology, 73(6), 1394-1408. Retrieved from http://www.ncbi.nlm.nih.gov/pubmed/9418284

Griffiths, M. (2010). Online video gaming: what should educational psychologists know? Educational Psychology in Practice, 26(1), 35-40. doi:10.1080/02667360903522769

Grüsser, S. M., Thalemann, R., \& Griffiths, M. D. (2007). Excessive computer game playing: evidence for addiction and aggression? Cyberpsychology \& Behavior : The Impact of the Internet, Multimedia and Virtual Reality on Behavior and Society, 10(2), 290-2. doi:10.1089/cpb.2006.9956

Hair, J. F., Black, W. C., Babin, B. J., \& Anderson, R. E. (2009). Multivariate data analysis.

Hassanein, K., \& Head, M. (2007). Manipulating perceived social presence through the web interface and its impact on attitude towards online shopping. International Journal of Human-Computer Studies, 65(8), 689-708. doi:10.1016/j.ijhcs.2006.11.018

Hernon, P., \& Whitman, J. R. (2001). Delivering satisfaction and service quality: A customerbased approach for libraries. American Library Association.

Hodgins, H. S., Liebeskind, E., \& Schwartz, W. (1996). Getting out of hot water: Facework in social predicaments. Journal of Personality and Social Psychology, 71(2), 300-314. doi:10.1037//0022-3514.71.2.300

Hoffman, D. L., \& Novak, T. P. (1996). Marketing in Hypermedia Computer-Mediated Environments: Conceptual Foundations. Journal of Marketing, 60(3), 50. doi:10.2307/1251841

Hoffman, D. L., \& Novak, T. P. (2009). Flow Online: Lessons Learned and Future Prospects. Journal of Interactive Marketing , 23(1), 23-34. doi:10.1016/j.intmar.2008.10.003 
Ph.D. Thesis - Sepandar Sepehr; McMaster University - DeGroote School of Business.

Holsapple, C. W., \& Wu, J. (2007). User acceptance of virtual worlds: the Hedonic framework. ACM SIGMIS Database, 38(4), 86-89. Retrieved from http://portal.acm.org/citation.cfm?id=1314250

Hsu, C.-L. (2010). Exploring the Player Flow Experience in E-Game Playing. International Journal of Technology and Human Interaction, 6(2), 47-64 doi:10.4018/jthi.2010040104

Hsu, C.-L., \& Lu, H.-P. (2004). Why do people play on-line games? An extended TAM with social influences and flow experience. Information \& Management, 41(7), 853-868. doi:10.1016/j.im.2003.08.014

Hsu, C.-L., Yu, C.-C., \& Wu, C.-C. (2014). Exploring the continuance intention of social networking websites: an empirical research. Information Systems and E-Business Management, 12(2), 139-163. doi:10.1007/s10257-013-0214-3

Jang, H., Reeve, J., Ryan, R. M., \& Kim, A. (2009). Can self-determination theory explain what underlies the productive, satisfying learning experiences of collectivistically oriented Korean students? Journal of Educational Psychology, 101(3), 644-661. doi:10.1037/a0014241

Jennett, C., Cox, a, Cairns, P., Dhoparee, S., Epps, a, Tijs, T., \& Walton, a. (2008). Measuring and defining the experience of immersion in games. International Journal of HumanComputer Studies, 66(9), 641-661. doi:10.1016/j.ijhcs.2008.04.004

Johnson, D., \& Johnson, R. T. (1991). Learning together and alone: Cooperative, competitive, and individualistic learning . (3rd ed.). Prentice-Hall, Inc.

Kang, Y. S., \& Lee, H. (2010). Understanding the role of an IT artifact in online service continuance: An extended perspective of user satisfaction. Computers in Human Behavior, 26(3), 353-364. doi:10.1016/j.chb.2009.11.006

Kelle, S., Sigurðarson, S., Westera, W., \& Specht, M. (2010). Game-Based Life-Long Learning. In E-Infrastructures and Technologies for Lifelong Learning: Next Generation Environments. IGI Global. Retrieved from http://dspace.ou.nl/handle/1820/2430

Kelley, H. H., \& Stahelski, A. J. (1970). Social interaction basis of cooperators' and competitors' beliefs about others. Journal of Personality and Social Psychology, 16(1), 66-91. doi:10.1037/h0029849

Kim, J., Hong, S., Min, J., \& Lee, H. (2011). Antecedents of application service continuance: A synthesis of satisfaction and trust. Expert Systems with Applications, 38(8), 9530-9542. doi:10.1016/j.eswa.2011.01.142

King, D. L., \& Delfabbro, P. H. (2009). Motivational differences in problem video game play. Journal of Cybertherapy and Rehabilitation, 2(2), 139-149. Retrieved from http://www.vrphobia.eu/downloads/full/JCR_2(2).pdf\#page=49 
Ph.D. Thesis - Sepandar Sepehr; McMaster University - DeGroote School of Business.

Kolb, D. A., \& others. (1984). Experiential learning: Experience as the source of learning and development. Prentice-Hall Englewood Cliffs, NJ.

Koo, D.-M., \& Lee, J.-H. (2011). Inter-relationships among dominance, energetic and tense arousal, and pleasure, and differences in their impacts under online vs. offline environment. Computers in Human Behavior, 27(5), 1740-1750. doi:10.1016/j.chb.2011.03.001

Korzaan, M. L. (2003). Going with the flow: Predicting online purchase intentions. Journal of Computer Information Systems, 43(4), 25-31. Retrieved from http://scholar.google.com/scholar?hl=en\&btnG=Search\&q=intitle:GOING+WITH+THE+F LOW+:+PREDICTING+ONLINE+PURCHASE+INTENTIONS\#0

Koufaris, M. (2002). Applying the Technology Acceptance Model and Flow Theory to Online Consumer Behavior. Information Systems Research, 13(2), 205-223. doi:10.1287/isre.13.2.205.83

Léger, P. M. (2006). Using a simulation game approach to teach ERP concepts. Journal of Information Systems Education, 17(4), 441-448.

Léger, P., Montréal, H. E. C., Davis, F. D., Perret, J., Dunaway, M. M., Walton, S. M., \& Ph, D. (2010). Psychophysiological Measures of Cognitive Absorption Psychophysiological Measures of Cognitive Absorption. Human-Computer Interaction.

Liang, H., Saraf, N., Hu, Q., \& Xue, Y. (2007). Assimilation of enterprise systems: the effect of institutional pressures and the mediating role of top management. MIS Quarterly, 31(1), 5987. Retrieved from http://www.jstor.org/stable/25148781

Lin, C., Lin, J., \& Wu, S. (2008). Exploring Consumers' Keyword Ads Search Behaviors : An Integration of Theory of Planned Behavior and Flow Theory. Information Systems.

Lin, C.-P., \& Bhattacherjee, A. (2010). Extending technology usage models to interactive hedonic technologies: a theoretical model and empirical test. Information Systems Journal, 20(2), 163-181. doi:10.1111/j.1365-2575.2007.00265.x

Liu, D., Li, X., \& Santhanam, R. (2013). Digital games and beyond: what happens when players compete. MIS Quarterly. Retrieved from http://aisel.aisnet.org/cgi/viewcontent.cgi? article=3086\&context=misq

Maciejovsky, B., \& Budescu, D. V. (2007). Collective induction without cooperation? Learning and knowledge transfer in cooperative groups and competitive auctions. Journal of Personality and Social Psychology, 92(5), 854-70. doi:10.1037/0022-3514.92.5.854

Mackenzie, S. B., Podsakoff, P. M., \& Podsakoff, N. P. (2011). CONSTRUCT MEASUREMENT AND VALIDATION PROCEDURES IN MIS AND BEHAVIORAL RESEARCH. MIS Quarterly, 35(2), 293-334. 
Ph.D. Thesis - Sepandar Sepehr; McMaster University - DeGroote School of Business.

Malone, T. W. (1981). Toward a theory of intrinsically motivating instruction. Cognitive Science, 5(4), 333-369.

Matthews, G., \& Davies, D. (2001). Individual differences in energetic arousal and sustained attention: a dual-task study. Personality and Individual Differences, 31(4), 575-589. doi:10.1016/S0191-8869(00)00162-8

McAuley, E., \& Tammen, V. V. (1989). The effects of subjective and objective competitive outcomes on intrinsic motivation. Journal of Sport and Exercise Psychology, 11(1), 84-93. Retrieved from http://selfdeterminationtheory.org/SDT/documents/1989_McAuleyTammen_JESP.pdf

McGonigal, J. (2011). Reality is broken: Why games make us better and how they can change the world. Penguin Pr.

Meyers, L. S., Gamst, G., \& Guarino, A. J. (2006). Applied multivariate research: Design and interpretation. Sage Publications, Inc.

Michael, D. R., \& Chen, S. L. (2005). Serious games: Games that educate, train, and inform. Muska \& Lipman/Premier-Trade.

Moon, J. (2001). Extending the TAM for a World-Wide-Web context. Information \& Management, 38(4), 217-230. doi:10.1016/S0378-7206(00)00061-6

Moreno-Ger, P., Burgos, D., Martínez-Ortiz, I., Sierra, J. L., \& Fernández-Manjón, B . (2008). Educational game design for online education. Computers in Human Behavior, 24(6), 2530-2540. doi:10.1016/j.chb.2008.03.012

Newman, J. (2004). Videogames. Psychology Press.

Novak, T. P., Hoffman, D. L., \& Yung, Y. F. (2000). Measuring the customer experience in online environments: A structural modeling approach. Marketing Science, 19(1), 22-42. Retrieved from http://www.jstor.org/stable/193257

Nunnally, J. C., \& Bernstein, I. H. (1994). Psychological theory. New York: McGraw-Hill.

Oblinger, D. (2003). Boomers, Gen-Xers, and Millennials: Understanding the“ New Students.”. Educause Review.

Oblinger, D., \& Oblinger, J. (2005). Educating the net generation (Vol. 264). Educause Washington, DC. Retrieved from http://content.imamu.edu.sa/Scholars/it/net/onedayv2ho.pdf

Oliver, R. L. (1977). Effect of expectation and disconfirmation on postexposure product evaluations: An alternative interpretation. Journal of Applied Psychology, 62(4), 480-486. doi:10.1037//0021-9010.62.4.480 
Ph.D. Thesis - Sepandar Sepehr; McMaster University - DeGroote School of Business.

Oliver, R. L. (1980). A cognitive model of the antecedents and consequences of satisfaction decisions. Journal of Marketing Research. Retrieved from http://www.jstor.org/stable/3150499

Oncu, S., \& Cakir, H. (2011). Research in online learning environments: Priorities and methodologies. Computers \& Education, 57(1), 1098-1108. doi:10.1016/j.compedu.2010.12.009

Pace, S. (2004). A grounded theory of the flow experiences of Web users. International Journal of Human-Computer Studies, 60(3), 327-363. doi:10.1016/j.ijhcs.2003.08.005

Papert, S. (1980). Mindstorms: Children, computers, and powerful ideas. Basic Books, Inc.

Pedhazur, E. J. (1997). Multiple regression in behavioral research: Explanation and prediction.

Piaget, J., \& Roberts, G. A. (1976). To understand is to invent: The future of education. Penguin Books.

Podsakoff, P. M., MacKenzie, S. B., Lee, J.-Y., \& Podsakoff, N. P. (2003). Common method biases in behavioral research: a critical review of the literature and recommended remedies. The Journal of Applied Psychology, 88(5), 879-903. doi:10.1037/0021-9010.88.5.879

Podsakoff, P. M., \& Organ, D. W. (1986). Self-reports in organizational research: Problems and prospects. Journal of Management, 12(4), 531-544.

Polites, G. L., Roberts, N., \& Thatcher, J. (2012). Conceptualizing models using multidimensional constructs: a review and guidelines for their use. European Journal of Information Systems, 21(1), 22-48. doi:10.1057/ejis.2011.10

Prensky, M. (2001). True believers: Digital game-based learning in the military. Learning Circuits, 1-18. Retrieved from http://www.marcprensky.com/writing/Prensky - Digital Game-Based Learning-Ch10-Military.pdf

Przybylski, A. K., Rigby, C. S., \& Ryan, R. M. (2010). A motivational model of video game engagement. Review of General Psychology, 14(2), 154-166. doi:10.1037/a0019440

Qin, Z., Johnson, D. W., \& Johnson, R. T. (1995). Cooperative versus Competitive Efforts and Problem Solving. Review of Educational Research, 65(2), 129. doi:10.2307/1170710

Raju, P. S. (1980). Optimum Stimulation Level: Its Relationship to Personality, Demographics, and Exploratory Behavior. Journal of Consumer Research, 7(3), 272. doi:10.1086/208815

Ratan, R., \& Ritterfeld, U. (2009). Classifying serious games. Serious Games: Mechanisms and Effects, 10-24. 
Ph.D. Thesis - Sepandar Sepehr; McMaster University - DeGroote School of Business.

Ravaja, N., Saari, T., Turpeinen, M., Laarni, J., Salminen, M., \& Kivikangas, M. (2006). Spatial Presence and Emotions during Video Game Playing: Does It Matter with Whom You Play? Presence: Teleoperators and Virtual Environments, 15(4), 381-392. doi:10.1162/pres.15.4.381

Reeve, J., \& Deci, E. L. (1996). Elements of the Competitive Situation that Affect Intrinsic Motivation. Personality and Social Psychology Bulletin, 22(1), 24-33. doi:10.1177/0146167296221003

Reeves, B., \& Read, J. L. (2009). Total engagement: using games and virtual worlds to change the way people work and businesses compete. Harvard Business School Press.

Rigby, C. S., \& Przybylski, a. K. (2009). Virtual worlds and the learner hero: How today's video games can inform tomorrow's digital learning environments. Theory and Research in Education, 7(2), 214-223. doi:10.1177/1477878509104326

Ritterfeld, U., Cody, M. J., \& Vorderer, P. (2009). Serious games: Mechanisms and effects. Taylor \& Francis.

Robbins, T. W. (1997). Arousal systems and attentional processes. Biological Psychology, 45(13), 57-71. Retrieved from http://www.ncbi.nlm.nih.gov/pubmed/9083644

Ross, R. G., \& den Haag, E. (1957). The fabric of society. Harcourt, Brace \& Company.

Russell, J. a., Weiss, A., \& Mendelsohn, G. a. (1989). Affect Grid: A single-item scale of pleasure and arousal. Journal of Personality and Social Psychology, 57(3), 493-502. doi:10.1037//0022-3514.57.3.493

Ryan, R. M., \& Deci, E. L. (2000a). Intrinsic and Extrinsic Motivations: Classic Definitions and New Directions. Contemporary Educational Psychology, 25(1), 54-67. doi:10.1006/ceps.1999.1020

Ryan, R. M., \& Deci, E. L. (2000b). Self-determination theory and the facilitation of intrinsic motivation, social development, and well-being. The American Psychologist, 55(1), 68-78. Retrieved from http://www.ncbi.nlm.nih.gov/pubmed/11392867

Ryan, R. M., Rigby, C. S., \& Przybylski, A. (2006). The Motivational Pull of Video Games: A Self-Determination Theory Approach. Motivation and Emotion, 30(4), 344-360. doi:10.1007/s11031-006-9051-8

Sánchez, J., \& Olivares, R. (2011). Problem solving and collaboration using mobile serious games. Computers \& Education, 57(3), 1943-1952. doi:10.1016/j.compedu.2011.04.012

Sawyer, B., \& Smith, P. (2008). Serious games taxonomy. In Slides from the Serious Games Summit at the Game Developers Conference. 
Ph.D. Thesis - Sepandar Sepehr; McMaster University - DeGroote School of Business.

Seok, S., \& DaCosta, B. (2014). Distinguishing Addiction From High Engagement: An Investigation Into the Social Lives of Adolescent and Young Adult Massively Multiplayer Online Game Players. Games and Culture, 9(4), 227-254. doi:10.1177/1555412014538811

Sepehr, S., \& Head, M. (2011). The Role of Competitiveness in the Cognitive Absorption of Video Games. The 10th Pre-ICIS Annual Workshop on HCI Research in MIS. Retrieved from http://aisel.aisnet.org/sighci2011/7/

Sepehr, S., \& Head, M. (2012a). A Meta-Analysis of The Effect of Flow on Attitude and Intention to Use of IT Systems. In Administrative Sciences Association of Canada (ASAC). Halifax.

Sepehr, S., \& Head, M. (2012b). Dualistic Model of Passionate Video Gameplay: Addiction or Flow? In the 11th Pre-ICIS Annual Workshop on HCI Research in MIS. Orlando, Florida, USA, December 16, 2012. Retrieved from http://aisel.aisnet.org/sighci2012/13/

Sepehr, S., \& Head, M. (2013a). Competition as an element of gamification for learning: an exploratory longitudinal investigation. In Proceedings of the First International Conference on Gameful Design, Research, and Applications (pp. 2-9).

Sepehr, S., \& Head, M. (2013b). Online Video Game Addiction: A Review and an Information Systems Research Agenda. In the Nineteenth Americas Conference on Information Systems, (pp. 1-11). Chicago, Illinois. Retrieved from http://aisel.aisnet.org/amcis2013/HumanComputerInteraction/GeneralPresentations/3/

Sherry, J. L., Lucas, K., Greenberg, B. S., \& Lachlan, K. (2006). Video game uses and gratifications as predictors of use and game preference. Playing Video Games: Motives, Responses, and Consequences, 213-224.

Shin, N. (2006). Online learner's “flow" experience: an empirical study. British Journal of Educational Technology, 37(5), 705-720. doi:10.1111/j.1467-8535.2006.00641.x

Siekpe, J. (2005). An examination of the multidimensionality of flow construct in a computermediated environment. Journal of Electronic Commerce Research, 6(1), 31-43. Retrieved from http://citeseerx.ist.psu.edu/viewdoc/download?doi=10.1.1.125.5308\&amp;rep=rep1\&amp;t ype $=$ pdf

Sitzmann, T. (2011). A meta-analytic examination of the instructional effectiveness of computerbased simulation games. Personnel Psychology, 64(2), 489-528. Retrieved from http://onlinelibrary.wiley.com/doi/10.1111/j.1744-6570.2011.01190.x/full

Skoric, M. M., Teo, L. L. C., \& Neo, R. L. (2009). Children and video games: addiction, engagement, and scholastic achievement. Cyberpsychology \& Behavior : The Impact of the Internet, Multimedia and Virtual Reality on Behavior and Society, 12(5), 567-72. doi:10.1089/cpb.2009.0079 
Ph.D. Thesis - Sepandar Sepehr; McMaster University - DeGroote School of Business.

Song, H., Kim, J., Tenzek, K. E., \& Lee, K. M. (2013). The effects of competition and competitiveness upon intrinsic motivation in exergames. Computers in Human Behavior, 29(4), 1702-1708. doi:10.1016/j.chb.2013.01.042

Spence, J., \& Helmreich, R. (1983). Achievement-Related Motives and Behaviors. Achievement and Achievement Motives: Psychological .... Retrieved from http://scholar.google.com/scholar?hl=en\&btnG=Search\&q=intitle:AchievementRelated+Motives+and+Behaviors\#0

Sterman, J. (1992). Flight simulators for management education. OR/MS Today. Retrieved from http://www.uni-klu.ac.at/users/gossimit/pap/guest/beer.pdf

Stevens, J. P. (2012). Applied multivariate statistics for the social sciences. Routledge.

Straub, D. W., \& Karahanna, E. (1998). Knowledge Worker Communications and Recipient Availability: Toward a Task Closure Explanation of Media Choice. Organization Science, 9(2), 160-175. doi:10.1287/orsc.9.2.160

Susi, T., Johannesson, M., \& Backlund, P. (2007). Serious games--An overview. Skövde: University of Skövde (Technical Report HS-IKI-TR-07-001). Retrieved from http://www.autzones.com/din6000/textes/semaine12/SusiEtAl(2005).pdf

Sweetser, P., \& Wyeth, P. (2005). GameFlow: a model for evaluating player enjoyment in games. Computers in Entertainment (CIE), 3(3), 1-24. Retrieved from http://dl.acm.org/citation.cfm?id=1077246.1077253

Tabachnick, B., \& Fidell, L. (2001). Using multivariate statistics. Retrieved from http://www.ulb.tu-darmstadt.de/tocs/135813948.pdf

Tauer, J. M., \& Harackiewicz, J. M. (1999). Winning Isn't Everything: Competition, Achievement Orientation, and Intrinsic Motivation•. Journal of Experimental Social Psychology, 35(3), 209-238. Retrieved from http://www.sciencedirect.com/science/article/pii/S0022103199913835

Tauer, J. M., \& Harackiewicz, J. M. (2004). The effects of cooperation and competition on intrinsic motivation and performance. Journal of Personality and Social Psychology, 86(6), 849-61. doi:10.1037/0022-3514.86.6.849

Titz, K., Andrus, D., Miller, J., \& others. (2001). Hedonistic differences between mechanical game players and table game players: an exploratory investigation on the road to a comprehensive theory for gambling. UNLV Gaming Research \& Review Journal, 6(1), 23 32. Retrieved from http://www.cabdirect.org/abstracts/20023161454.html

Turel, O., Serenko, A., \& Giles, P. (2011). Integrating Technology Addiction and Use: An Empirical Investigation of Online Auction Websites. MIS Quarterly. Retrieved from http://aisel.aisnet.org/amcis2009/395/ 
Ph.D. Thesis - Sepandar Sepehr; McMaster University - DeGroote School of Business.

Twenge, J. M. (2006). Generation me: Why today's young Americans are more confident, assertive, entitled--and more miserable than ever before. (Simon and Schuster, Ed.). Free Press.

Twenge, J. M., Campbell, W. K., \& Freeman, E. C. (2012). Generational differences in young adults' life goals, concern for others, and civic orientation, 1966-2009. Journal of Personality and Social Psychology, 102(5), 1045-62. doi:10.1037/a0027408

Udvari, S., \& Schneider, B. (2000). Competition and the adjustment of gifted children: A matter of motivation. Roeper Review, 22(4), 212-216. doi:10.1080/02783190009554040

Vallerand, R. J., Gauvin, L. I., \& Halliwell, W. R. (1986a). Effects of zero-sum competition on children's intrinsic motivation and perceived competence. The Journal of Social Psychology, 126(4), 465-472. Retrieved from http://www.tandfonline.com/doi/abs/10.1080/00224545.1986.9713614

Vallerand, R. J., Gauvin, L. I., \& Halliwell, W. R. (1986b). Negative Elfects of Competition on Children's Intrinsic Motivation. Social Psychology.

Vallerand, R. J., \& Losier, G. F. (1999). An integrative analysis of intrinsic and extrinsic motivation in sport. Journal of Applied Sport Psychology, 11(1), 142-169. Retrieved from http://www.tandfonline.com/doi/abs/10.1080/10413209908402956

Van der Heijden, H. (2004). User Acceptance of Hedonic Information Systems. MIS Quarterly, 28(4), 695-704. Retrieved from http://www.jstor.org/stable/25148660

Van der Zee, D.-J., Holkenborg, B., \& Robinson, S. (2012). Conceptual modeling for simulationbased serious gaming. Decision Support Systems. doi:10.1016/j.dss.2012.03.006

Van Eck, R. (2006). Digital game-based learning: It's not just the digital natives who are restless. EDUCAUSE Review, 41(2), 16. Retrieved from http://dl.acm.org/citation.cfm?id=950596

Vansteenkiste, M., \& Deci, E. L. (2003). Competitively contingent rewards and intrinsic motivation: Can losers remain motivated? Motivation and Emotion, 27(4), 273-299. Retrieved from http://link.springer.com/article/10.1023/A:1026259005264

Vorderer, P., Hartmann, T., \& Klimmt, C. (2003a). Explaining the enjoyment of playing video games: the role of competition. In Proceedings of the second international conference on Entertainment computing (pp. 1-9).

Vorderer, P., Hartmann, T., \& Klimmt, C. (2003b). Proceedings of the second international conference on Entertainment computing. Proceedings of the Second International Conference on Entertainment Computing, 1-9. Retrieved from http://dl .acm.org/citation.cfm?id=958735 
Ph.D. Thesis - Sepandar Sepehr; McMaster University - DeGroote School of Business.

Vorderer, P., Klimmt, C., \& Ritterfeld, U. (2004). Enjoyment: At the Heart of Media Entertainment. Communication Theory, 14(4), 388-408. doi:10.1111/j.14682885.2004.tb00321.x

Vygotsky, L. S. (1978). Mind and society: The development of higher mental processes. Cambridge, MA: Harvard University Press.

Wakefield, R. L., \& Whitten, D. (2006). Mobile computing: a user study on hedonic/utilitarian mobile device usage. European Journal of Information Systems, 15(3), 292-300. doi:10.1057/palgrave.ejis.3000619

Webster, J., \& Ho, H. (1997). Audience engagement in multimedia presentations. ACM SIGMIS Database, 28(2), 63-77. doi:10.1145/264701.264706

Webster, J., \& Martocchio, J. J. (1992). Microcomputer Playfulness: Development of a Measure with Workplace Implications. MIS Quarterly, 16(2), 201-226. doi:10.2307/249576

Weibel, D., Wissmath, B., Habegger, S., Steiner, Y., \& Groner, R. (2008). Playing online games against computer- vs. human-controlled opponents: Effects on presence, flow, and enjoyment. Computers in Human Behavior, 24(5), 2274-2291.

doi:10.1016/j.chb.2007.11.002

Weibel, D., Wissmath, B., Habegger, S., Steiner, Y., \& Groner, R. (2008). Playing online games against computer- vs. human-controlled opponents: Effects on presence, flow, and enjoyment. Computers in Human Behavior, 24(5), 2274-2291. doi:10.1016/j.chb.2007.11.002

Weinberg, R. S., \& Jackson, A. (1979). Competition and Extrinsic Rewards: Effect on Intrinsic Motivation and Attribution. Research Quarterly, 50(3), 494-502.

Wetzels, M., Odekerken-Schroder, G., \& Van Oppen, C. (2009). Using PLS path modeling for assessing hierarchical construct models: guidelines and empirical illustration. Management Information Systems Quarterly, 33(1), 11.

Williams, D., Yee, N., \& Caplan, S. E. (2008). Who plays, how much, and why? Debunking the stereotypical gamer profile. Journal of Computer-Mediated Communication, 13(4), 9931018. doi:10.1111/j.1083-6101.2008.00428.x

Wixom, B. H., \& Todd, P. a. (2005). A Theoretical Integration of User Satisfaction and Technology Acceptance. Information Systems Research, 16(1), 85-102. doi:10.1287/isre. 1050.0042

Wood, R. T. a, Griffiths, M. D., \& Parke, A. (2007). Experiences of time loss among videogame players: an empirical study. Cyberpsychology \& Behavior : The Impact of the Internet, Multimedia and Virtual Reality on Behavior and Society, 10(1), 38-44. doi:10.1089/cpb.2006.9994 
Ph.D. Thesis - Sepandar Sepehr; McMaster University - DeGroote School of Business.

Wu, J. H., Wang, S. C., \& Tsai, H. H. (2009). Why Do Players Stick to a Specific Online Game? The Users and Gratifications Perspective. In AMERICAS CONFERENCE ON INFORMATION SYSTEMS (AMCIS). Retrieved from http://aisel.aisnet.org/amcis2009/351/

Xia Skadberg, Y., \& Kimmel, J. R. (2004). Visitors' Flow experience while browsing a web site: its measurement, contributing factors and consequences. Computers in Human Behavior, 20(3), 403-422. doi:10.1016/S0747-5632(03)00050-5

Yee, N. (2006). Motivations for play in online games. Cyberpsychology \& Behavior : The Impact of the Internet, Multimedia and Virtual Reality on Behavior and Society, 9(6), 772-5. doi:10.1089/cpb.2006.9.772

Young, M. F., Slota, S., Cutter, a. B., Jalette, G., Mullin, G., Lai, B., ... Yukhymenko, M. (2012). Our Princess Is in Another Castle: A Review of Trends in Serious Gaming for Education. Review of Educational Research, 82(1), 61-89. doi:10.3102/0034654312436980

Zajonc, R. B. (1965). Social facilitation. Science, 149(3681), 269-274. Retrieved from http://neuron4.psych.ubc.ca/ schaller/Psyc591Readings/Zajonc1965.pdf 
Ph.D. Thesis - Sepandar Sepehr; McMaster University - DeGroote School of Business.

\section{APPENDIX 1 - FURTHER DETAILS ON THE META-ANALYSIS STUDY OF FLOW}

The use of hedonic IT systems has increasingly become a point of interest for researchers in the past decade. As various studies have shown before, the theory of flow can predict the intention of user to use hedonic systems (e.g. Agarwal \& Karahanna, 2000; Korzaan, 2003; Nah, Eschenbrenner, Wester, \& Park, 2010). Different measurement instruments have been developed for measuring the state of flow/CA, in particular during the use of IT systems. These studies have examined the theory of flow by finding the antecedents and outcomes of this concept by employing the constructs developed to measure it. Through an extensive literature review, the most common use of the concept of flow was identified, which is the extension of the Technology Acceptance Model (TAM) (Davis, Bagozzi, \& Warshaw, 1989), Theory of Reasoned Action (TRA) (Fishbein \& Ajzen, 1975) and Theory of Planned Behaviour (TPB) (Ajzen, 1991). In fact, there have been many different constructs that are connected to flow; but, the main theme of research is to predict the use of hedonic IT products by deploying the theory of flow. TAM is one of the most (if not the most) common and well-established models in the field of IS that has been used in other fields as well. TAM and TPB are based on TRA and all try to predict process of decision making of people for using a product based on their 'intention to use' a system, which in turn can be predicted by 'attitude towards' that product.

In contrast to the original TAM, subsequent models such as TAM2 and UTAUT (Unified Theory of Acceptance and Use of Technology), have claimed that the construct of attitude could be removed from technology adoption models for the purpose of parsimony (Venkatesh, Morris, Davis, \& Davis, 2003; Venkatesh \& Davis, 2000). Venkatesh et al. (2003) argue that the relationship between attitude and intention towards using technology is spurious. They show that this relationship can be eliminated given that the other constructs of UTAUT are present. 
Ph.D. Thesis - Sepandar Sepehr; McMaster University - DeGroote School of Business.

However, more recently, scholars have included the construct of attitude in their models to evaluate user perception of technology use (e.g. Hassanein \& Head, 2007; Kim, 2009; Lin \& Bhattacherjee, 2010). In situations where users are introduced to a new or fictitious technology or product, it may be unrealistic to inquire participants about their intention to use those products. To illustrate, Hassanein and Head's (2007) study employs a fictitious e-commerce website to measure how much participants' attitude towards products change based on manipulations on the website. As they stress, in such conditions, it may not be appropriate to ask for participants' intention, as they may not be intending to purchase any product from that website regardless of their attitude towards those products. Similarly, when users interact with a hedonic product/website during an experiment where they would have little or no opportunity to use the product /website post-experiment, regardless of their attitude, it is infeasible for them to express their intention to use the IT artefact. Therefore, it can be said that attitude is a construct that deserves more attention and should be considered in this meta-analysis.

Based on the previous discussion on the theory of flow and its relation with TRA, TAM, and TPB, it was decided to study this connection in more detail. In TAM, there are two other constructs, namely 'perceived usefulness' (PU) and 'perceived ease of use' (PEOU). PU and PEOU are the two main constructs that predict attitude towards an IT product. However, PU and PEOU are not widely used in the articles that measure the state of flow. In the hedonic context, it can be argued that PU may not be an influential construct due to the emotional experience of users that directs their decision towards using the system (which may actually non-rational or unplanned) (de Guinea \& Markus, 2009). Since the studies reviewed for the purpose of this study are taken from various disciplines, which may not use the same theories, PU and PEOU were not chosen for this study. On the other hand, many of the studies employ TRA and/or TPB, in which 
Ph.D. Thesis - Sepandar Sepehr; McMaster University - DeGroote School of Business.

the constructs of attitude and intention towards using a system, or some relevant concepts that can be used interchangeably. As previous studies have shown, flow/CA has a moderate to high effect on TAM constructs including attitude and intention to technology use (e.g. Agarwal \& Karahanna, 2000; Hsu \& Lu, 2004; Nah et al., 2010). Therefore, in alignment with the previous studies, this study aims to find the correlation between the construct of flow in IT use, with attitude and intention towards use of IT systems.

\section{Operationalization Mode of Flow/CA}

Hoffman \& Novak (2009) articulate that flow is conceptually defined and explained by Csikszentmihalyi $(1991,1997)$, but it has not been operationalized consistently among all the studies. This is perhaps due to the fact that the concept of flow is defined very broadly (Choi et al., 2007) as it entails various dimensions that can contribute to the feeling of being deeply involved and engaged in a task. To advance the research on theory of flow there is a need to clarify the operationalized constructs in empirical studies. Consequently, through this research, different operationalization methods of the concept of flow have been identified and categorized.

The two main categories of measures of flow are unidimensional and multidimensional measures (here referred to them as operationalization modes). The former are the measures that give a narrative description of flow in the survey followed by a few item instrument (usually three) to directly record the perception of participants from the level of flow that they experience through the use of system (e.g. Hsu, 2004; Korzaan, 2003; Novak, Hoffman, \& Yung, 2000). The multidimensional measures are the instruments that aim to aggregate different dimensions of flow such as enjoyment, concentration and transformation of time in one higher-order construct, namely flow or CA (e.g. Agarwal \& Karahanna, 2000; Saadé \& Bahli, 2005; Webster, Trevino, \& Ryan, 1993). For further clarification on the difference between these constructs, please refer 
Ph.D. Thesis - Sepandar Sepehr; McMaster University - DeGroote School of Business.

to Appendix A - selection of constructs used in the meta-analysis. Through the meta-analysis the method of operationalization of flow has been monitored constantly and analyzed through various steps in order to test the potential moderation effect.

Multidimensional constructs of flow (CA) tend to include different aspect of the concept of flow and explain the state of flow better. One can say that in it is necessary to include all the dimensions of this construct when one wants to measure this state and its relation with other constructs. In other words, "each dimension captures a unique aspect of the theoretical concept and demonstrates a unique relationship to the overarching construct" (Polites, Roberts, \& Thatcher, 2012, p. 29). As Ones \& Viswesvaran (1996) have shown, broader constructs (measured through multiple dimensions) could have better prediction and explanation in certain contexts when compared to narrow measures ${ }^{17}$. Thus, due to the higher-order nature of multidimensional measures of flow, which enables them to better represent the concept of flow, it is expected that the prediction power of these measurements will be higher than unidimensional measures.

The proposed research model of the study is presented in Figure 12.

${ }^{17}$ It should be mentioned here that using multidimensional constructs could add complications to the analysis of data. Also, prediction power of these constructs require more consideration as some scholars have warned researchers (Paunonen, Rothstein, \& Jackson, 1999). 
Ph.D. Thesis - Sepandar Sepehr; McMaster University - DeGroote School of Business.

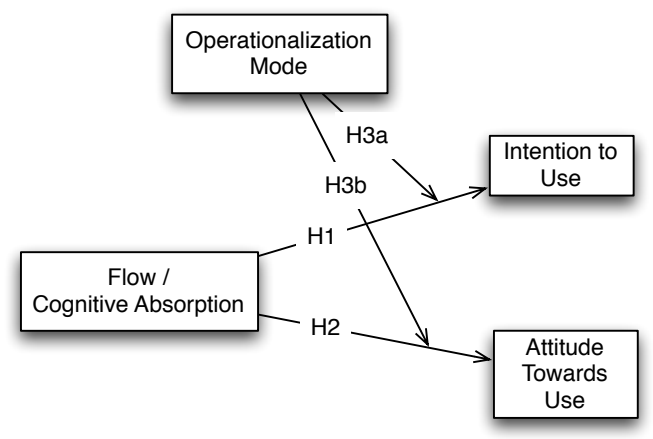

Figure 12 - Research Model

Respectively, it is hypothesized:

H1: There is a medium to strong positive relationship between Flow/CA and Intention to Use of IT systems.

H2: There is a medium to strong positive relationship between Flow/CA and Attitude Towards Use of IT systems.

H3a: Operationalization Mode of the concept of Flow/CA will moderate the relationship between this construct and Intention to Use of IT systems such that it will be higher for multidimensional representations of Flow/CA.

H3b: Operationalization Mode of the concept of Flow/CA will moderate the relationship between this construct and Attitude Towards Use of IT systems such that it will be higher for multidimensional representations of Flow/CA.

\section{Methodology}

In this study, meta-analysis technique was used (Glass, 1976; Hunter \& Schmidt, 1990) to combine the results of previous studies in order to gather a clear explanation of the power of the construct of flow in predicting usage of IT systems. To the best of my knowledge, flow theory has become very popular recently, considering the increase in the number of papers that 
Ph.D. Thesis - Sepandar Sepehr; McMaster University - DeGroote School of Business.

have been published in recent years ${ }^{18}$. However, a meta-analysis has not been conducted on this theory with respect to its relationship to attitude and intention to use.

\section{Sample}

The sample studies for this meta-analysis have been selected from several sources, including journals, books, dissertations, and conference proceedings. The effort was to capture all of the studies that were found in order to minimize the bias towards the effect size of a series of articles. To find appropriate articles, various databases (mentioned below) were searched and literature reviews on the theory of flow were used to capture all the relevant studies. The main challenge in finding relevant articles is that 'flow' is a term that is used for many other concepts such as flow in thermodynamics, which make the search for articles related to the theory of flow difficult. Therefore, some strategic approaches were also taken. For example, using Google Scholar, articles citing the seminal flow and CA works (Agarwal \& Karahanna, 2000; Csikszentmihalyi, 1991, 1997; Novak et al., 2000) were followed recursively to develop an effective search strategy. Additionally, all the articles including the "flow" term in AIS Electronic Library (AISEL), Business Source Complete, some HCI journals (such as Computers in Human Behavior), and HCI category of Google Scholar (2003+) were checked for relevance. Some reviews of flow theory (Agarwal \& Karahanna, 2000; Donna L. Hoffman \& Novak, 2009; Mahfouz \& Guo, 2011; F. Nah \& Eschenbrenner, 2011; Y. Poon, Wong, \& Zhang, 2006) were consulted in order to extract all the related studies. This search methodology found more than 2000 journal articles, conference proceedings, and unpublished dissertations. As such, it is reasonable to indicate that source bias was minimized through this extensive methodology, to

\footnotetext{
${ }^{18}$ The research shows that the number of studies on flow theory (in particular in the field of IS) has increased after the year 2000.
} 
Ph.D. Thesis - Sepandar Sepehr; McMaster University - DeGroote School of Business.

provide a reliable meta-analysis. Furthermore, to minimize the publication bias, an email was also sent to the largest IS academic mailing list (AISWorld) to inquire about unpublished, proceedings, and working papers that might be related to this research.

Among these studies, 153 were selected as potential studies for the meta-analysis based on their relevance to the flow theory or CA. From the 153 relevant studies, only 37 qualified for inclusion in the final analysis, based on the following selection criteria:

1. The study should operationalize flow or CA and its impact on the intention to use or attitude towards use (or any construct that could be justified as measuring the same concept $\left.^{19}\right)$.

2. The study should report reliabilities of the above mentioned measurement instruments ${ }^{20}$.

3. Sample size of the study is reported ${ }^{21}$.

4. The correlation among flow/CA and attitude toward use or intention to use should be present, including their values as $r, r^{2}$ or any other scale that can be transformed to $r$.

For some studies that qualified for selection but were missing one of the criteria above (e.g. correlation table), the authors were contacted to inquire about the missing data. However, no response was received from any of the authors. All the studies were monitored for independence by comparing the papers and their reported data. In a case where a particular author had published a series of conference proceedings and a journal paper that had used the same data set, only one was selected for inclusion in this meta-analysis.

${ }^{19}$ This is done because studies were selected from different disciplines that might have different names for the same construct. To be included, there had to be significant overlap in the operationalization of the constructs with those of attitude and intention in the IS literature.

${ }^{20}$ Or it was possible to calculate the reliabilities from the given data.

${ }^{21}$ There was no case with missing sample size. Thus, there was no need for considering other approaches to deal with missing values. 
Ph.D. Thesis - Sepandar Sepehr; McMaster University - DeGroote School of Business.

One study that qualified for analysis (P. Zhang, Li, \& Sun, 2006) was removed from the analysis. The rationale for making this decision was that the correlation of flow and intention to use of system (in their case use of web) was unreasonably low compared to other studies. With further investigation, it was clarified that these authors had tested the construct of flow, which is a hedonic construct in nature, on student samples. Later on, they asked the students if they intended to use the university's website. Intention to use the university's website is clearly a utilitarian use because the use of that website is out of students' control. Therefore, it is expected that regardless of student's positive experience in using the university's website they still would intend to use the system because they are expected to for their coursework. Thus, it would be expected that combining a hedonic measure within a utilitarian context would decrease its actual effect. Based on the same rationale (inappropriateness of this evaluation for such e-Learning contexts), three other studies (Choi et al., 2007; Lee, 2010; Saadé \& Bahli, 2005) were removed from the final analysis, leaving us with 34 studies.

For the detailed information about the studies that were selected for this meta-analysis, please refer to Appendix B.

\section{Analysis}

All the studies that were selected for the meta-analysis were meticulously reviewed to extract the required data. The correlations (of flow with attitude and intension) and their reliabilities were recorded in a spreadsheet. For some studies, flow/CA was measured as a multidimensional construct and separate correlation values were not reported. But, the correlations were reported between the dimensions of that construct with other constructs (e.g. attitude or intention). For those studies, correlation of flow with attitude or intension was used using the following formula by measuring the correlation of the composite variable (Ley, 1972): 
Ph.D. Thesis - Sepandar Sepehr; McMaster University - DeGroote School of Business.

$$
r_{o C}=\frac{\overline{r_{o l}}}{\sqrt{\frac{n}{n^{2}}+\frac{n(n-1)}{n^{2}} \overline{r_{l \jmath}}}}=\frac{\overline{r_{o l}}}{\sqrt{\frac{1}{n}+\frac{n-1}{n} \overline{r_{l \jmath}}}}
$$

Where $\overline{r_{o l}}$ is the average correlation of dimensions with attitude or intention, $\mathrm{n}$ is the number of dimensions, and $\overline{r_{l j}}$ is the average of the correlation among components themselves.

Reliabilities in several studies required further a mention. In articles where reliabilities were reported as Cronbach's alpha, no change was made to their values. If both Cronbach's alpha and Composite Reliability (CR) was reported in the study, the Cronbach's alpha was used in alignment with most of the studies considering the low sensitivity of the final results to slight variations in reliability values. In fact, the difference between these two values is not expected to be much ${ }^{22}$ if any. This was also true in the final findings of this meta-analysis. By monitoring this difference, sensitivity analysis was conducted (similar to the approach used by Sabherwal, Jeyaraj, \& Chowa, 2006) to make sure that the choice of one of the reliability reports instead of the other one would not considerably affect the results of the meta-analysis.

The main issue in reporting reliabilities arises in cases that flow/CA is measured as a second-order construct. In those cases, some studies have only reported reliabilities for each of the dimensions separately. For these cases, if the only information given was the reliabilities of each dimension separately, the average of reliabilities was used. In most of the cases, by using the factor loading of the outer model (model of the weights of the relation from flow to its dimensions), composite reliability of flow/CA was calculated. The formula for calculating composite reliability is as follows:

$$
C R=\frac{\left(\sum_{i=1}^{n} L_{i}\right)^{2}}{\left(\sum_{i=1}^{n} L_{i}\right)^{2}+\left(\sum_{i=1}^{n} e_{i}\right)}
$$

${ }^{22}$ If not equal (for non tau-equivalent results), CR reports a slightly higher value compared to Cronbach alpha, but not much higher. 
Ph.D. Thesis - Sepandar Sepehr; McMaster University - DeGroote School of Business.

Where $L_{i}$ is the loading of each dimension, and $e_{i}$ is the error for that factor that is $1-L_{i}^{2}$. In addition, the type of operationalization of flow was recorded as number 1 for unidimensional, 2 for multidimensional corresponding to CA, 3 for multidimensional that entails some or another variation of the dimensions of $\mathrm{CA}$, and 4 for others.

The analysis was then performed by following Hunter \& Schmidt's (1990) meta-analysis technique. For this reason, the following five steps were taken:

1. Effect sizes (correlation weights) were corrected for unreliability using the following formula $\left(r_{x x}\right.$ is the reliability):

$$
r_{x y}^{\prime}=r_{x y} / \sqrt{r_{x x} \times r_{y y}}
$$

2. Corrected effect sizes were transformed to standard scores as follows:

$$
E S_{Z r}=.5 \times \ln \left[\frac{1+r}{1-r}\right]
$$

3. Weights were also corrected for unreliability and adjusted:

$$
w^{\prime}=w \times r_{x x} \times r_{y y}
$$

4. Then, overall weighted mean effect size was calculated:

$$
\overline{E S}=\frac{\sum w \times E S}{\sum w}
$$

5. And finally average $r$ was measured by transforming the overall average back into $r$ using $Z_{r}$ transformation:

$$
r=\left(e^{2 E S z}-1\right) /\left(e^{2 E S z}+1\right)
$$


Ph.D. Thesis - Sepandar Sepehr; McMaster University - DeGroote School of Business.

\section{Results}

The steps mentioned above were conducted for the relationships of flow/CA with both attitude towards use and intention to use separately. Average corrected (weighted mean) effect size for relationship between flow and attitude was .68 , and .57 for relationship between flow and intention, supporting hypotheses $\mathbf{H 1}$ and $\mathbf{H 2}$. The final transformed $r$ value was .59 for the relation with attitude and .52 for the relation with intention, showing a high effect size for both relations. Standard error was also calculated for both correlations (.02 and .01$)$ for finding the confidence intervals. The $95 \%$ confidence intervals are $.59 \pm .01$ and $.52 \pm .01$ for attitude and intention's relations respectively. It can be seen that none of the confidence intervals includes zero and are actually very small, showing a very significant effect. $z$-score was also measured for both values: 35.06 for correlation of flow and attitude, and 39.93 for flow and intention, showing again a very significant result in the findings.

A $Q$-test was conducted for checking the existence of potential moderators in the findings. $Q$ values of both relations are very high: 261.81 for correlation between flow and attitude, and 275.98 for flow and intention. The total number of studies that had measured the effect size for attitude were 13, leaving 12 degrees of freedom. Obviously, 261.81 is much higher than 21.03 (chi-square value for $d f=12$ and $p=.05$ ), showing that the effect sizes are heterogeneous and possible moderators exist. The same issue was observed for correlation of flow and intention: $Q=275.98$ for $d f=27$ (chi-square value of 30.14 for $p=.05$ ).

\section{Moderator: Operationalization Method}

Considering the $Q$ values mentioned above, it is expected to find that moderators play a role in the meta-analysis. Based on the literature review, it was hypothesized that the method of operationalization of the construct of flow (e.g. multi vs. uni-dimensional) is a moderator of the 
Ph.D. Thesis - Sepandar Sepehr; McMaster University - DeGroote School of Business.

relationship between this construct and constructs of attitude and intention. To the best of my knowledge, no one has explored which operationalization predicts use and/or attitude better.

Even though some scholars have indicated that unidimensional and multidimensional instruments can be correlated in some contexts (Guo \& Ro, 2008), the outcomes of these two operationalization methods have not been discussed before.

The coding of flow/CA operationalization was conducted as:

- Code 1: Studies using unidimensional constructs (consistent with Hoffman \& Novak, 1996)

- $\quad$ Code 2: Studies using the multidimensional construct of CA (developed by Agarwal \& Karahanna, 2000)

- Code 3: Studies that deploy multidimensional constructs that had more than two dimensions of the constructs of 'Code 2' but could not be categorized as CA

- Code 4: Various studies that could not be categorized as any of the above $\operatorname{codes}^{23}$

Total number of studies for each code is shown in Table 14.

Table 14 - Total number of studies for each code and each relationship

\begin{tabular}{|c|c|c|}
\hline Including relationship with: & Attitude Towards Use & Intention to Use \\
\hline Code 1: & 3 & 5 \\
\hline Code 2: & 0 & 4 \\
\hline Code 3: & 5 & 7 \\
\hline Code 4: & 5 & 14 \\
\hline
\end{tabular}

${ }^{23}$ These studies occasionally use very small subsets of multidimensional instruments or they use other constructs that were not identical to attitude or intention to use (such as intention to continue to use). 
Ph.D. Thesis - Sepandar Sepehr; McMaster University - DeGroote School of Business.

In the final analysis after controlling for the moderator, the studies in code 1 were compared with the studies in codes 2 and 3 . Code 1 includes all the studies that have unidimensional flow construct and codes 2 and 3 are the multidimensional constructs. Code 4 studies were eliminated in the final analysis because they could not be easily categorized as unidimensional or multidimensional studies due to the variations in the flow constructs or the other constructs of interest. The results were also calculated for the studies including codes 1,2 , and 3 in order to check if high $Q$ value is due to the anomaly of the measurements of code 4 studies. However, the $Q$ value was still very high for codes 1 to 3 (229.23 and 138.83 for the relations with attitude and intention respectively), showing the existence of moderator among those studies. This finding supports the choice of comparing code 1 with codes 2 and 3 . The final results are summarized in Table 15 .

Table 15 - The results of the meta-analysis after controlling for the moderator (operationalization mode)

\begin{tabular}{|c|c|c|c|c|}
\hline Operationalization Group/Code: & \multicolumn{2}{|c|}{ Only 1 } & \multicolumn{2}{c|}{ 2 \& 3 } \\
\hline Flow relation with: & Attitude & Intention & Attitude & Intention \\
\hline $\boldsymbol{n}$ (number of studies) & 3 & 5 & 5 & 11 \\
\hline$\overline{E S}$ (corrected weighted mean \\
effect size)
\end{tabular}


Ph.D. Thesis - Sepandar Sepehr; McMaster University - DeGroote School of Business.

As can be seen in the table above, there is a significant difference between the effect sizes of the outcomes related to each type of measurement of flow. To be precise, unidimensional implementations have a moderate effect on intention while multidimensional constructs have a very large effect size. All of the findings have a high $z$-value showing their significance.

However, the $Q$-value for the value of studies on attitude toward use that deploy multidimensional measures of flow is still too high, making it difficult to draw any certain conclusion about those relationships. Still, the results show that operationalization of flow plays the role of a moderator on the relation between being in the state of flow/CA and intention to use the system. Thus, hypothesis $\mathbf{H 3 a}$ is supported. While hypothesis $\mathbf{H 3 \mathbf { b }}$ is supported, there is a possibility of other moderators in this relationship that need to be considered and further investigation is required.

\section{Selection of Constructs Used in Meta-analysis}

As it is explained in the article, the analysis was done by choosing four codes for the studies. Here, the main constructs used for the first three codes and an example of code 4 studies were included.

\section{Unidimensional (Code 1)}

The first code was given to the unidimensional constructs of flow. Novak et al. (2000) have been repeatedly cited for the unidimensional construct of flow, which they developed for measuring the experience of flow among web users as follows:

The word "flow" is used to describe a state of mind sometimes experienced by people who are deeply involved in some activity. One example of flow is the case where a professional athlete is playing exceptionally well and achieves a state of mind where 
Ph.D. Thesis - Sepandar Sepehr; McMaster University - DeGroote School of Business.

nothing else matters but the game; he or she is completely and totally immersed in it. The experience is not exclusive to athletics: Many people report this state of mind when playing games, engaging in hobbies, or working.

Activities that lead to flow completely captivate a person for some period of time. When one is in flow, time may seem to stand still, and nothing else seems to matter. Flow may not last for a long time on any particular occasion, but it may come and go over time. Flow has been described as an intrinsically enjoyable experience.

Thinking about your own use of the Web:

F1) Do you think you have ever experienced flow on the Web?

F2) In general, how frequently would you say you have experienced "flow" when you use the Web?

F3) Most of the time I use the Web I feel that I am in flow.

\section{Multidimensional (Code 2 \& 3)}

Multidimensional constructs are divided in two groups. The first one (code 2) are the studies that use Cognitive Absorption (CA) (Agarwal \& Karahanna, 2000) and the second group (code 3) are the other multidimensional constructs with more than two dimensions, such as Engagement (Webster \& Ho, 1997). These constructs are as follow:

\section{Cognitive Absorption.}

In the original studies, CA was measured for participants about their interaction with Web.

\section{Temporal Dissociation.}

TD1) Time appears to go by very quickly when I am using the Web. 
Ph.D. Thesis - Sepandar Sepehr; McMaster University - DeGroote School of Business.

TD2) Sometimes I lose track of time when I am using the Web.

TD3) Time flies when I am using the Web.

TD4) Most times when I get on to the Web. I end up spending more time that I had planned.

TD5) I often spend more time on the Web than I had intended.

\section{Focused Immersion.}

FI1) While using the Web I am able to block out most other distractions.

FI2) While using the Web, I am absorbed in what I am doing.

FI3) While on the Web, I am immersed in the task I am performing

FI4) When 0n the Web, I get distracted by other attentions very easily.

FI5) While on the Web, my attention does not get diverted very easily.

\section{Heightened Enjoyment.}

HE1) I have fun interacting with the Web.

HE2) Using the Web provides me with a lot of enjoyment.

HE3) I enjoy using the Web. Using the Web bores me.

\section{Control.}

CO1) When using the Web I feel in control.

$\mathrm{CO} 2$ ) I feel that I have no control over my interaction with the Web.

CO3) The Web allows me to control my computer interaction.

\section{Curiosity.}

CU1) Using the Web excites my curiosity.

CU2) Interacting with the Web makes me curious. 
Ph.D. Thesis - Sepandar Sepehr; McMaster University - DeGroote School of Business.

CU3) Using the Web arouses my imagination.

\section{Engagement.}

Engagement was measured for participants' involvement during a multimedia presentation.

Attention focus.

AF1) This presentation medium keeps me totally absorbed in the presentation. AF2) This presentation medium holds my attention.

\section{Curiosity.}

CU1) This presentation medium excites my curiosity.

CU2) This presentation medium arouses my imagination.

\section{Intrinsic interest.}

II1) This presentation medium is fun.

II2) This presentation medium is intrinsically interesting.

Overall.

OV) This presentation medium is engaging.

\section{Miscellaneous (code 4)}

Code 4 includes the studies that did not use the classical unidimensional measures (code 1), any multidimensional construct that could be categorized as code 2 or code 3 , or one of the other constructs could not be categorized as a normal TAM construct. One example of these studies is Shin and Shin (2010) that uses three items flow construct as follows:

FL1) During an SNG game, I was intensely absorbed in the activity. 
Ph.D. Thesis - Sepandar Sepehr; McMaster University - DeGroote School of Business.

FL2) I strongly feel that I am inside a different world when playing SNGs.

FL3) When playing with SNGs, I do not feel any control.

\section{Data and Calculations}

From the papers that were eligible for use in the meta-analysis, a few of them are not included here due to their missing data (authors were contacted but they did not respond) or they were measuring exploratory use, which did not closely match the concept of intention to use or attitude to use a system. The pool of studies considered for the calculations are shown in the following table.

Table 16 - Studies Qualified for the Meta-analysis

\begin{tabular}{|c|c|c|c|}
\hline $\mathrm{k}$ & Flow Type & Authors (citation) & Context \\
\hline 1 & 1 & Hsu and Lu (2004) & Play online games \\
\hline 2 & 1 & Korzaan (2003) & (Online) Purchase \\
\hline 3 & 4 & Liao (2006) & e-Learning \\
\hline 4 & 4 & Liu et al. (2009) & e-Learning \\
\hline 5 & 4 & Jung et al. (2009) & Mobile TV \\
\hline 6 & 4 & Shin and Shin (2010) & Social Net. Games \\
\hline 7 & 1 & Choi et al. (2007)* & ERP Training \\
\hline 8 & 1 & Nah et al. (2010) & Brand Equity in Virtual World \\
\hline 9 & 2 & Lin (2009) & Virtual Community \\
\hline 10 & 2 & Zhang et al. (2006)* & TAM extension (web use) \\
\hline 11 & 2 & Wakefield and Whitten (2006) & Mobile Computing \\
\hline 12 & 2 & Agarwal and Karahanna (2000) & CA and TAM (web use) \\
\hline 13 & 4 & Deng et al. (2010) & Mobile internet services \\
\hline
\end{tabular}


Ph.D. Thesis - Sepandar Sepehr; McMaster University - DeGroote School of Business.

\begin{tabular}{|c|c|c|c|}
\hline 14 & 4 & Kamis (2010) & Online shopping \\
\hline 15 & 3 & Koufaris (2002) & Online shopping \\
\hline 16 & 3 & Saade and Bahli (2005)* & Online learning \\
\hline 17 & 3 & Siekpe (2005) & Online shopping \\
\hline 18 & 4 & Roca et al (2006) & e-Learning \\
\hline 19 & 2 & Chandra et al. (2009) & Virtual World Collaboration \\
\hline 20 & 4 & Shiau et al. (2011) & Blog Use \\
\hline 21 & 3 & Mahfouz (2004) & Online shopping \\
\hline 22 & 3 & Jiang et al. (2009) & Web Browsing \\
\hline 23 & 3 & Lin et al. (2008) & e-Commerce \\
\hline 24 & 1 & Hooker (2010) & Online shopping (VW) \\
\hline 25 & 3 & Guo and Klein (2009) & Online shopping \\
\hline 26 & 3 & Webster and Ahuja (2006) & Web Browsing \\
\hline 27 & 4 & Tung et al. (2006) & Website Advertising \\
\hline 28 & 3 & Trevino et al. (2000) & Media Attitude \\
\hline 29 & 3 & Lee (2009) & Online Gaming \\
\hline 30 & 4 & Lu et al. (2009) & IM use (Chinese context) \\
\hline 31 & 4 & Lee $(2010)^{*}$ & e-Learning \\
\hline 32 & 1 & Sicilia and Ruiz (2007) & Online shopping \\
\hline 33 & 4 & Zhou (2011a) & Mobile Purchase \\
\hline 34 & 4 & Zhou (2011b) & Mobile Banking \\
\hline 35 & 4 & Sanchez-Franco and Ray (2006) & Web Use \\
\hline 36 & 4 & Zhou (2011c) & Mobile Use \\
\hline 37 & 4 & Zhou and $\mathrm{Lu}(2011)$ & Mobile Use \\
\hline
\end{tabular}


Ph.D. Thesis - Sepandar Sepehr; McMaster University - DeGroote School of Business.

Note: Studies marked with asterisks $(*)$ are the studies that were eliminated for the final calculations in the meta-analysis as explained earlier in the "methodology" section.

The following table shows the information that was required for performing metaanalysis extracted from the studies mentioned in the previous table.

Table 17 - The extracted data for the studies that were used in the final meta-analysis

\begin{tabular}{|c|c|c|c|c|c|c|}
\hline $\mathrm{k}$ & $\mathrm{n}$ & $\mathrm{r}(\mathrm{ATT})$ & $\mathrm{r}(\mathrm{INT})$ & $\begin{array}{l}\text { flow } \\
\text { alpha }\end{array}$ & $\begin{array}{l}\text { ATT } \\
\text { alpha }\end{array}$ & $\begin{array}{l}\text { INT } \\
\text { alpha }\end{array}$ \\
\hline 1 & 233 & 0.2 & 0.28 & 0.907 & 0.82 & 0.805 \\
\hline 2 & 342 & 0.24 & 0.21 & 0.92 & 0.89 & 0.94 \\
\hline 3 & 253 & N/A & 0.57 & 0.86 & N/A & 0.91 \\
\hline 4 & 102 & 0.39 & 0.42 & 0.83 & 0.88 & 0.87 \\
\hline 5 & 208 & N/A & 0.46 & 0.85 & N/A & 0.9 \\
\hline 6 & 280 & 0.42 & 0.19 & 0.88 & 0.82 & 0.91 \\
\hline 7 & 223 & 0.63 & N/A & 0.92 & 0.89 & N/A \\
\hline 8 & 211 & $\mathrm{~N} / \mathrm{A}$ & 0.23 & 0.9 & N/A & 0.91 \\
\hline 9 & 172 & N/A & 0.51 & 0.89 & N/A & 0.81 \\
\hline 10 & 194 & $\mathrm{~N} / \mathrm{A}$ & 0.26 & 0.89 & N/A & 0.97 \\
\hline 11 & 185 & N/A & 0.61 & 0.95 & N/A & 0.92 \\
\hline 12 & 270 & $\mathrm{~N} / \mathrm{A}$ & 0.60 & 0.87 & N/A & 0.97 \\
\hline 13 & 289 & N/A & 0.43 & 0.87 & N/A & 0.91 \\
\hline 14 & 230 & N/A & 0.76 & 0.91 & N/A & 0.91 \\
\hline 15 & 280 & $\mathrm{~N} / \mathrm{A}$ & 0.57 & 0.89 & N/A & 1 \\
\hline 16 & 102 & $\mathrm{~N} / \mathrm{A}$ & 0.33 & 0.76 & N/A & 0.62 \\
\hline 17 & 281 & $\mathrm{~N} / \mathrm{A}$ & 0.57 & 0.85 & $\mathrm{~N} / \mathrm{A}$ & 0.87 \\
\hline
\end{tabular}


Ph.D. Thesis - Sepandar Sepehr; McMaster University - DeGroote School of Business.

\begin{tabular}{|c|c|c|c|c|c|c|}
\hline 18 & 172 & N/A & 0.49 & 0.84 & N/A & 0.88 \\
\hline 19 & 197 & N/A & 0.58 & 0.92 & N/A & 0.94 \\
\hline 20 & 303 & N/A & 0.46 & 0.95 & N/A & 0.79 \\
\hline 21 & 310 & 0.56 & 0.52 & 0.77 & 0.88 & 0.91 \\
\hline 22 & 224 & 0.42 & N/A & 0.83 & 0.91 & N/A \\
\hline 23 & 280 & 0.71 & 0.62 & 0.9 & 0.93 & 0.97 \\
\hline 24 & 348 & N/A & 0.32 & 0.94 & N/A & 0.95 \\
\hline 25 & 354 & N/A & 0.51 & 0.85 & N/A & 0.93 \\
\hline 26 & 207 & N/A & 0.67 & 0.92 & N/A & 0.9 \\
\hline 27 & 307 & 0.7 & N/A & 0.88 & 0.93 & N/A \\
\hline 28 & 1704 & 0.74 & N/A & 0.71 & 0.88 & N/A \\
\hline 29 & 628 & 0.51 & 0.5 & 0.85 & 0.83 & 0.91 \\
\hline 30 & 250 & 0.67 & 0.61 & 0.84 & 0.91 & 0.86 \\
\hline 31 & 487 & $\mathrm{Neg}$ & $\mathrm{Neg}$ & 0.81 & 0.91 & N/A \\
\hline 32 & 240 & 0.3 & 0.14 & 0.9 & 0.89 & 0.73 \\
\hline 33 & 285 & N/A & 0.58 & 0.83 & N/A & 0.85 \\
\hline 34 & 200 & N/A & 0.52 & 0.81 & N/A & 0.84 \\
\hline 35 & 87 & 0.4 & 0.51 & 0.64 & 1 & 0.92 \\
\hline 36 & 437 & N/A & 0.66 & 0.81 & N/A & 0.74 \\
\hline 37 & 225 & N/A & 0.77 & 0.80 & N/A & 0.89 \\
\hline
\end{tabular}

Based on the data above, the calculations (as explained in the paper) were conducted. The results of the calculations are as follows: 
Ph.D. Thesis - Sepandar Sepehr; McMaster University - DeGroote School of Business.

Table 18 - Calculations for the studies that had correlation between flow and intention

\begin{tabular}{|c|c|c|c|c|c|c|}
\hline $\mathrm{k}$ & ES' (INT) & $\mathrm{ESz}(\mathrm{INT})$ & $\mathrm{w}$ & $\mathrm{w}^{\prime}(\mathrm{INT})$ & $\begin{array}{c}\mathrm{w}^{\prime} * \text { Esz } \\
(\mathrm{INT})\end{array}$ & $\begin{array}{c}\mathrm{w}^{\prime} * \mathrm{ESz}^{\wedge} 2 \\
(\mathrm{INT})\end{array}$ \\
\hline \multicolumn{7}{|c|}{ Studies of Flow type 1} \\
\hline 1 & 0.33 & 0.29 & 230.00 & 167.93 & 49.28 & 14.46 \\
\hline 2 & 0.23 & 0.22 & 339.00 & 293.17 & 63.74 & 13.86 \\
\hline 8 & 0.25 & 0.24 & 208.00 & 170.35 & 40.69 & 9.72 \\
\hline 32 & 0.34 & 0.17 & 0.14 & 237.00 & 155.71 & 22.38 \\
\hline 24 & 0.34 & 0.34 & 345.00 & 308.09 & 104.22 & 35.26 \\
\hline \multicolumn{7}{|c|}{ Studies of Flow type $2 \& 3$} \\
\hline 9 & 0.60 & 0.57 & 169.00 & 121.83 & 69.91 & 40.12 \\
\hline 11 & 0.65 & 0.72 & 182.00 & 159.07 & 115.02 & 83.17 \\
\hline 12 & 0.65 & 0.71 & 267.00 & 225.32 & 159.30 & 112.63 \\
\hline 19 & 0.62 & 0.68 & 194.00 & 167.77 & 113.37 & 76.60 \\
\hline 15 & 0.61 & 0.67 & 277.00 & 246.25 & 163.94 & 109.14 \\
\hline 17 & 0.66 & 0.66 & 278.00 & 206.19 & 135.13 & 88.57 \\
\hline 21 & 0.62 & 0.59 & 307.00 & 215.11 & 126.46 & 74.34 \\
\hline 23 & 0.66 & 0.74 & 277.00 & 241.82 & 178.83 & 132.24 \\
\hline 25 & 0.57 & 0.57 & 351.00 & 277.47 & 159.46 & 91.64 \\
\hline 26 & 0.74 & 0.83 & 204.00 & 168.91 & 139.68 & 115.51 \\
\hline 29 & 0.57 & 0.56 & 625.00 & 483.44 & 270.87 & 151.76 \\
\hline \multicolumn{7}{|c|}{ Studies of Flow type 4} \\
\hline 3 & 0.64 & 0.66 & 250.00 & 195.65 & 129.22 & 85.35 \\
\hline 4 & 0.49 & 0.46 & 99.00 & 71.49 & 32.64 & 14.91 \\
\hline 5 & 0.53 & 0.51 & 205.00 & 156.83 & 79.55 & 40.35 \\
\hline
\end{tabular}


Ph.D. Thesis - Sepandar Sepehr; McMaster University - DeGroote School of Business.

\begin{tabular}{|c|c|c|c|c|c|c|}
\hline 6 & 0.21 & 0.20 & 277.00 & 221.82 & 43.52 & 8.54 \\
\hline 13 & 0.48 & 0.47 & 286.00 & 225.62 & 105.13 & 48.99 \\
\hline 14 & 0.83 & 1.01 & 227.00 & 186.95 & 188.85 & 190.77 \\
\hline 18 & 0.57 & 0.55 & 169.00 & 124.92 & 68.31 & 37.35 \\
\hline 20 & 0.53 & 0.51 & 300.00 & 225.15 & 114.21 & 57.93 \\
\hline 30 & 0.72 & 0.73 & 247.00 & 177.37 & 128.94 & 93.74 \\
\hline 33 & 0.69 & 0.68 & 282.00 & 198.95 & 134.43 & 90.84 \\
\hline 34 & 0.63 & 0.59 & 197.00 & 134.04 & 78.80 & 46.32 \\
\hline 35 & 0.66 & 0.57 & 84.00 & 49.43 & 28.37 & 16.29 \\
\hline 36 & 0.85 & 0.81 & 434.00 & 260.14 & 209.47 & 168.66 \\
\hline 37 & 0.92 & 1.05 & 222.00 & 157.41 & 165.61 & 174.24 \\
\hline
\end{tabular}

Table 19 - Calculations for the studies that had correlation between flow and attitude

\begin{tabular}{|c|c|c|c|c|c|c|}
\hline $\mathrm{k}$ & $\mathrm{ES}(\mathrm{ATT})$ & $\mathrm{ESz}(\mathrm{ATT})$ & $\mathrm{w}$ & $\mathrm{w}^{\prime}(\mathrm{ATT})$ & $\begin{array}{c}\mathrm{w}^{\prime} * \mathrm{Esz} \\
(\mathrm{ATT})\end{array}$ & $\begin{array}{c}\mathrm{w}^{\prime} * \mathrm{Esz}^{\wedge} 2 \\
(\mathrm{ATT})\end{array}$ \\
\hline 1 & 0.23 & 0.21 & 230.00 & 171.06 & 35.37 & 7.31 \\
\hline 2 & 0.27 & 0.25 & 339.00 & 277.57 & 69.30 & 17.30 \\
\hline 32 & 0.34 & 0.32 & 237.00 & 189.84 & 59.93 & 18.92 \\
\hline 29 & 0.61 & 0.57 & 625.00 & 440.94 & 253.09 & 145.27 \\
\hline 21 & 0.68 & 0.65 & 307.00 & 208.02 & 134.28 & 86.67 \\
\hline 22 & 0.48 & 0.46 & 221.00 & 166.92 & 76.22 & 34.81 \\
\hline 23 & 0.78 & 0.90 & 277.00 & 231.85 & 209.81 & 189.86 \\
\hline 28 & 0.94 & 0.97 & 1701.00 & 1062.78 & 1030.36 & 998.92 \\
\hline 4 & 0.46 & 0.42 & 99.00 & 72.31 & 30.37 & 12.76 \\
\hline 6 & 0.49 & 0.46 & 277.00 & 199.88 & 91.28 & 41.68 \\
\hline
\end{tabular}


Ph.D. Thesis - Sepandar Sepehr; McMaster University - DeGroote School of Business.

\begin{tabular}{|l|l|l|l|l|l|l|}
27 & 0.77 & 0.88 & 304.00 & 248.79 & 220.09 & 194.71 \\
\hline 30 & 0.77 & 0.83 & 247.00 & 187.68 & 155.04 & 128.08 \\
\hline 35 & 0.50 & 0.43 & 84.00 & 53.73 & 23.22 & 10.03 \\
\hline
\end{tabular}

\section{Conclusion}

The meta-analysis that was conducted in this study supported the hypotheses that the construct of Flow can be used in various contexts to predict the intention and attitude towards use of IT products. The meta-analysis showed that the correlation between Flow and TAM's endogenous constructs is moderate to high in all the previous studies. This supports the reliability and validity of the theory of Flow in IS contexts and its suitability for use in predicting IT use, in particular for hedonic systems. Moreover, it was shown that the method of operationalization of Flow constructs can be a determining factor of the constructs relationship with relevant TAM constructs of attitude and intention. Multidimensional measurements of Flow are better determinants of intention and attitude towards use of IT systems based on this metaanalysis, despite their complexity in conducting the study and data analysis. Therefore, researchers need to consider these implementation issues when deciding to choose Flow as a construct to measure the holistic experience of IT use. The main goal of this study was to shed some light on the ambiguity on different constructs used to measure the concept of Flow.

\section{References for the Meta-Analysis ${ }^{24}$}

\footnotetext{
* Agarwal, R., \& Karahanna, E. (2000). Time Flies When You're Having Fun: Cognitive Absorption and Beliefs about Information Technology Usage. MIS Quarterly, 24(4), 665. doi:10.2307/3250951
}

Ajzen, I. (1991). The theory of planned behavior. Organizational behavior and human decision processes, 50(2), 179-211. Elsevier.

${ }^{24}$ Studies that are included in the meta-analysis are marked with Asterisks (*). 
Ph.D. Thesis - Sepandar Sepehr; McMaster University - DeGroote School of Business.

* Chandra, S., Srivastava, S., \& Theng, Y.-L. (2009). Role of Cognitive Absorption and Trust for Collaboration in Virtual World. Proceedings of the Pacific Asia Conference on Information Systems (PACIS).

* Choi, D., Kim, J., \& Kim, S. (2007). ERP training with a web-based electronic learning system: The flow theory perspective. International Journal of Human-Computer Studies, 65(3), 223-243. doi:10.1016/j.ijhcs.2006.10.002

Chou, T.-J., \& Ting, C.-C. (2003). The role of flow experience in cyber-game addiction. Cyberpsychology \& behavior : the impact of the Internet, multimedia and virtual reality on behavior and society, 6(6), 663-75. doi:10.1089/109493103322725469

Csikszentmihalyi, M. (1991). Flow: The psychology of optimal experience: Steps toward enhancing the quality of life. Harper Collins Publishers.

Csikszentmihalyi, M. (1997). Finding flow: The psychology of engagement with everyday life. Basic Books.

Csikszentmihalyi, M., \& Csikszentmihalyi, I. S. (1988). Optimal experience. Cambridge University Press.

Csikszentmihalyi, M., \& LeFevre, J. (1989). Optimal experience in work and leisure. Journal of personality and social psychology, 56(5), 815-22.

Davis, F. D., Bagozzi, R. P., \& Warshaw, P. R. (1989). User Acceptance of Computer Technology: A Comparison of Two Theoretical Models. Management Science, 35(8), 982-1003. doi:10.1287/mnsc.35.8.982

* Deng, L., Turner, D. E., Gehling, R., \& Prince, B. (2010). User experience, satisfaction, and continual usage intention of IT. European Journal of Information Systems, 19(1), 60-75. Palgrave Macmillan. doi:10.1057/ejis.2009.50

Dimoka, A. (2010). What does the brain tell us about trust and distrust? Evidence from a functional neuroimaging study. MIS Quarterly, 34(2), 373-396. Society for Information Management and The Management Information Systems Research Center.

Ellis, G. D., Voelkl, J. E., \& Morris, C. (1994). Measurement and analysis issues with explanation of variance in daily experience using the flow model. Journal of Leisure Research, 26(4), 337-337. NATIONAL RECREATION AND PARK ASSOCIATION.

Fishbein, M., \& Ajzen, I. (1975). Belief, attitude, intention and behaviour: An introduction to theory and research. Addison-Wesley.

Ghani, J. A., \& Deshpande, S. P. (1994). Task Characteristics and the Experience of Optimal Flow in HumanComputer Interaction. the journal of psychology, 128(4), 381-391. Taylor \& Francis.

Glass, G. V. (1976). Primary, Secondary, and Meta-Analysis of Research. Educational researcher, 5(10), 3-8. JSTOR.

* Guo, Y.M., \& Ro, Y. K. (2008). Capturing flow in the business classroom. Decision Sciences Journal of Innovative Education, 6(2), 437-462. Wiley Online Library.

Hassanein, K., \& Head, M. (2007). Manipulating perceived social presence through the web interface and its impact on attitude towards online shopping. International Journal of Human-Computer Studies, 65(8), 689-708. Elsevier. doi:10.1016/j.ijhcs.2006.11.018 
Ph.D. Thesis - Sepandar Sepehr; McMaster University - DeGroote School of Business.

Hoffman, Donna L., \& Novak, T. P. (1996). Marketing in Hypermedia Computer-Mediated Environments: Conceptual Foundations. Journal of Marketing, 60(3), 50. doi:10.2307/1251841

Hoffman, Donna L., \& Novak, T. P. (2009). Flow Online: Lessons Learned and Future Prospects. Journal of Interactive Marketing, 23(1), 23-34. Direct Marketing Educational Foundation, Inc. doi:10.1016/j.intmar.2008.10.003

Holsapple, C. W., \& Wu, J. (2007). User acceptance of virtual worlds: the Hedonic framework. ACM SIGMIS Database, 38(4), 86-89. ACM.

* Hooker, R. (2010). Going with the Flow: Linking Flow, Brand Attitudedes, and Purchase Intent in Virtual Worlds.

* Hsu, C., \& Lu, H. (2004). Why do people play on-line games? An extended TAM with social influences and flow experience. Information \&amp; Management, 41(7), 853-868. doi:10.1016/j.im.2003.08.014

Hunter, J. E., \& Schmidt, F. L. (1990). Methods of meta-analysis : correcting error and bias in research findings. Newbury Park: Sage Publications.

* Jiang, C., Kim, K. H., Sun, Y., \& Peng, Z. (2009). Does Content Relevance Lead to Positive Attitude toward Websites? Exploring the Role of Flow and Goal Specificity Does Content Relevance Lead to Positive Attitude toward. Information Systems.

* Jung, Y., Perez-Mira, B., \& Wiley-Patton, S. (2009). Consumer adoption of mobile TV: Examining psychological flow and media content. Computers in Human Behavior, 25(1), 123-129. Elsevier. doi:10.1016/j.chb.2008.07.011

* Kamis, A., Stern, T., \& Ladik, D. M. (2010). A flow-based model of web site intentions when users customize products in business-to-consumer electronic commerce. Information Systems Frontiers, 12(2), 157-168. Springer. doi:10.1007/s10796-008-9135-y

Kim, SS. (2009). The Integrative Framework of Technology Use: An Extension and Test. MIS Quarterly, 33(3), 513-537.

* Korzaan, M. L. (2003). Going with the flow: Predicting online purchase intentions. Journal of Computer Information Systems, 43(4), 25-31. ASSOCIATION FOR COMPUTER EDUCATORS.

* Koufaris, M. (2002). Applying the Technology Acceptance Model and Flow Theory to Online Consumer Behavior. Information Systems Research, 13(2), 205-223. doi:10.1287/isre.13.2.205.83

* Lee, M.-C. (2009). Understanding the behavioural intention to play online games: An extension of the theory of planned behaviour. Online Information Review, 33(5), 849-872. doi:10.1108/14684520911001873

* Lee, M.-C. (2010). Explaining and predicting users' continuance intention toward e-learning: An extension of the expectation-confirmation model. Computers \& Education, 54(2), 506-516. Elsevier Ltd. doi:10.1016/j.compedu.2009.09.002

Ley, P. (1972). Quantitative aspects of psychological assessment: An introduction. Duckworth \& Co.

* Liao, L. (2006). A Flow Theory Perspective on Learner Motivation and Behavior in Distance Education. Distance Education, 27(1), 45-62. doi:10.1080/01587910600653215 
Ph.D. Thesis - Sepandar Sepehr; McMaster University - DeGroote School of Business.

Lin, C.-P., \& Bhattacherjee, A. (2010). Extending technology usage models to interactive hedonic technologies: a theoretical model and empirical test. Information Systems Journal, 20(2), 163-181. doi:10.1111/j.13652575.2007.00265.x

* Lin, C., Lin, J., \& Wu, S. (2008). Exploring Consumers ' Keyword Ads Search Behaviors : An Integration of Theory of Planned Behavior and Flow Theory. Information Systems.

* Lin, H.-F. (2009). Examination of cognitive absorption influencing the intention to use a virtual community. Behaviour \& Information Technology, 28(5), 421-431. doi:10.1080/01449290701662169

* Liu, S.-H., Liao, H.-L., \& Pratt, J. a. (2009). Impact of media richness and flow on e-learning technology acceptance. Computers \& Education, 52(3), 599-607. Elsevier Ltd. doi:10.1016/j.compedu.2008.11.002

* Lu, Y., Zhou, T., \& Wang, B. (2009). Exploring Chinese users' acceptance of instant messaging using the theory of planned behavior, the technology acceptance model, and the flow theory. Computers in Human Behavior, 25(1), 29-39. Elsevier Ltd. doi:10.1016/j.chb.2008.06.002

Mahfouz, A. Y., \& Guo, Y. M. (2011). An Overview of Flow Theory in Ecommerce.

* Mahfouz, A. Y. M. (2004). Interactive eshopping experience: an empirical investigation. MIS Quarterly. Texas A\&M University.

Massimini, F., \& Carli, M. (1988). The systematic assessment of flow in daily experience. Cambridge University Press.

Moon, J. (2001). Extending the TAM for a World-Wide-Web context. Information \& Management, 38(4), 217-230. doi:10.1016/S0378-7206(00)00061-6

* Nah, F. F.-hoon, Eschenbrenner, B., DeWester, D., \& Park, S. R. (2010). Impact of flow and brand equity in 3D virtual worlds. Journal of Database Management. doi:10.4018/jdm.2010070

Nah, F., \& Eschenbrenner, B. (2011). Enhancing Brand Equity Through Flow and Telepresence: A Comparison of 2D and 3D Virtual Worlds. Information Systems Quarterly, 35(3), 731-747.

Novak, T.P., Hoffman, D. L., \& Yung, Y. F. (2000). Measuring the customer experience in online environments: A structural modeling approach. Marketing Science, 22-42. JSTOR.

Ones, D. S., \& Viswesvaran, C. (1996). Bandwidth-fidelity dilemma in personality measurement for personnel selection. Journal of Organizational Behavior, 17(6), 609-626. Wiley Online Library.

Paunonen, S. V., Rothstein, M. G., \& Jackson, D. N. (1999). Narrow reasoning about the use of broad personality measures for personnel selection. Journal of Organizational Behavior, 20(3), 389-405. Wiley Online Library.

Polites, G. L., Roberts, N., \& Thatcher, J. (2012). Conceptualizing models using multidimensional constructs: a review and guidelines for their use. European Journal of Information Systems, 21(1), 22-48. Nature Publishing Group. doi:10.1057/ejis.2011.10

* Roca, J., Chiu, C., \& Martinez, F. (2006). Understanding e-learning continuance intention: An extension of the Technology Acceptance Model. International Journal of Human-Computer Studies, 64(8), 683-696.

doi:10.1016/j.jhhcs.2006.01.003 
Ph.D. Thesis - Sepandar Sepehr; McMaster University - DeGroote School of Business.

* Saadé, R., \& Bahli, B. (2005). The impact of cognitive absorption on perceived usefulness and perceived ease of use in on-line learning: an extension of the technology acceptance model. Information \& Management, 42(2), 317-327. doi:10.1016/j.im.2003.12.013

Sabherwal, R., Jeyaraj, A., \& Chowa, C. (2006). Information system success: individual and organizational determinants. Management Science, 52(12), 1849-1864. Citeseer. doi:10.1287/mnsc.1060.0583

* Sánchez-Franco, M. J. (2006). Exploring the influence of gender on the web usage via partial least squares. Behaviour \& Information Technology, 25(1), 19-36. doi:10.1080/01449290500124536

* Shiau, W. L., Huang, L. C., \& Shih, C.-hui. (2011). Understanding Continuance Intention of Blog Users: A Perspective of Flow and Expectation Confirmation Theory. Journal of Convergence Information Technology, 6(4), 306-317. doi:10.4156/jcit.vol6.

* Shin, D.-H., \& Shin, Y.-J. (2010). Why do people play social network games? Computers in Human Behavior.

Shin, N. (2006). Online learner's "flow" experience: an empirical study. British Journal of Educational Technology, 37(5), 705-720. doi:10.1111/j.1467-8535.2006.00641.x

* Sicilia, M., \& Ruiz, S. (2007). The role of flow in web site effectiveness. Journal of Interactive Advertising, 8(1), $33-44$.

* Siekpe, J. (2005). An examination of the multidimensionality of flow construct in a computer-mediated environment. Journal of Electronic Commerce Research, 6(1), 31-43.

Takatalo, J., Nyman, G., \& Laaksonen, L. (2008). Components of human experience in virtual environments. Computers in Human Behavior, 24(1), 1-15. doi:10.1016/j.chb.2006.11.003

* Treviño, L. K., Webster, J., \& Stein, E. W. (2000). Making connections: complementary influences on communication media choices attitudes, and use. Organization Science, 11(2), 163-182. JSTOR.

Trevino, L. K., \& Webster, J. (1992). Flow in Computer-Mediated Communication: Electronic Mail and Voice Mail Evaluation and Impacts. Communication Research, 19(5), 539-573. doi:10.1177/009365092019005001

* Tung, W., Moore, R., \& Engelland, B. (2006). Exploring attitudes and purchase intentions in a brand-oriented, highly interactive web site setting. Marketing Management Journal, 16(2), 94-106.

Van der Heijden, H. (2004). User Acceptance of Hedonic Information Systems. MIS quarterly, 28(4), 695-704. JSTOR.

Venkatesh, V, Morris, M. G., Davis, G. B., \& Davis, F. D. (2003). User acceptance of information technology: Toward a unified view. MIS quarterly, 27(3), 425-478. JSTOR.

Venkatesh, Viswanath, \& Davis, F. D. (2000). A Theoretical Extension of the Technology Acceptance Model: Four Longitudinal Field Studies. Management science, 46(2), 186-204. JSTOR.

* Wakefield, R. L., \& Whitten, D. (2006). Mobile computing: a user study on hedonic/utilitarian mobile device usage. European Journal of Information Systems, 15(3), 292-300. doi:10.1057/palgrave.ejis.3000619

* Webster, J., \& Ahuja, J. S. (2006). Enhancing the Design of Web Navigation Systems: The Influence of User Disorientation on Engagement and Performance. MIS Quarterly, 30(3), 661-678. Society for Information Management and The Management Information Systems Research Center. 
Ph.D. Thesis - Sepandar Sepehr; McMaster University - DeGroote School of Business.

Webster, Jane, \& Ho, H. (1997). Audience engagement in multimedia presentations. ACM SIGMIS Database, 28(2), 63-77. doi:10.1145/264701.264706

Webster, Jane, Trevino, L. K., \& Ryan, L. (1993). The dimensionality and correlates of flow in human-computer interactions. Computers in Human Behavior, 9(4), 411-426. doi:10.1016/0747-5632(93)90032-N

Xia Skadberg, Y., \& Kimmel, J. R. (2004). Visitors' Flow experience while browsing a web site: its measurement, contributing factors and consequences. Computers in human behavior, 20(3), 403-422. Elsevier. doi:10.1016/S0747-5632(03)00050-5

Y. Poon, C., Wong, Y., \& Zhang, Y.-ting. (2006). M-Health: The Development of Cuff-less and Wearable Blood Pressure Meters for Use in Body Sensor Networks. 2006 IEEE/NLM Life Science Systems and Applications Workshop, 1-2. Ieee. doi:10.1109/LSSA.2006.250377

* Zhang, P., Li, N., \& Sun, H. (2006). Affective Quality and Cognitive Absorption: Extending Technology Acceptance Research. Proceedings of the 39th Annual Hawaii International Conference on System Sciences (HICSS'06), OO(C), 207a-207a. Ieee. doi:10.1109/HICSS.2006.39

* Zhou, T. (2011a). Examining mobile banking user adoption from the perspectives of trust and flow experience. Information Technology and Management. doi:10.1007/s10799-011-0111-8

* Zhou, T. (2011b). Understanding mobile Internet continuance usage from the perspectives of UTAUT and flow. Information Development, 27(3), 207-218. doi:10.1177/0266666911414596

* Zhou, T. (2011c). An empirical examination of the determinants of mobile purchase. Personal and Ubiquitous Computing. doi:10.1007/s00779-011-0485-y

* Zhou, T., \& Lu, Y. (2011). The effect of interactivity on the flow experience of mobile commerce user. International Journal of Mobile Communications, 9(3), 225-242. Inderscience.

de Guinea, A., \& Markus, M. L. (2009). Why break the habit of a lifetime? Rethinking the roles of intention, habit, and emotion in continuing information technology use. Management Information Systems Quarterly, 33(3), 433-444. 
Ph.D. Thesis - Sepandar Sepehr; McMaster University - DeGroote School of Business.

\section{APPENDIX 2 - PRELIMINARY STUDY: FOCUS GROUP + LONGITUDINAL SURVEY}

In Winter 2012, a small focus group study was conducted with four graduate students. The participants were recruited from an MBA course in which students played a competitive game called ERPSim to learn to interact with SAP ERP system. This study supported the effectiveness of situational competitiveness in engaging students in the classroom. In this course, the instructor has been successful in using the informative feedback of competition and not valuing the outcomes excessively (the highest reward is $5 \%$ of the final mark), which increases intrinsic motivation among students while adding extrinsic rewards.

In the following year, informed by the focus group study's findings regarding the positive effect of competition in creating Flow during ERPSim sessions, the second stage of the study (a longitudinal study) was conducted with another set of students taking the same course. The MBA course through which ERPsim was used is offered only once a year with less than 20 students, limiting the pool of participants. The participants were mature male and female students. To maintain the confidentiality of the participants (due to the small sample size), their demographic information was not collected. In the longitudinal study it was sought to examine potential changes in participants' perceptions about their engagement in the game as the game progressed and when they won or lost the game. In the studied course, students were divided into 4 randomly assigned teams and practiced with temporary ERPsim accounts for two weeks before starting the game. Students played 5 rounds of ERPsim over the span of 4 weeks. Each round of the game takes 30 minutes and represents 30 days of simulated business activity. The first round of the game had no effect on the final mark of the students. However, the last four round results could affect their marks. A longitudinal survey was given to the students after the first, fourth, 
Ph.D. Thesis - Sepandar Sepehr; McMaster University - DeGroote School of Business.

and fifth rounds (played in the first, fourth, and fifth week after starting the game) to monitor the change of users' perceptions throughout the gameplay cycle. The findings of the longitudinal study provided some insightful information that helped in the design of the main study. The goal of the longitudinal study was to better understand the foundational concept of this research and inform the design of the experiment. In particular, understanding the conceptualization of engagement as a Flow construct as well as identifying the ideal time for measuring engagement during a competitive video gameplay.

In the focus group and the longitudinal study, regardless of the outcome of the game, students reported the game to be highly engaging and informative prior to the end of the game. The results of the analysis showed that competition played an important role for students in the class that used ERPsim for training students to work with SAP ERP. In the longitudinal survey study potential changes in participants' perceptions about their engagement throughout the game as they won or lost a round was examined. Students were divided into 4 teams in the course and practiced with temporary ERPsim accounts for two weeks before starting the game. Students played 5 rounds of ERPsim (after the training periods) over the span of 4 weeks. Each round of the game takes 30 minutes and represents 30 days of simulated business activity. The first round of the game had no effect on the final mark of the students. However, the last four round results could affect their marks. The longitudinal survey was given to the students after the first, fourth, and fifth rounds (played in the first, third, and fifth week after starting the game and referred to here as T1, T2, and T3) to monitor the change of users' perceptions as the significance of the results of the game increased.

The main objective of the longitudinal survey study was to explore Flow and Engagement in competitive video gameplay and to gain an understanding of when to best ask 
Ph.D. Thesis - Sepandar Sepehr; McMaster University - DeGroote School of Business.

participants about their engagement and enjoyment during gameplay. As has been previously shown, losing a competition can have negative consequences on people's perception of their enjoyment of an activity (Tauer \& Harackiewicz, 1999). Mean comparison of the latent variables across $\mathrm{T} 1, \mathrm{~T} 2$, and $\mathrm{T} 3$ shows the variation of responses as the gameplay reached the end stage, in which participants had no more hope of playing and winning or losing the game. Among the studied variables, clear goals, skill, challenge, balance, Positive Affect (PA), satisfaction, and Flow dimension of control had increasing means as shown in Figure 13.

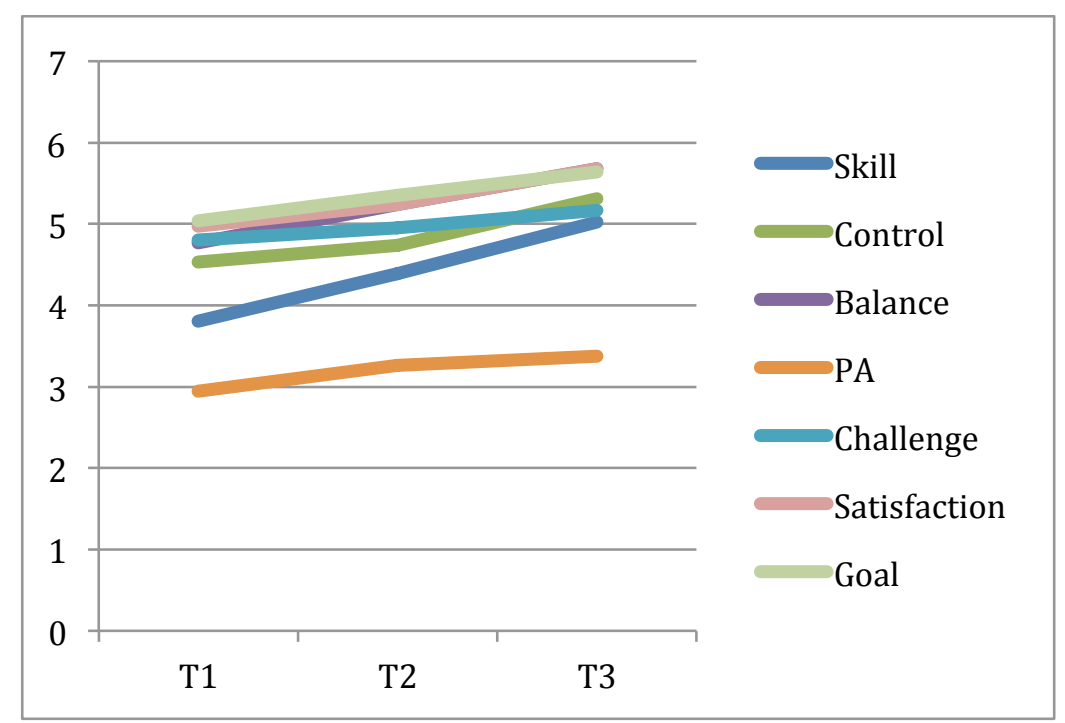

Figure 13 - Variables with Increasing Means

Immediate feedback, Negative Affect (NA), and Flow dimensions of focused attention, curiosity, and enjoyment, in addition to the aggregate variable of Flow did not change significantly over T1, T2, and T3. These variations are plotted in Figure 14. 
Ph.D. Thesis - Sepandar Sepehr; McMaster University - DeGroote School of Business.

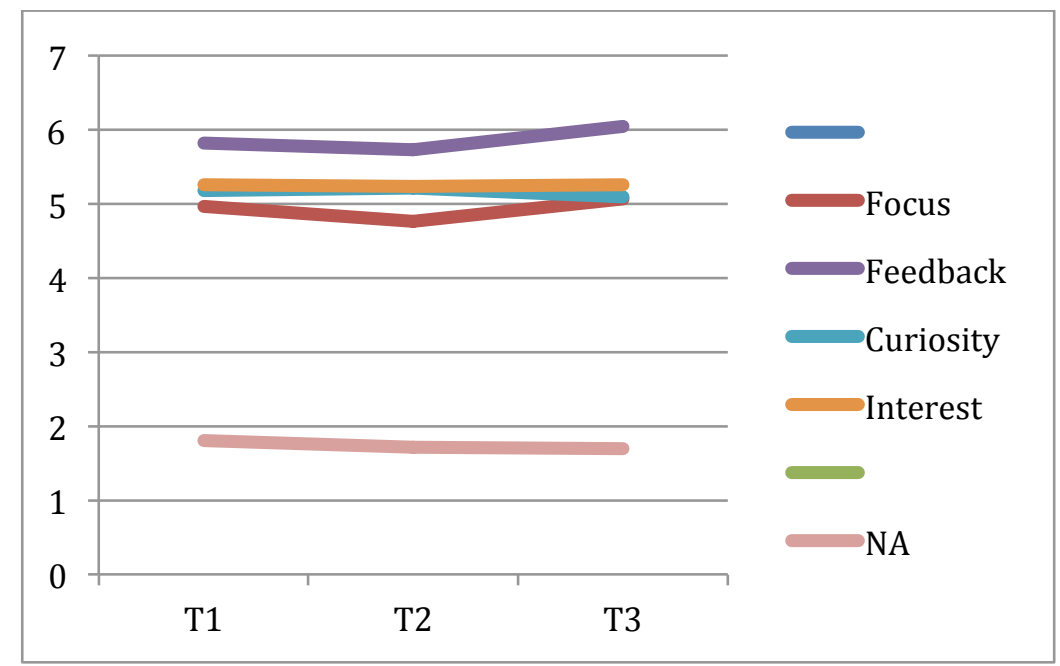

Figure 14 - Variables with no Observable Mean Change

\section{Between Team Comparison}

In order to analyze the effect of winning and losing on different teams, differences in mean scores of each of the measured variables between the teams were compared. The teams' ranking at the end of each round is shown in Table 20. As is shown, team Q has been mostly winning and team P mostly losing throughout the game.

\begin{tabular}{|l|l|l|l|l|}
\hline Round & $\mathrm{N}$ & $\mathrm{O}$ & $\mathrm{P}$ & $\mathrm{Q}$ \\
\hline $1(\mathrm{~T} 1)$ & 2 & 3 & 4 & 1 \\
\hline 2 & 2 & 3 & 4 & 1 \\
\hline 3 & 3 & 2 & 4 & 1 \\
\hline $4(\mathrm{~T} 2)$ & 3 & 1 & 4 & 2 \\
\hline $5(\mathrm{~T} 3)$ & 3 & 1 & 4 & 2 \\
\hline Average & 2.6 & 2 & 4 & 1.4 \\
\hline
\end{tabular}

Table 20. Teams Ranking at each Round

Based on the teams rankings, for the purpose of this experiment only, teams were labeled as: Q: Early Leader-to-Second Place, P: Lowest Rank, O: Most Improved-to-Winners, and N:

\section{Mid-achievers.}


Ph.D. Thesis - Sepandar Sepehr; McMaster University - DeGroote School of Business.

The most significantly large differences between teams were in the levels of skill, balance, PA, and satisfaction. Among these, skill showed the highest difference between teams, which had one-way analysis of variance (ANOVA) of difference significant at $\mathrm{p}<0.05^{25}$ for the pooled data and at T1 and T2. This difference diminished at T3 (refer to Table 3). Team Q (the Early Leader team) expressed that their members had the highest levels of skill and team P (the Lowest Ranked team) the lowest. Similarly, the difference in the levels of balance reported started at high margins and at T3 the difference was not very high. Regarding satisfaction, the differences were moderately high and significant at all time periods. PA does not have the same level of difference as the other variables, but considering that it is measured with 5-point Likert scale, the reported differences are considerable. At all times, the highest difference reported was between the team that was first in that round of game and the team that was the last. In the pooled data, team Q (Early Leader) reported the highest and team P (Lowest Rank) the lowest in PA.

\begin{tabular}{|l|l|l|l|l|}
\hline & T1 & T2 & T3 & Pooled \\
\hline Skill & 3.44 & 3.08 & $1.75(\text { n.s. })^{26}$ & 2.86 \\
\hline Balance & 2.04 & 1.75 & 1 & 1.69 \\
\hline Satisfaction & 2.5 & 2 & 2.12 & 2.3 \\
\hline PA & 0.83 (n.s.) & 1.02 & 1.8 & 0.89 \\
\hline
\end{tabular}

${ }^{25}$ Due to this study's exploratory nature, significant statistical conclusions cannot be expected to be made from the collected data. Therefore, complete statistics results are not reported.

${ }^{26}$ n.s.: One-way ANOVA of difference between the teams is not significant. 
Ph.D. Thesis - Sepandar Sepehr; McMaster University - DeGroote School of Business.

Table 21. Largest Differences Between Teams

Figure 15 further clarifies the differences in the above-mentioned variables among the four teams. As the graphs show, the narrowing gap is mainly due to the increase in the average reported values by Team O (Most Improved team) that mostly reported the lowest values.

Moreover, the differences between the reported levels of focus, feedback, control, curiosity, NA, and enjoyment were at some points significant, but this difference is not very high. However, no significant (or significant but small) difference in Flow or challenge between teams was observed. The results showed that the state of teams in the game did not have a large impact on how challenging the task is or how much users would be in the state of Flow.

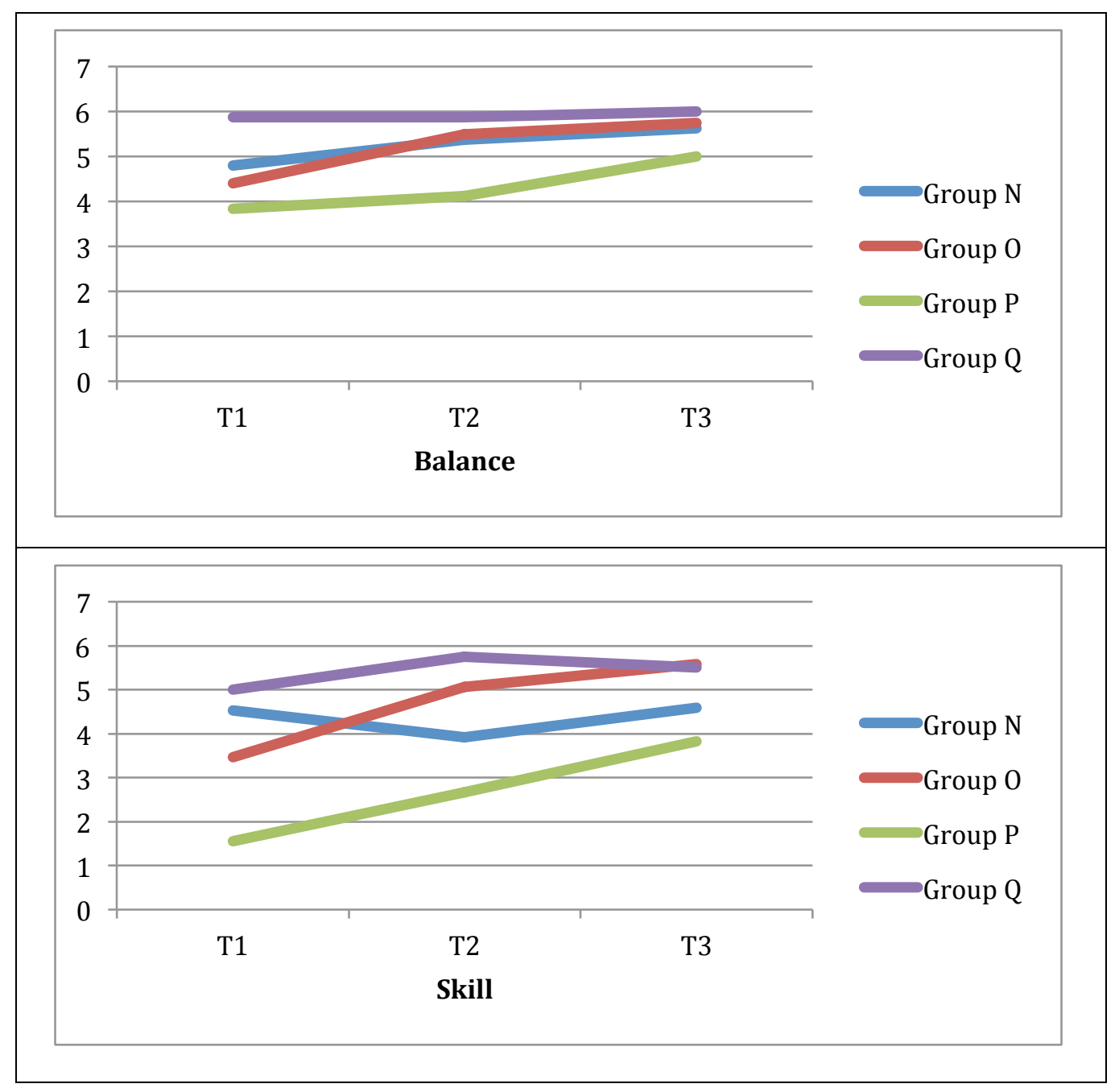


Ph.D. Thesis - Sepandar Sepehr; McMaster University - DeGroote School of Business.

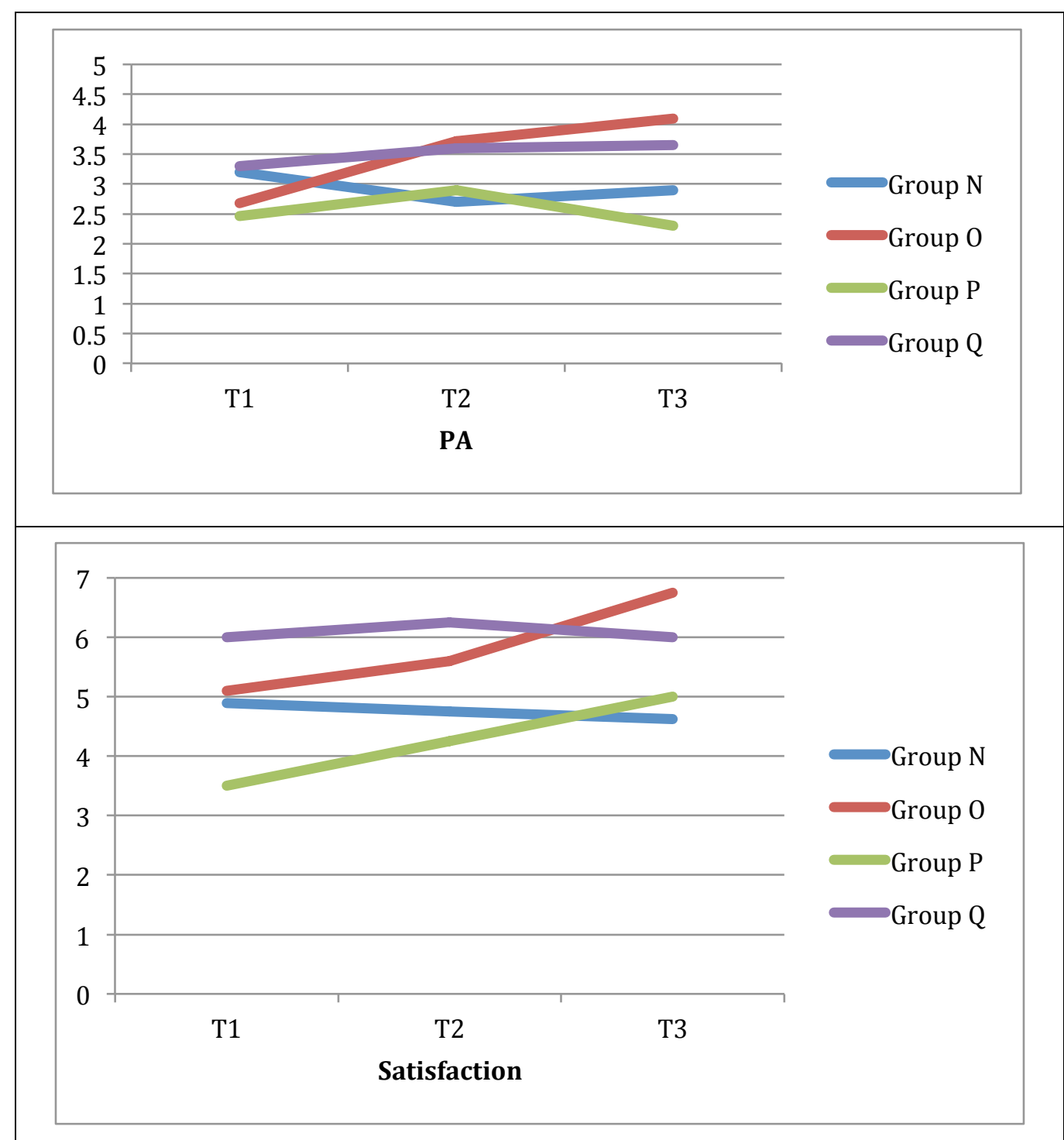

Figure 15. Variation of Team's Average Score for the Variables with the Largest Differences from T1 to T3

Figure 16 further shows the relationship between the rankings of teams and their reported scores. The $\mathrm{x}$-axis is the team with ranking from 1 to 4 and $y$-axis is the corresponding average for a team with that ranking at $\mathrm{T} 1, \mathrm{~T} 2$, or $\mathrm{T} 3$. It can be interpreted from these charts that there is almost a negative linear relationship between ranking of teams and their evaluation of their level of Skill, Balance, Satisfaction, and PA. 
Ph.D. Thesis - Sepandar Sepehr; McMaster University - DeGroote School of Business.

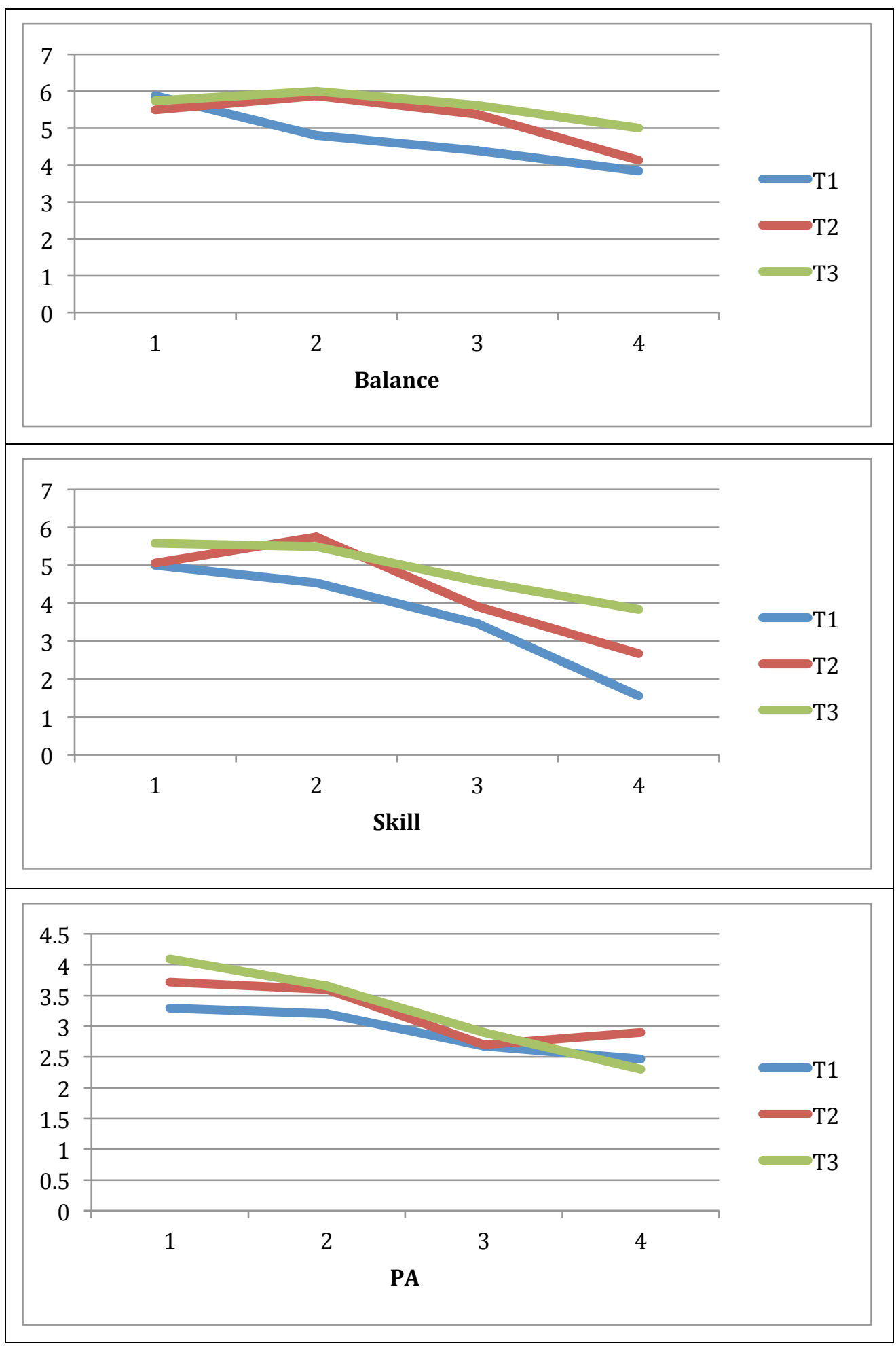


Ph.D. Thesis - Sepandar Sepehr; McMaster University - DeGroote School of Business.

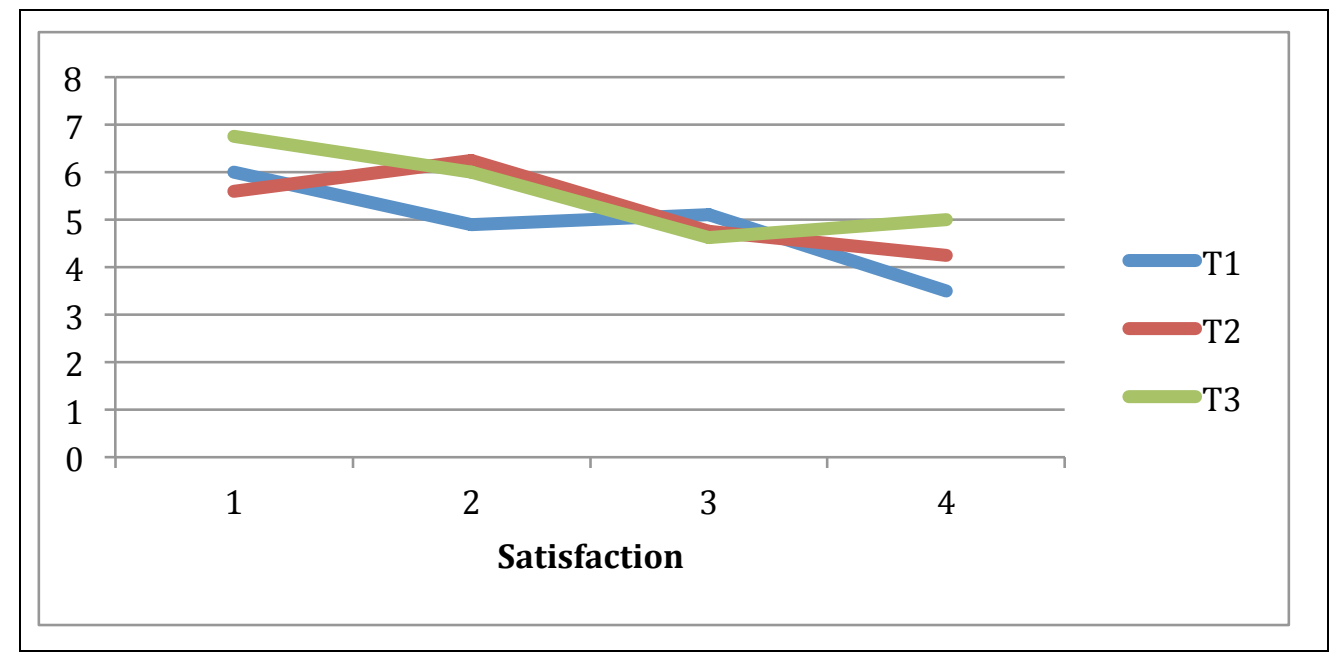

Figure 16. Average Values for Each Team at T1, T2, and T3 Based on Their Rankings

In sum, the longitudinal study shows that at the end of competition, students would have increased their skills, and therefore achieved a better balance of skill and challenge in the game. However, because of the negative emotions resulting from losing, the bottom ranked teams may feel less satisfied, less skilful, and less enjoyment with the game. On the other hand, at the beginning of the game, players are not aware of their skill level relative to their opponents and cannot form a proper judgement of the state of the game. As a result, the ideal time for asking the participants about their (Flow) experience through the gameplay is midway through the competition.

The longitudinal survey study also enabled us to perform some preliminary examination of the relationships between the antecedents of Flow and itself. The results showed that the previously developed measure of "balance of skill and challenge" does not properly measure the construct, as it has no effect on Flow beyond the effect of skill. Furthermore, this study showed that Flow can be measured as a multidimensional construct. In this research, Control has a very weak relationship with Flow and lowers its reliability significantly. Thus, Control was deemed to be an inappropriate construct in this context. 
Ph.D. Thesis - Sepandar Sepehr; McMaster University - DeGroote School of Business.

\section{APPENDIX 3 - MAIN STUDY'S EXPERIMENT DOCUMENTS}

\section{Experiment Guideline}

These are the steps that each facilitator should follow in the experiments:

\section{Before the experiment:}

1) First check with the other facilitator what mode of the game (no competition/playing by themselves, playing against computer, and playing against a person) the participants are going to be assigned to.

2) Sync both devices (Q-sensors for measuring skin responses) with the computers they are using with.

3) If the mode is competing with someone, only one side should be logged in with Sepandar's universal username (that is the same for everyone and does not identify participants) and the other side should have the link to follow.

4) Have a notepad for taking notes (taking as many notes as possible can be useful). Especially if something goes wrong or forget to press the marker button on the Q-sensor.

5) Have your cellphone in reach to communicate with the other facilitator.

6) Make sure both devices have the page for racing each other open.

7) Make sure the recording application is running and all the survey pages and the game website are open.

8) Have an ID for each participant. For the mini surveys, besides the ID take note of the round of the game.

9) When both the participants are in the separate rooms (check via cellphone with the other facilitator), start the experiment. 
Ph.D. Thesis - Sepandar Sepehr; McMaster University - DeGroote School of Business.

10) During the experiment take note of the length of the text in each game (how many lines it is) and WPM (word-per minute; used for measuring game scores) of the participants at the end of each round.

11) Note the general mood/condition of the participant (stressed, relaxed, has a cold, etc.)

\section{Experiment - Intro:}

1) Start the screen-recording app to record the screen (Before the participant comes in the room).

2) Welcome the participants and thank them for coming.

3) Consent form is given (2min). Remind them that if they feel they have to leave the experiment at any time they can simply let you know and leave.

4) Brief about using the Q-Sensor device (preferably while fitting the device), then the device is fitted to their arms. (1min)

a. Briefing script: "Please let me put this device around your arms. This device, as briefly described in the consent form, is used to measure your excitement/arousal level. The signals are recorded on the device to analyze later, so we cannot monitor the data live. In a minute, we will give you a short article to read that would more precisely explain how this device works."

5) Press the marker button twice. Also explain what is the purpose of the marker and ask them to press it themselves during the experiment.

a. Briefing script: "When we press this button, it adds a marker on the signal in the collected data in order to identify what point during the experiment we are. We will ask you to press the marker later during the experiment, before and after each round of the game." 
Ph.D. Thesis - Sepandar Sepehr; McMaster University - DeGroote School of Business.

6) Give the participants the first part of the survey on demographics. ( 2min)

7) Ask the participants to read the article on EDA and theory just for 10 minutes (10min).

a. Briefing script: "This device needs about 10 minutes to warm up and pick up the right signals. Therefore, we ask you to please spend about 10 minutes reading these articles that are related to the device and some other random articles."

8) Brief them about the experiment.

a. Briefing script: "In this experiment, we are going to give you a small typing game to play for 5 rounds. Before that, you have two rounds of practice to learn how to play the game."

9) Show them the options of typeracer (racing real world, practice, racing with friends) and briefly explain what each does.

10) Explain how the game works clearly by going to "practice" option. Show them the car and the score (explain WPM), and explain that they have to type exactly the sentence and avoid getting red text.

11) Let them play two rounds on their own.

Based on the randomization, each participant has been assigned to one of the following treatments. Follow the instruction for the corresponding treatment.

\section{Experiment - Treatment A: No Competition (competing against self)}

1) Brief them about the process of this mode. 
Ph.D. Thesis - Sepandar Sepehr; McMaster University - DeGroote School of Business.

a. Briefing script: "in this mode of gameplay, you will play by yourself like the practice rounds for another 5 rounds, and we will ask you to kindly fill a short survey after each time you play the game, and once a longer survey."

2) Let them play the single player (competing against themselves that is "practice" option in the game) mode for 5 rounds. After each round give them the mini survey (Appendix-C Part 2) to complete. ( 10min: for the 5 rounds of gameplay and 5 mini surveys)

a. Give the mini survey and the complete survey 1 (Appendix-C - Part 3) to fill after the $3^{\text {rd }}$ round. $(\sim 10 \mathrm{~min}$ : to fill out the complete survey)

\section{Experiment - Treatment B: Competing against computer}

1) Brief them about the process of this mode.

a. Briefing script: "in this experiment, you will play against the computer for 5 rounds, and we will ask you to kindly fill a short survey after each time you play the game, and once a longer survey."

2) Set the competition against computer mode for them to play for 5 rounds.

a. On one side, the first facilitator with the participant sets the "race your friends" option for the participant. The other side starts the computer simulator to run against the person, based on his/her typing speed. Make sure to test this option beforehand. This can perhaps be done via one facilitator only.

3) After each round give them the mini survey to complete (Appendix-C - Part 2). (10min)

a. Give the mini survey and the complete survey 2 (Appendix-C - Part 3) to fill after the $3^{\text {rd }}$ round. $(\sim 10 \mathrm{~min}$ to fill out the complete survey $)$ 
Ph.D. Thesis - Sepandar Sepehr; McMaster University - DeGroote School of Business.

\section{Experiment - Treatment C: Competing against a person}

1) Brief them about the process of this mode.

a. Briefing script: "in this experiment, you will play against another person for 5 rounds, and we will ask you to kindly fill a short survey after each time you play the game, and once a longer survey."

2) Let them know that they are playing against someone else by saying: "in this mode you are going to play against another participant who is sitting in the other room."

3) Make sure the other facilitator is ready (via cellphone).

4) Select playing against your friend option and allow the participants to play for 5 rounds. After each round give them the mini survey to complete (Appendix-C - Part 2). (10min)

a. Give the complete survey to fill after round 3 (Appendix-C - Part 3). ( 10min)

\section{Experiment - Closure:}

1) At the end of the experiment, tell the participants that they have to stay there for 5 minutes as you leave the room "to check if everything was recorded properly and bring back their gift card." Show them the options of the game (racing real world or playing by themselves) and say that they can feel free to play any of them.

2) When you go back in, thank them for participating in the study and give them their gift cards.

\section{Experiment document - Articles To read 1}

\section{The power of electrodermal activity (EDA)}

EDA has been studied for over a century; it is not new. What is new is that now you can do 
Ph.D. Thesis - Sepandar Sepehr; McMaster University - DeGroote School of Business.

things with it that could never be done before: Measure and communicate it continuously in the wild, on a child climbing a rock wall, in an audience at the theatre, on a patient undergoing 24/7 testing, in a focus group, on a couple interacting, and more, easily and without wires.

EDA is the phenomenon whereby the skin's electrical properties change when activated by various brain circuits. For example, when your brain detects a stressful event, it triggers the sweat glands to fill. Even if the glands don't fill to the point where your skin feels "sweaty," while your skin feels dry to the touch, an electrical signal measured across the skin can still register a change.

The most common measure of EDA is skin conductance, which captures one of the main dimensions of emotion: the "arousal" dimension. Skin conductance usually increases when a person is more aroused - whether engaged, stressed, or excited. Skin conductance tends to stay low or drop when a person is less aroused - disengaged, bored, or calm.

For example, researchers at the MIT Media Lab measured a large audience during a daylong set of presentations ${ }^{\mathrm{i}}$. They found that audience skin conductance increased when a new speaker came onstage, when there was laughter, and during live demonstrations or question-and-answer periods; however, each time there was a lengthy PowerPoint presentation the audience skin conductance dropped, steadily downward, with an exponential decay.

Almost all scientific studies of EDA have used old-style measurement devices that require taping gelled electrodes to the fingers or to the soles of the feet. While such measurement has been considered the "gold standard" and gives a very sensitive reading, it has been nearly impossible to use it to measure EDA long-term. For example, you can't easily wash your hands when the 
Ph.D. Thesis - Sepandar Sepehr; McMaster University - DeGroote School of Business.

old sensor is taped to your fingertips, and walking messes with the signal on the soles of your feet. Also, the gooey gels break down over time. Consequently, most studies on EDA have only examined data for short periods of time, usually in labs. But emotion can be very different outside the lab in real life, where relationships, events, and experiences really matter to a person.

Questionnaires are commonly used for measuring emotion but responses are inherently subjective, and vary enormously depending on one's ability to convey feelings to words or numbers. What's more, people often forget what they felt, even moments ago. A questionnaire is an imperfect snapshot of emotion, like representing Beethoven's Ninth Symphony using just ten notes.

By capturing EDA in a new way, researchers are able to objectively characterize people's bodily responses to a variety of emotional, cognitive, and physical experiences, and do so continuously for long or short periods of time, without interrupting the experience.

\section{What is the QTM Sensor?}

Affectiva's QTM sensor is a small electronic device that can be comfortably worn longterm on the surface of the skin, where it measures three kinds of data:

- Skin conductance Skin temperature• Acceleration (3 signals: one for each of the X,Y, and $\mathrm{Z}$ axes)

Skin conductance, in addition to representing the arousal dimension of emotion, is also of use for measuring cognitive load as well as for measuring stressors - whether positive or negative. This measure has many applications (see examples below.)

Skin temperature helps identify events during the day such as when you were in the cold conference room, got into a hot car, or crawled into a warm bed. Usually temperature does not 
Ph.D. Thesis - Sepandar Sepehr; McMaster University - DeGroote School of Business.

affect skin conductance, unless temperature changes dramatically. Skin temperature 24/7 can show patterns in a person's lifestyle - like what time each day you climb out of that warm bed. Sometimes skin temperature marks drug use, for example, becoming unusually cool with vasoconstriction.

Accelerometers on the sensor register motion changes in three directions and can provide “actigraphy," a measure used in sleep research to guess that you're asleep if you don't move for long periods of time. The accelerometer data can also quantify when and how much an audience is fidgeting. Accelerometer patterns have interest in many medical conditions, for example, characterizing repetitive movements such as arm flapping in autism. Q's acclerometer data can also be used to characterize physical activity like running, walking, or other forms of exercise. Product test researchers use the Q motion information to zoom in on physical activities like combing hair, washing dishes, shaving, or counting how many times your hand went in and out of that bag of delicious M\&M's.

Many applications benefit from combining the measures above. For example, severe seizures usually contain patterns of both skin conductance and motion changes, and certain kinds of drugs can also affect all three measures.

\section{Experiment document - Articles To read 2}

Gestalt is a general description for the concepts that make unity and variety possible in design. It is a German word that roughly translates as "whole" or "form." Gestalt theory is involved with visual perception and the psychology of art among other things. It is concerned with the relationship between the parts and the whole of a composition. 
Ph.D. Thesis - Sepandar Sepehr; McMaster University - DeGroote School of Business.

In this section you will study five gestalt concepts:

Closure the mind supplies the missing pieces in a composition

Continuance the eye continues in the direction it is going

Similarity what an items looks like and how that effects gestalt

Proximity where items are in relationship to each other and how that effects gestalt

Alignment lining up objects to organize and form groups

The objective of studying gestalt is to put the designer in control of what the viewers see when they look at a composition. See emphasis for more information.

Gestalt theory holds that the whole is more than the sum of its parts.

\section{GESTALT}

The study of gestalt originated in Germany in the 1920s. It is a form of psychology that is interested in higher order cognitive processes relative to behaviorism. The aspects of gestalt theory that interests designers are related to gestalt's investigations of visual perception, principally the relationship between the parts and the whole of visual experience.

The visual world is so complex that the mind has developed strategies for coping with the confusion. The mind tries to find the simplest solution to a problem. One of the ways it does this is to form groups of items that have certain characteristics in common.

Most of what you will study about gestalt is concerned with how these groups are formed and what effect they have on perception. The stronger the grouping, the stronger the gestalt. It is this grouping that contributes to the unity in a design. Gestalt is one of the most powerful tools available to a designer for creating unity.

The same concepts that form groups can be reversed to ungroup items -- to make them look unique and stand alone. That is the basis for creating variety. Variety is what adds interest to an image.

The trick is to strike a balance between unity and variety. Too much unity and the design can look boring and repetitive; too much variety and it can look chaotic and disconnected.

Understanding gestalt concepts can help a designer control unity and variety. 


\section{CLOSURE}

A complex object is really a group of simple items that the mind puts together as a single entity. A face is a collection of eyes, ears, nose, mouth, etc. You can recognize a familiar face even if part of it hidden (with a hat or sunglasses for instance). Your mind supplies the missing parts if enough of the significant features are visible.

A simple example of this can be seen with this series of circles. As more and more of each is removed the circle still remains identifiable until more is missing than is present. This is called closure because the mind "closes" the image by supplying the missing parts.

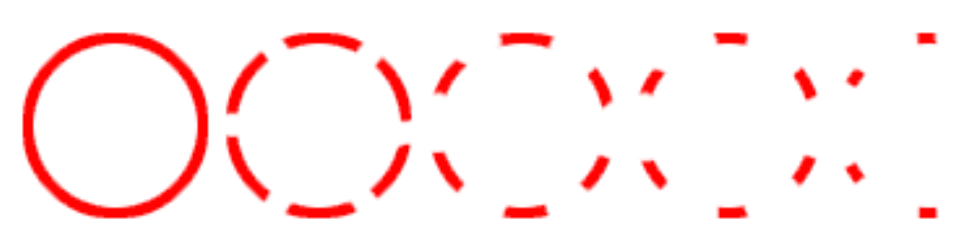

This works with a simple geometric shape because you need only a few clues to remind you of the shape. More complex objects require more careful consideration as to what can and cannot be removed. Some information is critical and must be included; some information is unessential and can (and perhaps should) be eliminated.

Closure is used extensively in art. It is not so much the quantity, but rather the quality of the information that lets you read an image. A clever artist leaves some things for the viewers to supply when they look at an image. It is a little like when the singer at a concert gets the audience to sing along. You feel like part of the show.

\section{CONTINUANCE}

Continuance describes a device for directing the viewer's attention when looking at a composition. It is based on the idea that once you start looking in a particular direction you will continue looking in that direction until you see something significant.

A simple example of this is illustrated. You notice the small circle that the hand points at in preference to the closer, larger circle. In a sense this is a kind of closure -- a grouping of disconnected items by momentum.

This feature is built into typography since we are taught to read 
Ph.D. Thesis - Sepandar Sepehr; McMaster University - DeGroote School of Business.

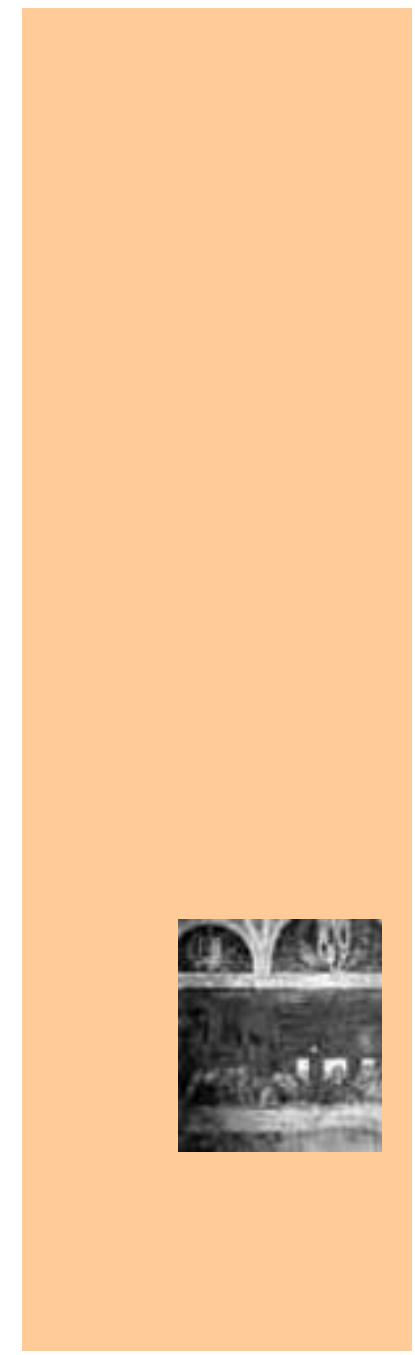

left to right in our culture. Once you start reading you will continue across a gap to the next words.

All kinds of pointing devices are used in design. Many of these are more subtle than a pointing hand or arrow:

Eye direction: If the subject of a composition is looking in a particular direction, you will look to see what they are looking at. It is an old trick to look up into the sky and see how many other will look with you.

Paths: Rivers, roads, railroad tracks and rows of trees or telephone poles are just a few of the devices that artists have used to lead viewers to particular places in their compositions.

Perspective: Lines of perspective, like paths, can be used to direct attention to a focal point in a composition. You will study perspective in a few weeks when you study the design element space.

Leonardo de Vinci used some of these devices in his mural "The Last Supper." Notice how you look from one apostle to another because of the way they are looking at each other, but finally end up looking at Jesus. The building they are in uses one point linear perspective to also focus you on the central figure of Jesus. 
Ph.D. Thesis - Sepandar Sepehr; McMaster University - DeGroote School of Business.

\section{APPENDIX 4 - EXPERIMENT'S CONSENT FORM}

DATE:

\section{LETTER OF INFORMATION / CONSENT}

Typing Gaming Study:

the Role of Competition in Video Games

\section{Investigators:}

Principal Investigator:

Sepandar Sepehr

DeGroote School of Business (DSB A211)

McMaster University

Hamilton, Ontario, Canada

(905) 525-9140 ext. 23126

E-mail:sepehrs@mcmaster.ca

\author{
Faculty Supervisor: \\ Dr. Milena Head \\ DeGroote School of Business (DSB A206) \\ McMaster University \\ Hamilton, Ontario, Canada
}

(905) 525-9140 ext. 24435

E-mail: headm@mcmaster.ca

\section{Purpose of the Study}

You are invited to take part in this study that focuses on the role of competition element of video games.

We aim to better understand how competitive environment of video games can affect video gameplayers experience during the gameplay.

\section{Procedures involved in the Research}

Before the study has been started, we will ask you to fill a survey that would ask you some general information including demographics and some personality questions.

During this study, you will play a simple game that is used for improving typing speed. You will be randomly assigned to different groups that you could be playing against yourself or other people or against computer. You will be asked to wear a bracelet that would help us to measure your excitement level during the 
Ph.D. Thesis - Sepandar Sepehr; McMaster University - DeGroote School of Business.

gameplay. This bracelet includes a sensor that is a wearable, wireless biosensor that measures emotional arousal via skin conductance, a form of electrodermal activity that grows higher during states such as excitement, attention or anxiety and lower during states such as boredom or relaxation. The sensor also measures temperature and activity.

In the middle of the study, you will be asked to complete a survey and answer some questions about your feelings during your last gameplay. These questions are mostly about your level of engagement that have been previously identified by scholars.

\section{Potential Harms, Risks or Discomforts:}

It is not likely that there will be any harms or discomforts from/associated with this study. The typing game is a simple racing game and if you are playing against someone, you might be able to win or lose at the end of the game. There is no prise or negative consequences attached to winning or losing and the game is simply for practicing typing skills. Therefore, the only issue is that you might not win the competition, which is only a small typing game and has no effect on anything else including the chance for a draw.

Also, if you are assigned to an experiment that you compete with another person, he or she will know the results of your typing (how fast you type). We are expecting all the participants to be mindful that this is a small game and has no genelizable meaning as it is only a small game and the results show nothing about the participants.

You do not need to answer questions that you do not want to answer or that make you feel uncomfortable. You can withdraw (stop taking part) at any time. Described below are the steps that will be taken to protect your privacy.

\section{Reimbursement}

You will receive one gift card ( $\$ 10$ value) from Campus Store at the end of the experiment.

\section{Potential Benefits}

The research will not benefit you directly. We hope to learn more about engagement in educational computer games. We hope that what is learned as a result of this study will help us to better understand the motivational factors and the feelings during simulation games. 
Ph.D. Thesis - Sepandar Sepehr; McMaster University - DeGroote School of Business.

\section{Confidentiality}

All the information gathered in this study are anonymous. Any reports provided as a result of this study will be anonymous and no personal information will be revealed. Any information that might help to identify individuals participating in the study will be removed prior to preparing the report of findings.

The information/data you provide will be kept in a locked desk/cabinet where only the investigators will have access to it. Information kept on a computer will be protected by a password. Once the study has been completed, all identifying data will be destroyed. Once the study is complete, an archive of the data, without identifying information, will be kept under password protection.

Only if you are assigned to an experiment that you compete against someone else, the other person would know that you have participated in this experiment.

\section{Participation and Withdrawal}

Your participation in this study is voluntary. It is your choice to be part of the study or not. If you decide to be part of the study, you can decide to stop (withdraw), at any time, even after signing the consent form or part-way through the study. After the experiment, you can let us know up to one week after the experiment if you want your information to be removed completely. If you decide to withdraw, there will be no consequences to you. In cases of withdrawal, any data you have provided will be removed unless you indicate otherwise. You will still receive your gift card.

Survey questions are not related to sensitive matters and it is not likely that they evoke discomfort. If you are not willing to continue with the study, you can simply stop completing the survey or return the survey blank.

\section{Information about the Study Results}

We expect to have this study completed by the end of Summer 2014. If you would like a brief summary of the results, please contact the investigators.

\section{Questions about the Study}


Ph.D. Thesis - Sepandar Sepehr; McMaster University - DeGroote School of Business.

If you have questions or need more information about the study itself, please contact Sepandar Sepehr (sepehrs@mcmaster.ca) or Dr. Head (headm@mcmaster.ca).

This study has been reviewed by the McMaster University Research Ethics Board and received ethics clearance.

If you have concerns or questions about your rights as a participant or about the way the study is conducted, please contact:

\author{
McMaster Research Ethics Secretariat \\ Telephone: (905) 525-9140 ext. 23142 \\ c/o Research Office for Administrative Development and Support \\ E-mail: ethicsoffice@mcmaster.ca
}

\title{
CONSENT
}

I have read the information presented in the information letter about a study being conducted by Sepandar Sepehr and Dr. Milena Head, of McMaster University.

I have had the opportunity to ask questions about my involvement in this study and to receive additional details I requested.

I understand that if I agree to participate in this study, I may withdraw from the study at any time. I have been given a copy of this form. I agree to participate in the study.

Signature:

Name of Participant (Printed) 
Ph.D. Thesis - Sepandar Sepehr; McMaster University - DeGroote School of Business.

\section{APPENDIX 5 - EXPERIMENT GUIDELINE FOR THE PILOT STUDY}

These are the steps that the facilitator should follow in the experiments:

\section{Stage 1:}

12) Consent form is given $(2 \mathrm{~min})$

13) Brief about using the Q-Sensor device ${ }^{27}$, then the device is fitted to their hands. (1min)

14) Give the participants the first part of the survey on demographics (Appendix-C - Part 1). $(2 \mathrm{~min})$

15) Ask the participants to read the article on EDA. (5min)

16) Brief them about the process of the game. Let them play the single player (competing against themselves) mode for 5 rounds. After each round give them the mini survey to complete (Appendix-C - Part 2). (10min)

17) Give the mini survey and the complete survey to fill (Appendix-C - Part 3). (5-7min)

18) Give the participants the option of playing up to 5 more rounds if they are interested. (up to $5 \mathrm{~min})$

\section{Between Stage 1 \& 2:}

- Based on the skill level \& the relationship of participants, randomly assign each participant to two of the following treatment groups (give double weight to case 3):

1. Competing against themselves

2. Competing against computer

3. Competing against a person

${ }^{27}$ The data that was collected from Q-Sensor EDA measurement device appeared to be complicated to analyze. Thus, this data is kept separate in order for analysis and publication in a future work. 
Ph.D. Thesis - Sepandar Sepehr; McMaster University - DeGroote School of Business.

- Find out which of the 1 to 5 rounds in the process had an optimum level of engagement to use in the second stage.

\section{Stage 2:}

1) If two participants are involved in competition, make sure they sit in two separate rooms so they do not see each other.

2) Fit the Q-Sensor on the participant hand. (1min)

3) Give them the theoretical paper to read. ( 10min)

4) Based on the randomization, each participant has been assigned to two of the following treatments. Follow the instruction for the corresponding treatment.

\section{Stage 2 - Treatment: Competing against own previous score:}

1) Brief them about the process of the game. Let them play the single player (competing against themselves) mode for 5 rounds. After each round give them the mini survey to complete (Appendix-C - Part 2). (10min)

a. Give the complete survey to fill after round 3 or 4 or whatever number that was defined based on the analysis of the data from stage 1 (Appendix-C - Part 3). (5$7 \mathrm{~min})$

2) Give the participants the option of playing up to 5 more rounds if they are interested. (up to $5 \mathrm{~min})$

\section{Stage 2 - Treatment: Competing against computer}

4) Brief them about the process of the game. Set the competition against computer mode for them to play for 5 rounds. After each round give them the mini survey to complete (Appendix-C - Part 2). (10min) 
Ph.D. Thesis - Sepandar Sepehr; McMaster University - DeGroote School of Business.

a. Give the complete survey to fill after round 3 or 4 or whatever number that was defined based on the analysis of the data from stage 1 (Appendix-C - Part 3). (5$7 \mathrm{~min})$

5) Give the participants the option of playing up to 5 more rounds if they are interested. (up to $5 \mathrm{~min}$ )

\section{Stage 2 - Treatment: Competing against a person}

5) Brief them about the process of the game. Select playing against your friend option and allow the participants to play for 5 rounds. After each round give them the mini survey to complete (Appendix-C - Part 2). (10min)

a. Give the complete survey to fill after round 3 or 4 or whatever number that was defined based on the analysis of the data from stage 1 (Appendix-C - Part 3). (5$7 \mathrm{~min})$

6) Give the participants the option of playing up to 5 more rounds if they are interested. (up to $5 \mathrm{~min}$ ) 